Tesis de Graduación

Maestría en Economía de la Salud y Administración de

Organizaciones de Salud

\title{
EL ACCESO A LA CIMA GERENCIAL EN ORGANIZACIONES PRESTADORAS DE SERVICIOS DE SALUD PRIVADAS DEL GRAN LA PLATA.
}

Una mirada desde la Formación de Posgrado y el Género

Tesista: Lic. Andrea Lorena Mastropietro

Directora de tesis: Mg. Mariel Ortiz 


\section{Dedicatoria}

A la memoria de mi padre que siempre me inculcó los valores del esfuerzo, el estudio y el trabajo, a mi familia, mi gran sostén; a mi querido Dr. Alfredo Hernández y en memoria del Dr. Héctor Michelini

\section{Agradecimientos}

Al director de la EGSalud por haberme dado la posibilidad de realizar este posgrado y por la confianza depositada en mi persona.

A mi directora de tesis y gran amiga Mariel Ortiz por ser un soporte inquebrantable, por enseñarme a confiar en mí y a desarrollarme para lograr cumplir este gran objetivo.

A mis amigas de la EGSalud: Gisela, Ethel, Manuela, Nadia y Marisa por el aliento y apoyo brindado constantemente durante todo este proceso.

A mis compañeros de la inolvidable edición $14^{\circ}$ de la Maestría de quienes guardo los mejores recuerdos.

A todos los profesores que módulo a módulo han dejado en mí grandes enseñanzas con sus enriquecedoras experiencias y conocimientos.

A todos mis encuestados que tan amable y desinteresadamente han cooperado aportando datos valiosos que me permitieron arribar a conclusiones elocuentes

A todas aquellas personas e instituciones que de una u otra manera han aportado información, lo que permitió nutrir y enriquecer esta investigación.

Por último, y a modo personal, quiero agradecer por sobre todo a mi familia por ser el sostén, el respaldo y mi refugio en todo momento, sin la cual no hubiera podido llegar hasta aquí.

¡Gracias a todos!! 


\section{Índice de contenidos}

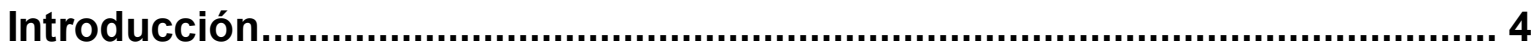

Ordenamiento y estructura del documento …….......................................... 4

Caracterización del problema por abordar- Justificación ................................ 6

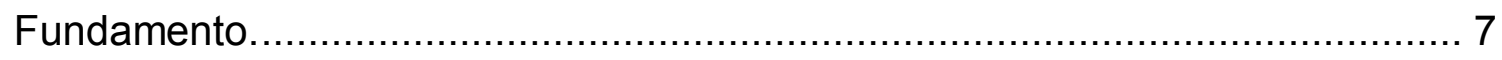

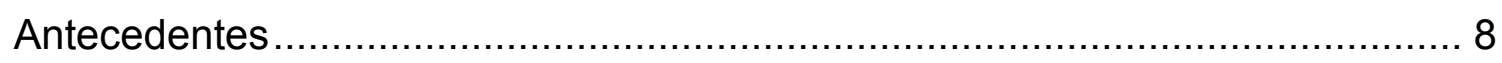

Marco Teórico

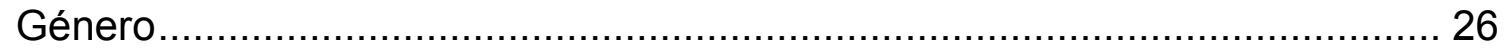

Management. Management Sanitario …………....................................... 34

Propósito y objetivos específicos ......................................................... 49

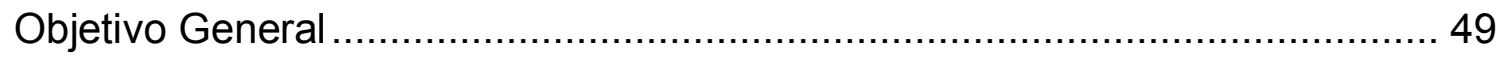

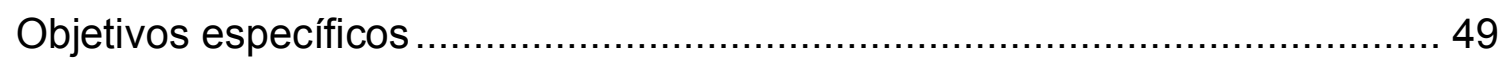

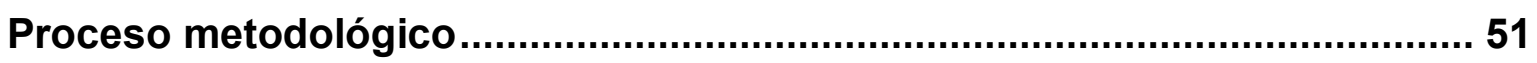

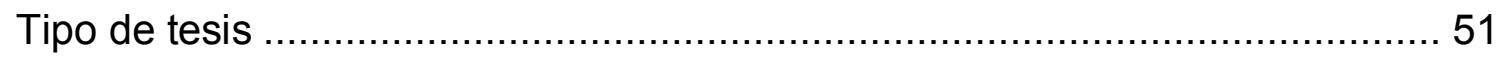

Descripción del trabajo de campo ......................................................... 51

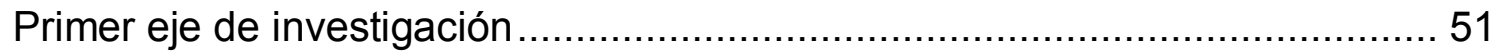

Criterios de recorte para este eje de estudio:................................................ 52

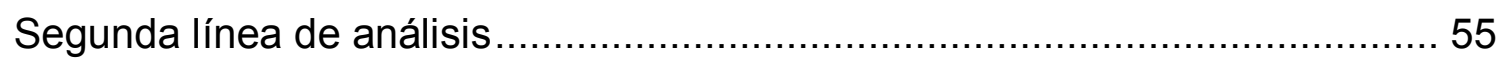

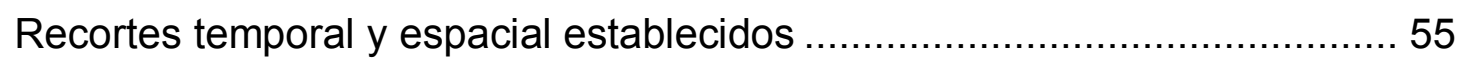

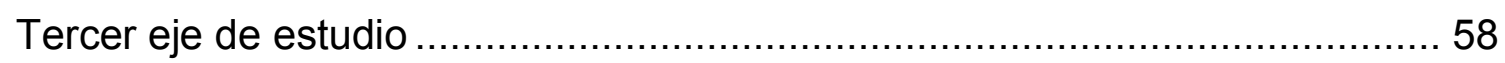

Recorte temporal y espacial de este eje de estudio .................................. 58

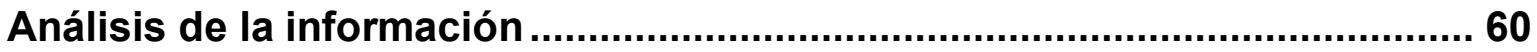

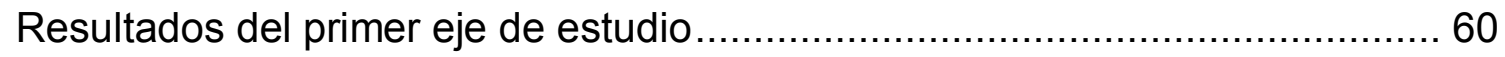

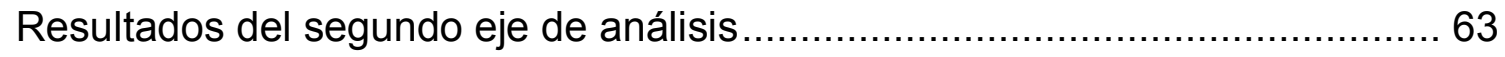

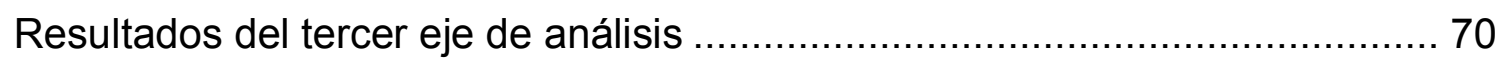

Conclusiones emergentes y desafíos pendientes....................................... 85

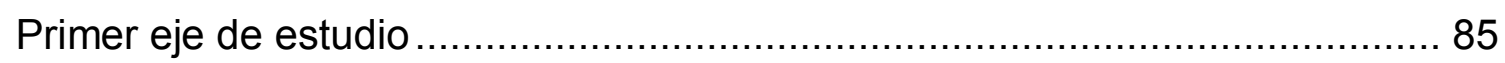

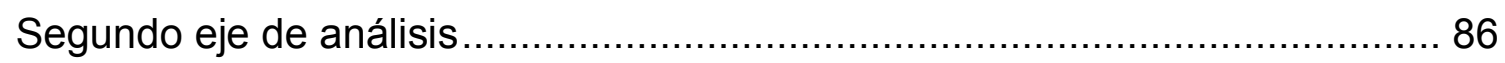

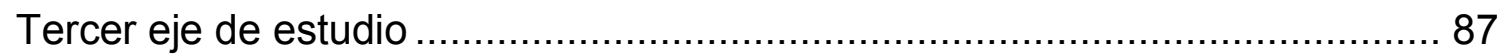

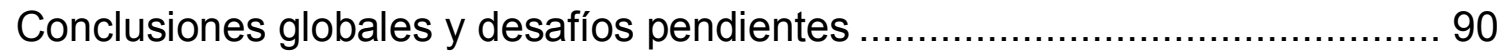

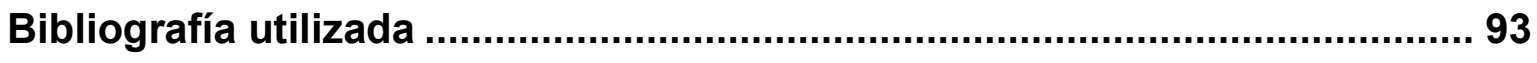

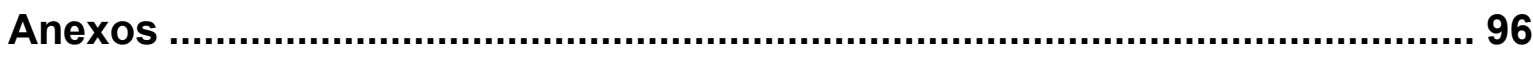




\section{Introducción}

El propósito esencial de este documento se basa en el análisis y estudio de la incidencia que poseen los factores Formación de Posgrado específico en Gestión Sanitaria y Género cómo determinantes del acceso a cargos de alta gerencia en Organizaciones Privadas de Salud locales, partiendo de las asimetrías que se visualizan en cuanto a la composición de género, entre quienes se vienen formando en los últimos años en los posgrados específicos en gestión sanitaria y quienes ocupan posiciones estratégicas de poder en las instituciones de salud.

\section{Ordenamiento y estructura del documento}

El documento está organizado en diferentes secciones las cuales se describirán brevemente a continuación.

En una primera parte, se presenta el problema central a abordar, su caracterización y se exponen los fundamentos que dieron origen a tal investigación, en el marco de la Maestría en Economía de la Salud y Administración de Organizaciones de Salud, para luego elaborar una reseña de los antecedentes, tanto locales como regionales y nacionales sobre el tema.

El siguiente capítulo está destinado al abordaje teórico realizado para esta investigación. El mismo genéricamente está basado en management y género, habiéndose optado específicamente por consultar fuentes bibliográficas referidas a management sanitario; complementando la mirada con el pronunciamiento de organismos de reconocido prestigio (OPS, PNUD; OIT) acerca del rol del género en el mercado de trabajo en general, es decir sin distinción del tipo de organización del que se trate.

Las discusiones teóricas consideradas aquí, versan sobre el estatus de la mujer y el varón en los ámbitos laborales; los frenos e impulsores a los que se enfrenta la mujer para acceder a puestos de decisión, estereotipos de género instalados en la sociedad sin distinción de fronteras geográficas; segregación horizontal y vertical como consecuencia de los estereotipos de género; los conceptos de techo de cristal, paredes de cristal, techo de cemento, pisos pegajosos y laberintos utilizados como metáforas para explicar las barreras invisibles a las que se 
enfrentan las mujeres cuando aspiran a ocupar posiciones de poder en las instituciones y el papel que desempeña la cultura organizacional en obstaculizar o facilitar el acceso a los puestos de alta gestión.

Cabe destacar que el apartado de bibliografía referida al management en su concepto amplio se recortó a la función gerencial y a las competencias gerenciales; mientras que la revisión sobre management sanitario se enfocó en los desafíos y ventajas de la gestión clínica según la mirada de autores españoles.

En el apartado siguiente se exponen los objetivos que se pretenden lograr en la presente investigación, indicando en primera medida el objetivo general, para luego detallar cada uno de los objetivos secundarios.

En la sección "Proceso Metodológico" se puntualiza el tipo de tesis, se especifican las herramientas y fuentes utilizadas, las técnicas aplicadas y los instrumentos de recolección diseñados especialmente para el presente trabajo de investigación. A su vez, se explica el desarrollo metodológico que descansa en tres grandes ejes de análisis, con criterios de recortes particulares para cada uno.

Por otra parte, en la sección "Análisis de la Información", se exponen los resultados arrojados en cada uno de los tres ejes de estudio, mostrando en detalle los datos conseguidos, enriqueciendo la presentación mediante el uso de cuadros y gráficas correspondientes.

Para finalizar, se trazan las conclusiones arribadas en cada uno de los tres ejes de estudio para luego reflexionar una conclusión global de la situación problemática planteada y trazar cuáles serían los desafíos pendientes.

Se concluye el documento con dos apartados, el primero donde se presenta un punteo de la bibliografía utilizada y la sección de anexos, donde se puede acceder básicamente a los modelos de encuestas diseñados especialmente para la presente investigación y demás datos considerados indispensables para fundamentar como se arribó a cada uno de los resultados expuestos en el presente trabajo de investigación. 


\section{Caracterización del problema por abordar- Justificación}

Desde la perspectiva de género, la distancia reinante entre quienes se están formando académicamente en los posgrados en gestión sanitaria, con tendencia creciente de mujeres en relación a varones y quienes ocupan hoy posiciones de poder formal en los establecimientos prestadores de servicios de salud privados locales, con dominio del género masculino, permite pensar un escenario futuro donde las mujeres estarán tan o más preparadas académicamente y contarán con las mismas o con mejores herramientas teóricas que los varones para enfrentar los desafíos que implica la función gerencial, no obstante continuarán enfrentando frenos paradigmáticos, tanto internos como externos, que les dificultará ocupar posiciones de poder formal en las organizaciones.

El objetivo de la presente investigación consiste en Identificar, describir y analizar, la incidencia que poseen los factores formación académica de posgrado en gestión sanitaria, y género, como determinantes de las posibilidades de acceso a puestos de alta gerencia en los establecimientos prestadores sanitarios privados del Gran La Plata.

La confrontación entre las posibilidades de acceso a puestos de alta gerencia en instituciones prestadoras privadas de salud y las habilidades y competencias que se generan y desarrollan a partir de la aplicación de herramientas aprendidas desde los ámbitos de la formación de posgrado, examinadas a través del enfoque de género, condujo a plantear interrogantes que se intentaron responder en esta investigación:

- ¿Existe una prevalencia de género en la conducción de las instituciones prestadoras privadas de salud del Gran La Plata?

- ¿Cuáles son los factores que explican dicha prevalencia?

- ¿Por qué se observa en los últimos años un incremento de matrículas femeninas en las formaciones de posgrado relacionadas a este campo? 
- ¿Son el género y la formación académica de posgrado factores determinantes para el acceso a puestos de alta gerencia en las instituciones sanitarias?

\section{Fundamento.}

Se pretendió con la presente investigación sembrar evidencia a nivel local de la asimetría que existe en cuanto a composición de género, entre quienes se forman académicamente en gestión sanitaria, y quienes ocupan actualmente altos cargos gerenciales en instituciones prestadoras privadas sanitarias locales, a fin de que sirva como referencia para emprender futuras acciones que generen oportunidades de acceso más equitativas entre varones y mujeres a cargos de dirección como así también, dejar una senda abierta a futuras investigaciones que deseen profundizar sobre este campo, dado que hasta el momento no existe evidencia científica a nivel local sobre esta temática.

Impulsaron la presente investigación el hecho de considerar el tema acertado en el marco de la Maestría para la cual se presenta la tesis, más un interés personal en estudiar la problemática planteada. 


\section{Antecedentes}

En las últimas décadas, tanto a nivel local, regional, como mundial, las mujeres han intensificaron su participación económica en el mercado laboral con lo cual ha crecido notablemente la tasa de feminización de la fuerza de trabajo. Sin embargo, prevalece aún en nuestros días, una inmensa desigualdad que sigue poniendo en desventaja a las mujeres que día a día tropiezan con innumerables obstáculos, que limitan y retrasan su inclusión en el ámbito social ${ }^{1}$, que frenan su desarrollo profesional y la posibilidad de acceder a la cima gerencial de las organizaciones.

Aún hoy, a pesar de que las mujeres llevan a cabo enormes esfuerzos invirtiendo en formación académica, que logran ser mayoría en las aulas universitarias obteniendo iguales e incluso mejores promedios que sus pares masculinos, ${ }^{2} \mathrm{y}$ que existe un considerable avance de la legislación en materia de igualdad de oportunidades, ellas siguen estancadas en los niveles medio y bajo de la estructura organizacional, ocupando solo una pequeña fracción en los puestos de conducción.

Visiblemente en la actualidad, no han alcanzado la paridad laboral entre varones y mujeres a pesar de los demostrados esfuerzos que estas últimas llevan a cabo en su formación, en capacitación, entrenamiento y en experiencias.

Incluso, muchas mujeres calificadas y con cuantiosas aptitudes siguen quedando afuera del mercado de trabajo y esto representa una notable pérdida de talento.

En su gran mayoría, las organizaciones no cuentan con políticas lo suficientemente capaces de aportar condiciones de flexibilidad a quienes se desempeñen en las altas esferas. De este modo las mujeres, que son generalmente las que asumen en mayor proporción el rol de compatibilizar la vida familiar con el trabajo ${ }^{3}$, se sienten forzadas a optar muchas veces, entre una u otra opción.

Diversas teorías sobre este tema concuerdan en resaltar la existencia, tanto de factores externos (institucionales, sociales, etc.) como internos a las propias

\footnotetext{
1 Ámbito Social o ámbito público: entendido como el ambiente externo, fuera del hogar, en contraposición al ámbito privado, familiar y doméstico.

${ }_{2}^{2}$ Héller, Lidia. 2015. Mujeres... y varones en las organizaciones. Ambiciones y aspiraciones. 1ra edición. Pluma Digital ediciones. Cuidad Autónoma de Bs. As.

3 Chinchilla, Nuria y otros. 2006. Frenos e Impulsores en la trayectoria profesional de las mujeres directivas. Centro Internacional Trabajo y Familia IESE Business School - Universidad de Navarra. España
} 
mujeres que juegan como barreras invisibles, denominadas "techo de cristal". Estas barreras actúan y operan como muros que simbolizan obstáculos implícitos derivados tanto de prejuicios organizacionales como psicológicos que se enlazan estructurando una sociedad, ${ }^{4}$ y que son inconscientemente asumidos tanto por mujeres como por varones, heredados de un sistema de creencias y valores arraigados en una cultura patriarcal.

Así es que, siguiendo la lógica del modelo patriarcal, tradicionalmente a los varones se los ha educado y socializado para que se desempeñen en el ámbito público y social (fuera del hogar) y desplieguen sus capacidades y trabajo productivo en él, mientras que al género femenino se lo ha educado y socializado para que permanezca en el ámbito privado (familiar, doméstico y afectivo), cumpliendo no sólo con el trabajo reproductivo y el cuidado de los hijos, sino también asumiendo el mantenimiento y la organización del hogar. ${ }^{5}$

Los estereotipos de género, -entendidos como las imágenes preconcebidas de cómo son y deben comportarse tanto los varones como las mujeres en la sociedad - potencian y refuerzan estos roles diferenciales entre varones y mujeres.

El esquema de familia patriarcal, predominante durante el siglo $X X$, que restringe el rol de la mujer a la esfera doméstica (privada y familiar) y de los varones a la pública y social (fuera del hogar), en la actualidad se ha resquebrajado.

Si bien en las últimas décadas, la intervención de los varones en la esfera familiar se ha incrementado, lo ha hecho a un ritmo mucho más lento que la participación de la mujer en el mercado laboral. En tal sentido, aún hoy las mujeres continúan como principales administradoras y proveedoras del cuidado del hogar y de los hijos. Coexiste, entre varones y mujeres, un reparto asimétrico del trabajo familiar y doméstico que genera en estas últimas la sensación de una "doble jornada"6. Por dicha razón, es viable pensar que ellas obtienen y/o conservan empleos más precarios y flexibles que los varones y que trabajan menos horas semanales fuera del hogar, situación que condiciona el tipo de ocupación al que pueden acceder.

\footnotetext{
${ }^{4}$ Dirección General de Economía Social y Emprendedores. Economía Social con perspectiva de Género. Análisis de "techo de Cristal" y establecimiento de un modelo equitativo de gestión empresarial. CEPES- Andalucía, Confederación de Entidades para la Economía Social. Sevilla. p 34

${ }^{5}$ Obra ya Citada. p 34

${ }^{6}$ Obra ya Citada p.58
} 
Se genera de este modo lo que se denomina "segregación ocupacional horizontal" que implica la concentración de mujeres en determinados sectores identificados y reconocidos habitualmente como "femeninos" (el cuidado de la salud, docencia y enseñanza, secretariado, recepción y asistencia en las organizaciones, etc.).

Por el contrario, la justicia, el derecho, las ciencias físico- químicas, la ingeniería, la gestión y dirección de empresas y la administración de los servicios de salud, donde pone el foco la presente investigación, son tradicionalmente contemplados y considerados como ámbitos "masculinos".

Por otra parte, existe una "segregación ocupacional vertical" que involucra mayor concentración de mujeres en puestos con calificación igual o equivalente respecto de los varones, pero con menor jerarquía ocupacional, lo que a su vez termina generando, una discriminación salarial. ${ }^{7}$ Esta última particularidad no ha sido objeto de análisis de la presente investigación.

Esta evidencia se despliega de un modo más evidente en aquellas ocupaciones que cuentan con un elevado nivel de responsabilidad y valoración social. De este modo, son los cargos gerenciales de las organizaciones y el sector privado los espacios donde, más se acentúa esta desigualdad. El diseño de esos puestos de trabajo no repara en determinados aspectos como los tiempos personales y familiares, tiempos de ocio y principalmente el cuidado y la educación filial, que continúan siendo acervo casi exclusivo del género femenino. ${ }^{8}$

Por otra parte, los cargos gerenciales exigen a quienes tienen en sus manos las decisiones estratégicas, que deban ocupar la totalidad de su tiempo, lo que implica largas jornadas de trabajo y dificultades para compatibilizar el ámbito social (fuera del hogar) con el privado y familiar, y este es uno de los principales obstáculos que encuentran, sobre todo las mujeres, cuando aspiran acceder a posiciones de poder formal en las organizaciones cualquiera sea su actividad.

Según datos obtenidos del informe Aportes de la Economía Feminista desde Argentina, de la Fundación Friedrich Ebert ${ }^{9}$, la tasa de actividad de acuerdo con los datos del tercer trimestre del 2017 relevados por la Encuesta Permanente de Hogares del INDEC fue del $39 \%$ para las mujeres, resultando superior para el

\footnotetext{
7 Programa de la Naciones Unidas para el Desarrollo (PNUD). 2011. Aportes para el Desarrollo Humano en Argentina/2011: Género en cifras: mujeres y Varones en la sociedad argentina. $1^{\circ}$ ed. Buenos Aires p 20

${ }^{8}$ Dirección General de Economía Social y Emprendedores. Obra ya citada.

${ }^{9}$ Fundación Friedrich Ebert. Julio 2018. Aportes de la Economía Feminista desde Argentina. Análisis № 27
} 
caso de los varones con el $55 \%$. En el mismo informe también se señala que el 10 $\%$ de las mujeres que buscó empleo en dicho período, no lo encontró, mientras que en el caso de los varones ese porcentaje fue menor, alcanzando el $7 \%$, lo que permite entrever que el desempleo afectó en mayor medida a mujeres que a varones.

Según el mismo documento, si se tiene en consideración la diferenciación entre sector de gestión estatal y privado, del total de personas ocupadas en el sector de gestión estatal, $53 \%$ representan al género femenino mientras que $47 \%$ reflejan al género masculino. Al analizar el sector privado, esta situación se invierte; los varones alcanzan el $59 \%$, mientras que las mujeres solo el $41 \%$ de los puestos ocupados. Los datos aquí permiten corroborar que la situación de las mujeres en el sector estatal es más alentadora que en el sector privado, sin distinción de la rama de actividad de que se trate.

Distinguiendo el mercado de trabajo por rama de actividad, en el mismo informe, puede contemplarse que la presencia de mujeres se concentra mayormente en sectores feminizados como son servicio doméstico, salud, enseñanza y servicios sociales.

Por su parte, según describe el resumen ejecutivo del libro Gasparini y Marchionni 2015. ¿Brechas que se cierran? Aumento y desaceleración de la participación laboral femenina en América Latina. CEDLAS FCE UNLP, en esta región, la participación de la mujer en el mercado laboral mostró a comienzos del año 2000 una clara desaceleración de su crecimiento. "Mientras la tasa de participación de las mujeres crecía a 0,9 puntos por año en los 90, a partir del año 2000 y posteriormente la velocidad se redujo a un tercio, es decir a 0,3 puntos por año"10. A su vez, resultó relevante para esta investigación observar que, según este documento, entre las mujeres más perjudicadas se encontraban las que tenían menor nivel educativo, si bien este marco de situación afectaba a todos los grupos de mujeres. Asimismo, las mujeres con mayor nivel educativo se encontraban a los mismos niveles de los países desarrollados, lo que permite reflexionar sobre la gran importancia que ejerce como factor impulsor la educación y formación para

\footnotetext{
10 Gasparini, Leonardo y Marchionni, Mariana. 2015. ¿Brechas que se cierran? Aumento y desaceleración de la participación laboral femenina en América Latina Resumen Ejecutivo CEDLAS Centro de Estudios Distributivos Laborales y Sociales FCE UNLP
} 
el género femenino, para mantener y aumentar su participación en el mercado laboral.

Por otra parte, según otro informe elaborado por el CEDLAS, $27 \%$ más de mujeres que varones en nuestro país, logran acceder a puestos calificados y esto resulta congruente con la idea de que cada vez son más las mujeres que acceden a más educación. Sin embargo, y tal como se vino observando que sucede en otras regiones, menos de la tercera parte de los cargos jerárquicos están ocupados por el género femenino. Así en Argentina, "de cada 10 puestos de gerente, funcionario o legislador, 7 son varones y sólo 3 son mujeres"11

Focalizando el análisis a las Organizaciones de Salud, donde pone la mirada la presente investigación, surge del informe: Aportes para el Desarrollo Humano en Argentina PNUD 2018 "Género en el sector de la Salud. Feminización y Brechas laborales". № 9, un antecedente que merece observación. El mismo expone datos sobre el crecimiento que ha tenido la participación de las mujeres en la medicina en las últimas décadas, señalado en dicho informe como, "la consolidación del proceso de feminización en la medicina", que reflejan cambios en las instituciones sanitarias y desafíos para alcanzar la paridad de género. Entre esos cambios, dicho informe expone que, si bien se feminizó la medicina, la brecha de género genera desigualdades que se manifiestan de forma evidente en el acceso a cargos de alta jerarquía. Las mujeres tienen una menor representación en instituciones hospitalarias, ministerios, asociaciones profesionales e incluso el ámbito académico.

Se presentan también diferencias visibles entre las especialidades. Estas desigualdades no parecieran ser aleatorias, sino que suelen vincularse a atributos generalmente asociados con las capacidades de los varones-mayor "control" y manejo de alto riesgo- y las mujeres -mayor predisposición a la atención materno-infantil-, y a la intensidad en términos de demandas horarias. ${ }^{12}$.

Por otro lado, de acuerdo con datos publicados en la Revista Pilquen, donde se menciona que, según datos de la Asociación de Profesionales de la Salud de la Provincia de Buenos Aires, en 2011 el $80 \%$ de los directores ejecutivos y el $72 \%$ de los directores asociados de hospitales públicos son varones. En coincidencia,

\footnotetext{
${ }^{11}$ Marchionni M. Diciembre 2018. Los Desafíos de la igualdad de género. Revista ECONO FCE UNLP N¹7 Año 9

12 Programa de las Naciones Unidas para el Desarrollo -PNUD, 2018 Aportes para el desarrollo humano en Argentina 2018. Género en el sector salud: feminización y brechas laborales. $1^{\mathrm{a}}$ ed. Buenos Aires:
} 
información sobre la distribución de cargos de conducción en la salud pública de la Ciudad de Buenos Aires muestra que la gran mayoría de los cargos de conducción de la rama asistencial están ocupados por profesionales médicos varones: el $81 \%$ de los cargos de dirección de hospitales, el $70 \%$ de las subdirecciones y el $68 \%$ de las jefaturas de unidades son varones ${ }^{13}$ También aquí se verifica la asimetría que existe en cuanto a género, en la conducción de las organizaciones sanitarias.

Se pretendió indagar en el presente trabajo de investigación, a través de uno de sus ejes de estudio, si este marco de situación que se observa en las organizaciones en general $y$, particularmente en las organizaciones sanitarias a nivel asistencial, se replica también en los ámbitos de la gestión de las organizaciones de Salud, dentro del sector privado, a nivel local.

Paralelamente a esta tendencia percibida dentro de las organizaciones y en el mercado laboral, se viene perfilando un fenómeno interesante, que se ha profundizado en la última década, y que tiene que ver con que las mujeres han venido registrando tanto a nivel nacional como regional y local, una mayor tasa de matriculación, egreso y desempeño educativo que los varones, en los diferentes niveles de educación.

Según los datos recogidos del INDEC, en el último Censo Nacional de Población, Hogares y Vivienda 2010, de un total de 1.929 .813 personas en todo el país que han completado su formación universitaria, ${ }^{14} 1.050 .662$ son mujeres, mientras que 879.151 pertenecen al género masculino, traducido en valores porcentuales, el $54 \%$ representa al género femenino mientras que el $46 \%$ lo integran los varones.

En las principales universidades del país, desde hace ya varios años, la matrícula femenina se ha incrementado, incluso entre aquellas facultades tradicionalmente masculinas.

En la Universidad de Buenos Aires (en adelante UBA) la participación de las mujeres se expandió del 58,2\% en el año 2004 al 60,9\% en el año 2011, según datos oficiales obtenidos del "Censo de Estudiantes 2011. SIP- Sistema de

\footnotetext{
13 Aspiazu Eliana. 2016. Heterogeneidad y desigualdad de género en el sector salud: entre las estadísticas y las percepciones sobre las condiciones de trabajo. Revista Pilquen. Sección ciencias Sociales. Vol. 19 N¹ p60 - $2016 S S N$ 1851-3123 • http://www.curza.net/revistapilquen/index.php/Sociales

${ }^{14}$ Total país, población de 20 años y más que ha completado la formación universitaria, incluido el nivel pos universitario completo e incompleto
} 
Información Permanente" de la UBA. En el mencionado reporte, se puede percibir que los últimos recintos masculinos se encuentran en las facultades de Ingeniería, Agronomía y Ciencias Exactas, sin embargo, en dichos sectores los varones han perdido espacio.

Muy por el contrario, en el mismo informe se puede observar que en las facultades de Psicología, Odontología, Ciencias Veterinarias, Farmacia y Bioquímica, y Medicina, la proporción de mujeres es superior al $70 \%$.

Un panorama similar puede apreciarse en la Universidad Nacional de La Plata (en adelante UNLP). Según datos oficiales obtenidos a través del CeSPI (Centro de Cómputos de la UNLP) para la presente investigación, en el año 2016 el $63 \%$ de los egresados a nivel de grado estuvo compuesto por mujeres, y esta realidad se ajusta a una tendencia que se viene intensificando año tras año.

Del mismo modo, es notorio que si bien el número de inscriptos femeninos en las carreras de grado, supera al masculino, (57\% para las mujeres, 43\% para los varones), esta diferencia se acentúa en 7 puntos porcentuales cuando se observa la cantidad de egresos, (63\% de mujeres egresadas, $37 \%$ de varones egresados). Lo expresado puede visualizarse en el cuadro 1 y gráfico 1 adjuntos:

Cuadro 1

\begin{tabular}{|c|c|c|c|c|c|}
\hline \multicolumn{5}{|c|}{ UNLP } \\
\hline \multicolumn{5}{|c|}{ Carreras de Grado } \\
\hline \multicolumn{5}{|c|}{ Inscriptos Año 2016 } & \multicolumn{3}{c|}{ Egresados Año 2016 } \\
\hline Femenino & Masculino & Total & Femenino & Masculino & Total \\
\hline 13357 & 9956 & 23313 & 3663 & 2114 & 5777 \\
\hline $57 \%$ & $43 \%$ & $100 \%$ & $63 \%$ & $37 \%$ & $100 \%$ \\
\hline
\end{tabular}


Gráfico 1

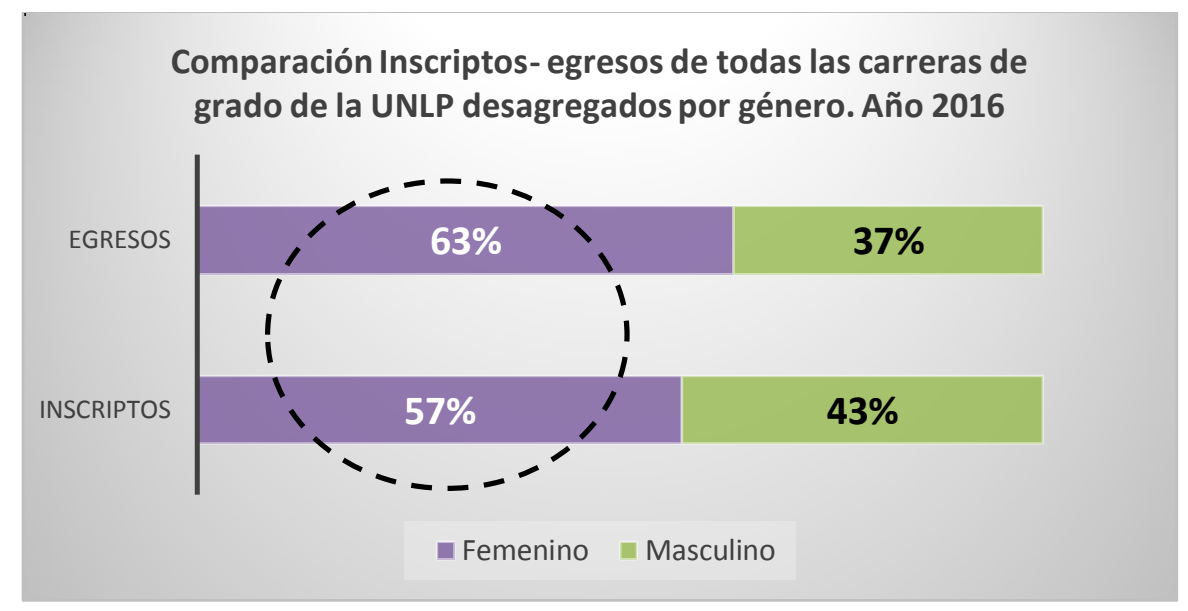

De las 17 unidades académicas de la UNLP, que fueron examinadas para este marco de estudio, sumado a la Escuela Universitaria de Recursos Humanos de Equipos de Salud, también dependiente de la UNLP, es notorio que en 11 de ellas el género femenino supera ampliamente al masculino tanto en cantidad de inscriptos como en egresos, mientras que sólo 4 unidades académicas mantengan el predominio masculino (Humanidades, Informática, Ingeniería y Agronomía). Lo expuesto, se aprecia con mayor detalle en el cuadro 2 y gráfico $2 a$ y $2 b$ adjuntos: 
Cuadro 2

\begin{tabular}{|c|c|c|c|c|c|c|}
\hline \multirow{3}{*}{ Facultades UNLP } & \multicolumn{6}{|c|}{ Carreras de grado UNLP } \\
\hline & \multicolumn{3}{|c|}{ Inscriptos Año 2016} & \multicolumn{3}{|c|}{ Egresados Año 2016} \\
\hline & Femenino & Masculino & Total & Femenino & Masculino & Total \\
\hline $\begin{array}{l}\text { Escuela de Recursos Humanos de } \\
\text { la Salud }\end{array}$ & 1513 & 270 & 1783 & 528 & 75 & 603 \\
\hline Trabajo Social & 317 & 97 & 414 & 98 & 14 & 112 \\
\hline Odontología & 293 & 97 & 390 & 170 & 79 & 249 \\
\hline Psicología & 1307 & 441 & 1748 & 418 & 72 & 490 \\
\hline Veterinaria & 381 & 150 & 531 & 61 & 40 & 101 \\
\hline Ciencias Médicas & 1969 & 882 & 2851 & 252 & 155 & 407 \\
\hline Exactas & 504 & 321 & 825 & 104 & 51 & 155 \\
\hline Ciencias Jurídicas y Sociales & 1143 & 872 & 2015 & 506 & 297 & 803 \\
\hline Ciencias Naturales y Museo & 296 & 238 & 534 & 81 & 61 & 142 \\
\hline Ciencias Económicas & 1246 & 1002 & 2248 & 243 & 165 & 408 \\
\hline Bellas Artes & 1813 & 1586 & 3399 & 309 & 188 & 497 \\
\hline Periodismo y Comunicación Social & 495 & 492 & 987 & 279 & 172 & 451 \\
\hline $\begin{array}{l}\text { Ciencias Astronómicas y } \\
\text { Geofísicas }\end{array}$ & 156 & 179 & 335 & 12 & 8 & 20 \\
\hline Arquitectura y urbanismo & 416 & 496 & 912 & 250 & 219 & 469 \\
\hline Agrarias y Forestales & 89 & 135 & 224 & 16 & 46 & 62 \\
\hline Ingeniería & 338 & 900 & 1238 & 93 & 224 & 317 \\
\hline $\begin{array}{l}\text { Humanidades y Ciencias de la } \\
\text { Educación }\end{array}$ & 354 & 1227 & 1581 & 27 & 186 & 213 \\
\hline Informática & 95 & 571 & 666 & 10 & 62 & 72 \\
\hline
\end{tabular}


Gráfico 2a

Inscriptos en las carreras de grado de la UNLP desegregados por facultad y por género. Año 2016

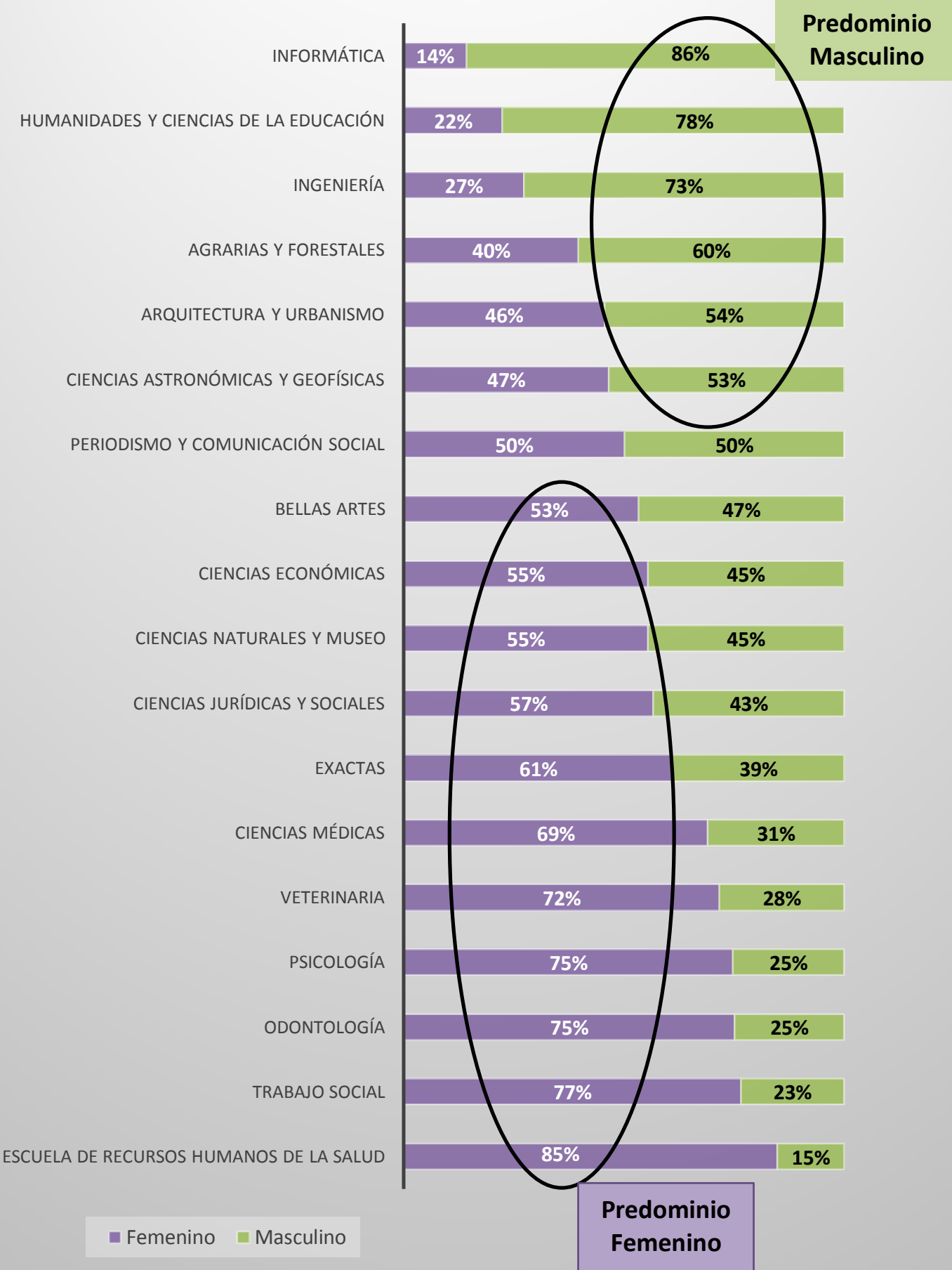


Gráfico $2 b$.

Egresos carreras de grado de la UNLP desagregados por facultad y por

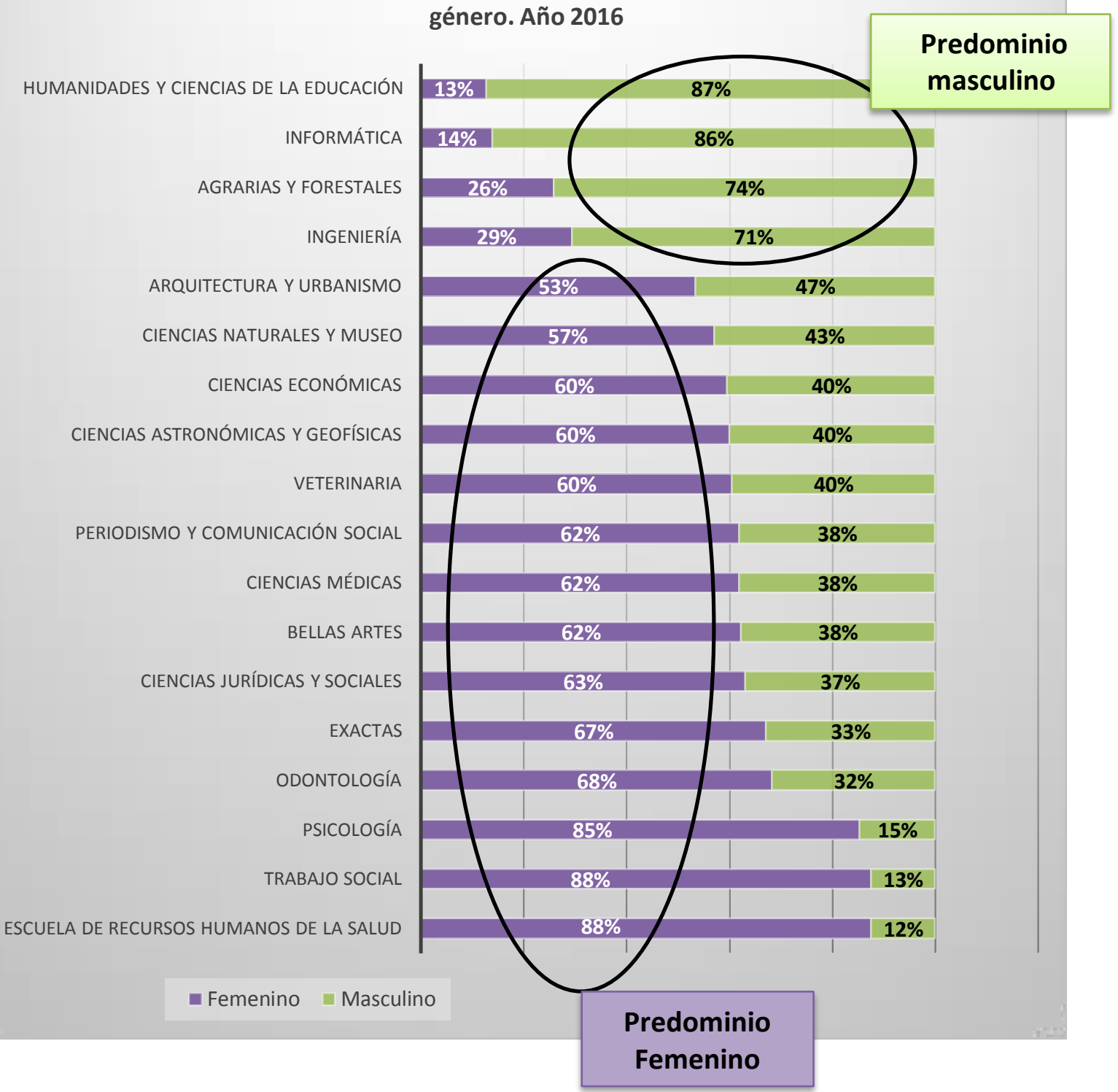

Es importante aclarar aquí que la presente investigación no cuenta con datos sobre cantidad de inscriptos por año académico de períodos anteriores al 2016. A su vez, resulta complejo establecer un período promedio de permanencia de los alumnos en las carreras ya que cada una cuenta con diferentes plazos de graduación, por lo tanto, no se han podido obtener las tasas de graduación diferenciadas por género. 
Al mismo tiempo, según el informe "Aportes para el desarrollo Humano en Argentina 2011", los avances educativos de las mujeres se reflejan también en la matrícula de estudios a nivel de posgrado.

Así lo demuestran los datos oficiales del "Censo de Estudiantes 2011. SIPSistema de Información Permanente" de la UBA, que acredita una mayor presencia de mujeres, alcanzando el $61,8 \%$ de los estudiantes de posgrado en el año 2011, lo que claramente señala una participación mayoritaria respecto de los varones.

La UNLP también mantiene el dominio del género femenino, sin embargo, presenta datos un tanto más uniforme en cuanto a los egresos de posgrado para ambos géneros, dado que las mujeres consiguen el $53 \%$ de las graduaciones de posgrado mientras que los varones alcanzan el $47 \%$.

En cuanto a la cantidad de inscriptos en las carreras de posgrado de la UNLP puede observarse que las mujeres superan con mayor amplitud los valores con un $60 \%$ de inscripciones contra el $40 \%$ del género opuesto. Situación que permite pensar que las necesidades de una formación de posgrado son mayores en las mujeres aun cuando enfrenten barreras, ligadas al género, que les dificulten alcanzar las metas deseadas. Lo descripto puede observarse en detalle en cuadro y gráfico 3 :

Cuadro 3

\begin{tabular}{|c|c|r|r|r|r|}
\hline \multicolumn{6}{|c|}{ UNLP } \\
\hline \multicolumn{6}{|c|}{ Carreras de Posgrado } \\
\hline Inscriptos Año 2016 & \multicolumn{3}{c|}{ Egresados Año 2016} \\
\hline Femenino & Masculino & Total & Femenino & Masculino & Total \\
\hline 1476 & 997 & 2473 & 296 & 258 & 554 \\
\hline $60 \%$ & $40 \%$ & $100 \%$ & $53 \%$ & $\mathbf{4 7 \%}$ & $100 \%$ \\
\hline
\end{tabular}


Gráfico 3

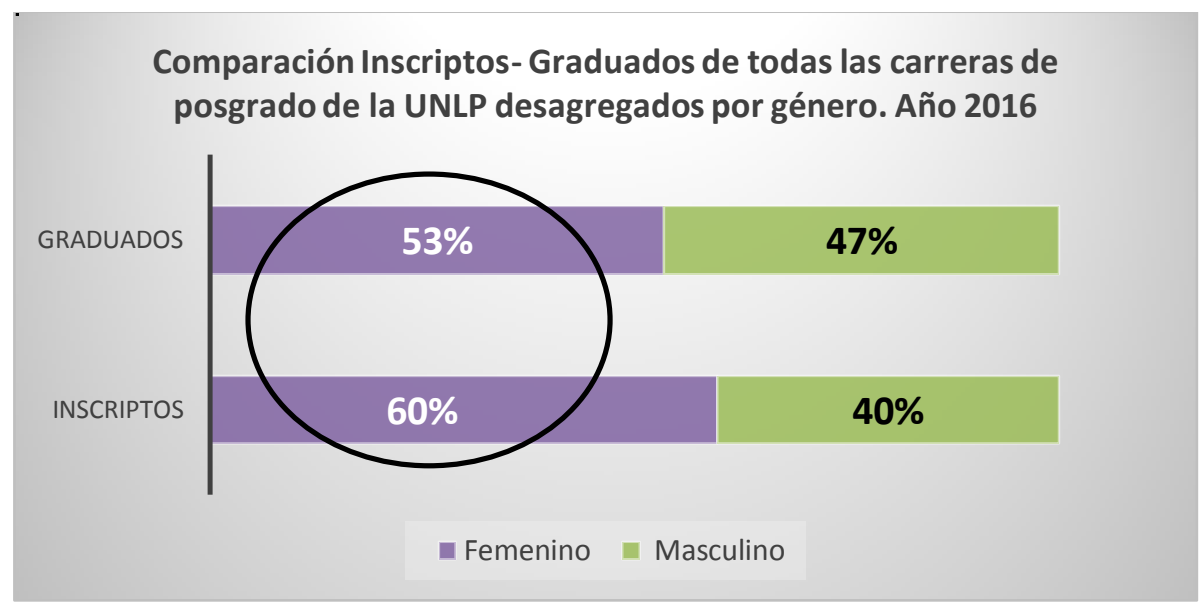

En la UNLP, de las 17 unidades académicas analizadas a nivel de posgrado, puede observarse que las mujeres superan en número los egresos en 8 recintos, mientras que los varones lo hacen en 6 , el resto de las entidades mantiene paridad de género.

Un dato que merece análisis es el de la Facultad de Informática, allí sólo el $20 \%$ de los inscriptos a nivel de posgrado pertenecen al género femenino, sin embargo, a la hora de analizar las graduaciones, el $50 \%$ de las mismas son otorgadas a las mujeres. Así, la tasa de graduación femenina alcanza el 76\% mientras que la tasa de graduación masculina es solo del 19\%, lo que permite inferir que ellas exhiben una superior performance que sus pares masculinos. Lo mencionado puede observarse con mayor precisión en los cuadros y gráficos 4 y 5 adjuntos: 
Cuadro 4

\begin{tabular}{|l|c|c|c|c|c|c|}
\hline \multirow{2}{*}{ Facultades UNLP } & \multicolumn{5}{|c|}{ Carreras de Posgrado UNLP } \\
\cline { 2 - 7 } & \multicolumn{7}{|c|}{ Inscriptos Año $\mathbf{2 0 1 6}$} & \multicolumn{2}{c|}{ Inscriptos Año 2016 (\%) } \\
\cline { 2 - 7 } & Femenino & Masculino & Total & Femenino & Masculino & Total \\
\hline Odontología & 44 & 8 & 52 & $\mathbf{8 5 \%}$ & $\mathbf{1 5 \%}$ & $\mathbf{1 0 0 \%}$ \\
\hline Psicología & 37 & 9 & 46 & $\mathbf{8 0 \%}$ & $\mathbf{2 0 \%}$ & $\mathbf{1 0 0 \%}$ \\
\hline Trabajo Social & 58 & 24 & 82 & $\mathbf{7 1 \%}$ & $\mathbf{2 9 \%}$ & $\mathbf{1 0 0 \%}$ \\
\hline $\begin{array}{l}\text { Periodismo y } \\
\text { Comunicación Social }\end{array}$ & 240 & 117 & 357 & $\mathbf{6 7 \%}$ & $\mathbf{3 3 \%}$ & $\mathbf{1 0 0 \%}$ \\
\hline Bellas Artes & 57 & 34 & 91 & $\mathbf{6 3 \%}$ & $\mathbf{3 7 \%}$ & $\mathbf{1 0 0 \%}$ \\
\hline Ciencias Médicas & 88 & 57 & 145 & $\mathbf{6 1 \%}$ & $\mathbf{3 9 \%}$ & $\mathbf{1 0 0 \%}$ \\
\hline $\begin{array}{l}\text { Ciencias Naturales y } \\
\text { Museo }\end{array}$ & 65 & 43 & 108 & $\mathbf{6 0 \%}$ & $\mathbf{4 0 \%}$ & $\mathbf{1 0 0 \%}$ \\
\hline $\begin{array}{l}\text { Arquitectura y } \\
\text { urbanismo }\end{array}$ & 52 & 37 & 89 & $\mathbf{5 8 \%}$ & $\mathbf{4 2 \%}$ & $\mathbf{1 0 0 \%}$ \\
\hline $\begin{array}{l}\text { Ciencias Jurídicas y } \\
\text { Sociales }\end{array}$ & 185 & 150 & 335 & $\mathbf{5 5 \%}$ & $\mathbf{4 5 \%}$ & $\mathbf{1 0 0 \%}$ \\
\hline Exactas & 43 & 35 & 78 & $\mathbf{5 5 \%}$ & $\mathbf{4 5 \%}$ & $\mathbf{1 0 0 \%}$ \\
\hline Veterinaria & 47 & 39 & 86 & $\mathbf{5 5 \%}$ & $\mathbf{4 5 \%}$ & $\mathbf{1 0 0 \%}$ \\
\hline Ciencias Económicas & 117 & 114 & 231 & $\mathbf{5 1 \%}$ & $\mathbf{4 9 \%}$ & $\mathbf{1 0 0 \%}$ \\
\hline Agrarias y Forestales & 32 & 32 & 64 & $\mathbf{5 0 \%}$ & $\mathbf{5 0 \%}$ & $\mathbf{1 0 0 \%}$ \\
\hline Ingeniería & 14 & 14 & $\mathbf{2 8}$ & $\mathbf{5 0 \%}$ & $\mathbf{5 0 \%}$ & $\mathbf{1 0 0 \%}$ \\
\hline $\begin{array}{l}\text { Ciencias Astronómicas y } \\
\text { Geofísicas }\end{array}$ & 18 & 18 & 36 & $\mathbf{5 0 \%}$ & $\mathbf{5 0 \%}$ & $\mathbf{1 0 0 \%}$ \\
\hline $\begin{array}{l}\text { Humanidades y Ciencias } \\
\text { de la Educación }\end{array}$ & 52 & 166 & 218 & $\mathbf{2 4 \%}$ & $\mathbf{7 6 \%}$ & $\mathbf{1 0 0 \%}$ \\
\hline Informática & $\mathbf{2 5}$ & 102 & 127 & $\mathbf{2 0 \%}$ & $\mathbf{8 0 \%}$ & $\mathbf{1 0 0 \%}$ \\
\hline
\end{tabular}


Gráfico 4

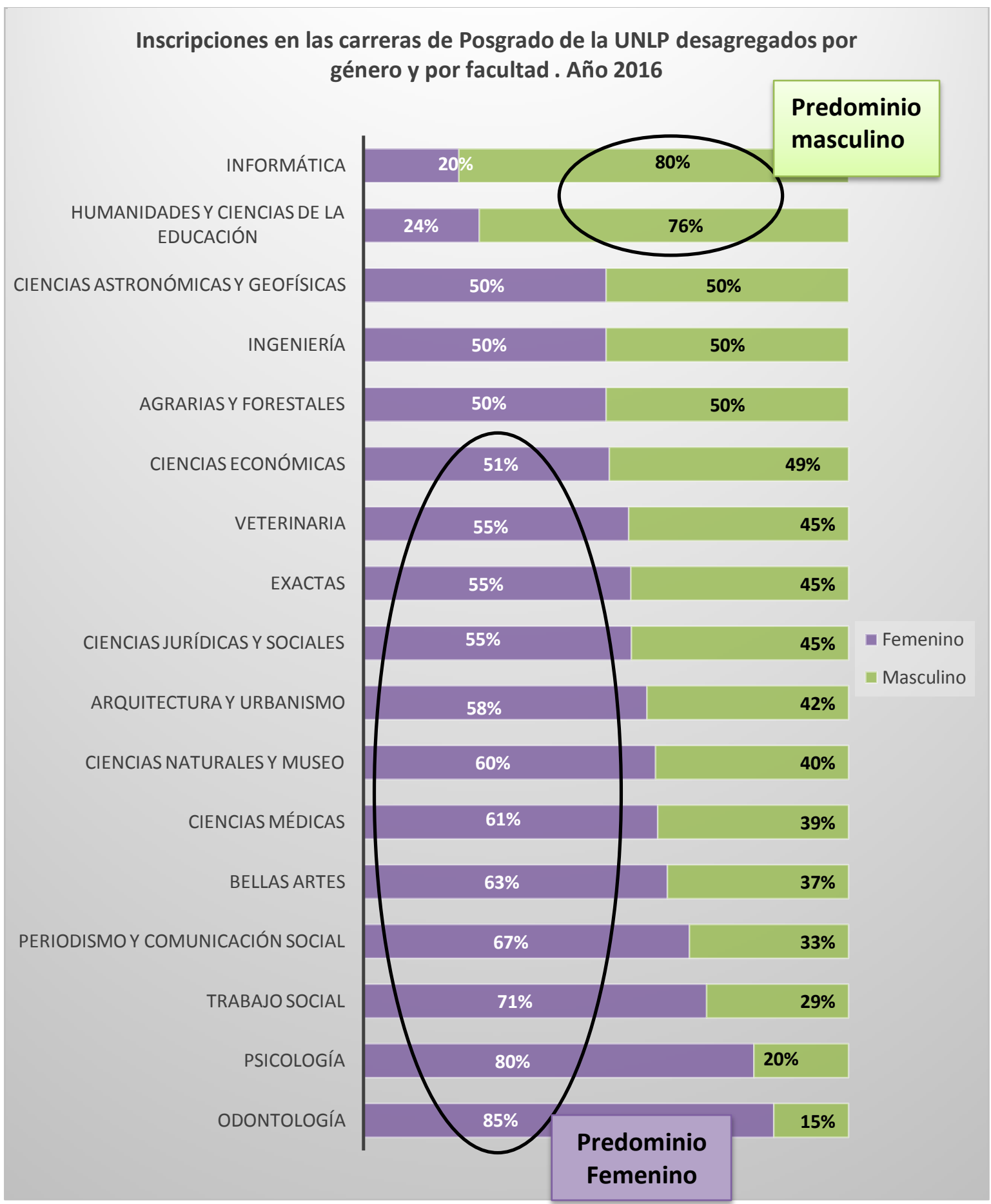


Cuadro 5

\begin{tabular}{|c|c|c|c|c|c|c|}
\hline \multirow[t]{3}{*}{ Facultades UNLP } & \multicolumn{6}{|c|}{ Carreras de Posgrado UNLP } \\
\hline & \multicolumn{3}{|c|}{ Egresados Año 2016} & \multicolumn{3}{|c|}{ Egresados Año 2016 (\%) } \\
\hline & Femenino & Masculino & Total & Femenino & Masculino & Total \\
\hline Arquitectura y urbanismo & 10 & 3 & 13 & $77 \%$ & $23 \%$ & $100 \%$ \\
\hline Bellas Artes & 6 & 2 & 8 & $75 \%$ & $25 \%$ & $100 \%$ \\
\hline Odontología & 7 & 3 & 10 & $70 \%$ & $30 \%$ & $100 \%$ \\
\hline Trabajo Social & 6 & 3 & 9 & $67 \%$ & $33 \%$ & $100 \%$ \\
\hline Ciencias Naturales y Museo & 40 & 22 & 62 & $65 \%$ & $35 \%$ & $100 \%$ \\
\hline Psicología & 10 & 6 & 16 & $63 \%$ & $38 \%$ & $100 \%$ \\
\hline Exactas & 45 & 29 & 74 & $61 \%$ & $39 \%$ & $100 \%$ \\
\hline Veterinaria & 19 & 18 & 37 & $51 \%$ & $49 \%$ & $100 \%$ \\
\hline Ciencias Jurídicas y Sociales & 17 & 17 & 34 & $50 \%$ & $50 \%$ & $100 \%$ \\
\hline Agrarias y Forestales & 13 & 13 & 26 & $50 \%$ & $50 \%$ & $100 \%$ \\
\hline Informática & 19 & 19 & 38 & $50 \%$ & $50 \%$ & $100 \%$ \\
\hline Ciencias Económicas & 39 & 40 & 79 & $49 \%$ & $51 \%$ & $100 \%$ \\
\hline Ciencias Médicas & 13 & 14 & 27 & $48 \%$ & $52 \%$ & $100 \%$ \\
\hline Ingeniería & 9 & 13 & 22 & $41 \%$ & $59 \%$ & $100 \%$ \\
\hline $\begin{array}{l}\text { Periodismo y Comunicación } \\
\text { Social }\end{array}$ & 13 & 19 & 32 & $41 \%$ & $59 \%$ & $100 \%$ \\
\hline $\begin{array}{l}\text { Ciencias Astronómicas y } \\
\text { Geofísicas }\end{array}$ & 3 & 7 & 10 & $30 \%$ & $70 \%$ & $100 \%$ \\
\hline $\begin{array}{l}\text { Humanidades y Ciencias de } \\
\text { la Educación }\end{array}$ & 10 & 30 & 40 & $25 \%$ & $75 \%$ & $100 \%$ \\
\hline
\end{tabular}


Gráfico 5

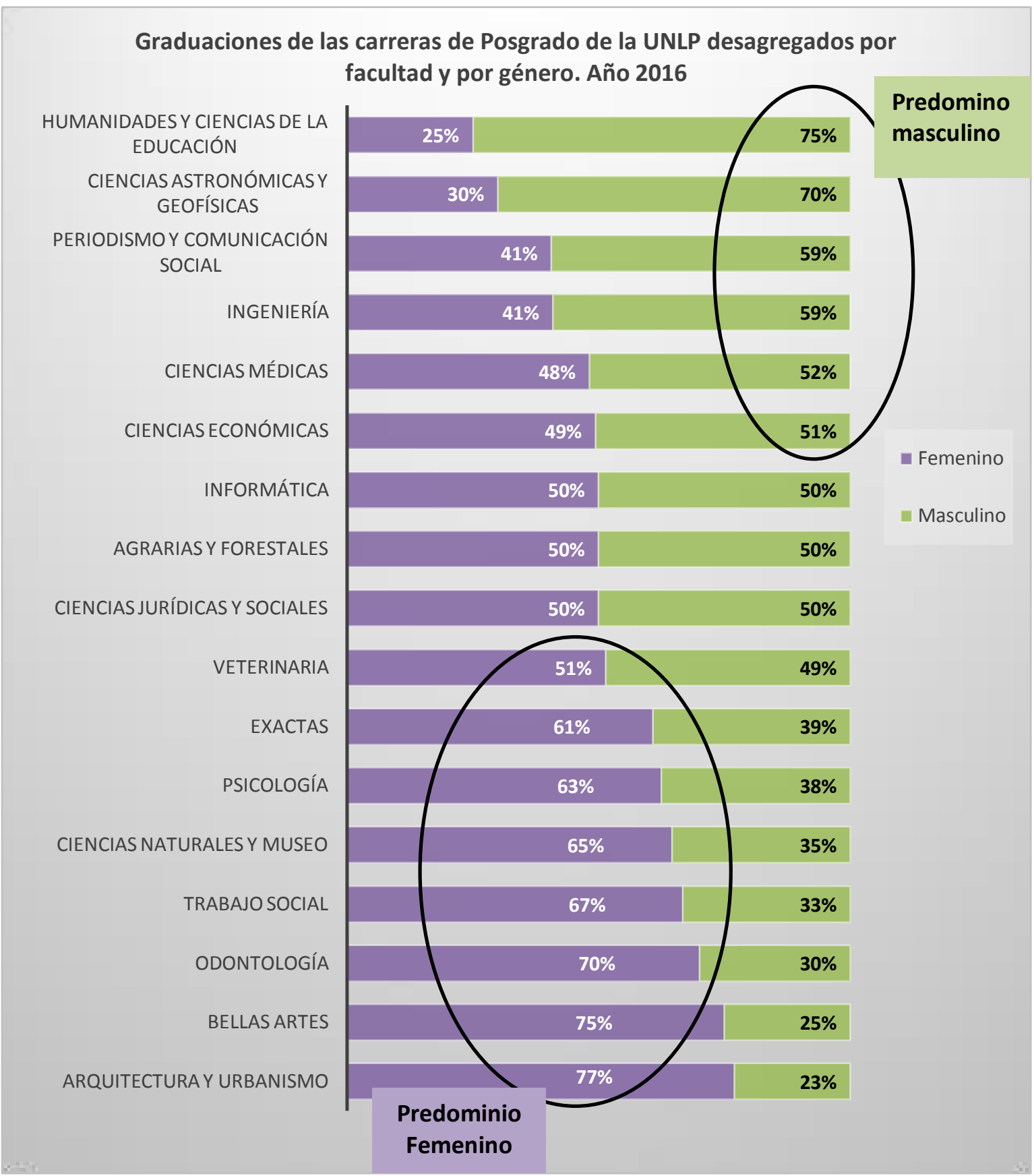

Aquí, al igual que se mencionó anteriormente en las carreras de grado de la UNLP (pág. 18), no se cuenta con datos certeros sobre cantidad de inscriptos por género en períodos anteriores al 2016, razón por la cual se desconocen las tasas de graduación femeninas y masculinas a nivel de posgrado 
Uno de los objetivos de la presente Investigación pretendió evidenciar si este fenómeno que se observa a nivel de grado y posgrado en las distintas carreras también se verifica en la formación de posgrados relacionados al campo de la gestión sanitaria.

En tal sentido, a nivel local, la UNLP sólo cuenta con dos unidades académicas que en las últimas décadas han abordado esta temática específica.

Una de ellas es la Facultad de Ciencias Económicas (en adelante FCE), que cuenta con una Escuela de Posgrado en Gestión de Organizaciones de Salud (EGSalud), cuya principal finalidad consiste en formar Administradores para el Sistema Sanitario. Entre sus actividades académicas dicha Escuela brinda dos carreras de posgrado:

- Maestría en Economía de la Salud y Administración de Organizaciones de Salud (MES) (discontinuada desde el año 2012)

- Especialización en Gestión de Organizaciones de Salud (ESAL) (actualmente en curso)

La segunda de las unidades académicas es la Facultad de Ciencias Médicas de la UNLP, que ofrece una Maestría en esta temática específica con tres orientaciones

- con orientación en Establecimientos y Servicios de Atención Médica

- con orientación en Sistemas de Salud

- con orientación en Sistemas Municipales de Salud.

Ambas unidades académicas fueron objeto de estudio en el presente trabajo. 


\section{Marco Teórico}

El abordaje teórico para la presente investigación se enfocó en dos grandes tópicos: Género; y Management haciendo foco en Management Sanitario.

\section{Género}

Antes de entrar en la temática del género, uno de los temas centrales de esta investigación, es importante diferenciar este término de lo que se entiende por sexo, que se refiere a las diferencias biológicas que existen entre hombres y mujeres e incluyen la anatomía, fisiología y el sistema hormonal ${ }^{15}$.

El termino Género adquiere otra implicancia, tiene que ver con lo cultural, con los diferentes significados que los integrantes de una sociedad o comunidad le asignan al ser femenino y masculino.

Así para abordar el tema de Género se escogieron los siguientes conceptos delineados en el informe: "Aportes para el Desarrollo Humano en Argentina 2011" del Programa de Naciones Unidas para el Desarrollo PNUD.

Género: "los atributos sociales y las oportunidades asociadas con el ser femenino y masculino $y$ las relaciones entre mujeres $y$ varones, niñas y niños, como también entre las mujeres y entre los varones. Estos atributos, oportunidades y relaciones están construidos socialmente, son aprendidos a través de procesos de socialización y varían según el contexto social y temporal”16

Al hablar de género, la distinción no solamente es física, la misma se configuración a partir del sentido que una comunidad, una institución o una persona le confiere a ser mujer o varón. ${ }^{17}$

Igualdad de género: "igualdad de derechos, responsabilidades y oportunidades de mujeres y varones, niños y niñas. Ello significa, entre otras cuestiones, que el acceso a estos derechos, responsabilidades y oportunidades no dependan de haber nacido con sexo masculino o femenino. ${ }^{18}$

Como construcción social el género, fue estableciendo y determinando roles y espacios propios para cada sexo de acuerdo con un sistema de dominación

\footnotetext{
${ }^{15}$ Castro Solano y otros 2007. Teoría y Evaluación del Liderazgo $1^{\circ}$ edición. Paidós Buenos Aires, p 69

${ }^{16}$ Programa de la Naciones Unidas para el Desarrollo (PNUD) 2011. Obra ya citada., p.1

${ }^{17}$ Aquí el término hombre se tomará como sinónimo de varón.

${ }^{18}$ Obra ya citada. $\mathrm{p} 1$
} 
masculina (sistema patriarcal), que fue cambiando de una sociedad a otra y de una época a la siguiente. De este modo, se imputan patrones, identidades y modos de conducta de cómo deben comportarse varones y mujeres de acuerdo con su sexo biológico. Asimismo, se delimitan y establecen cuáles son los roles, responsabilidades y trabajos que deben ejercer ambos géneros en una sociedad. ${ }^{19}$ Es a través del proceso de socialización que estos roles diferenciales son aprendidos y asumidos como normales generando esquemas mentales y estilos de vida cambiantes para varones y mujeres.

De manera que, a los varones se los ha educado para desarrollarse en el ámbito social o público, entendiéndose a este último como el ámbito fuera del hogar, mientras que a las mujeres se las ha educado para asumir y ejercer las responsabilidades del cuidado familiar y del hogar relacionadas con el ámbito privado, familiar y doméstico.

Se entiende en esta investigación a los estereotipos de género como aquellas imágenes preconcebidas de cómo son y cómo deben comportarse los varones y las mujeres en una sociedad.

Esta premisa trae asociado el concepto de los frenos e impulsores que consecuentemente dificultan o motorizan a cada género para ocupar posiciones de poder formal en las organizaciones.

Se consideró oportuno en la presente investigación, explorar y tomar algunos elementos del trabajo: "Economía Social con Perspectiva de Género. De la Dirección General de Economía Social y Emprendedores. CEPES - Andalucía", a fin de intentar establecer una clasificación de los factores considerados influyentes en la presente, para el acceso a los cargos de gestión en la alta gerencia.

Así, por el lado de los frenos o barreras que encuentran especialmente las mujeres a la hora de acceder o ascender en la escala jerárquica de las organizaciones se pueden mencionar tanto factores externos como internos, entre ellos:

\footnotetext{
19 Azpiazu Eliana. 2016. Heterogeneidad y desigualdades de Género en el sector salud: entre las estadísticas y las percepciones sobre las condiciones de trabajo Revista Pilquen Sección Ciencias Sociales • Vol. 19 No 1 • 2016 SSN 1851-

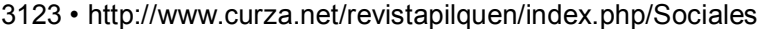


La cultura de la organización, definida aquí como "el sistema de significados compartidos por los miembros de una organización, que la distinguen de otra" ${ }^{20}$

En otras palabras, podría expresarse como el cúmulo de valores y creencias compartidas que evidencian las presunciones de los integrantes de una organización acerca de lo que se hace y debe hacerse en ella. ${ }^{21}$

Actuaría como un primer factor o barrera externa que encuentran, principalmente las mujeres, para acceder a puestos en la alta gerencia.

La cultura de la organización está compuesta por mecanismos o elementos visibles y palpables como son la estructura, la tecnología, las políticas, los relatos, el lenguaje, los símbolos, los procedimientos, los resultados en una institución y otros elementos menos visibles como son las percepciones, las premisas, los sentimientos, las conductas, los valores, las normas, etc.

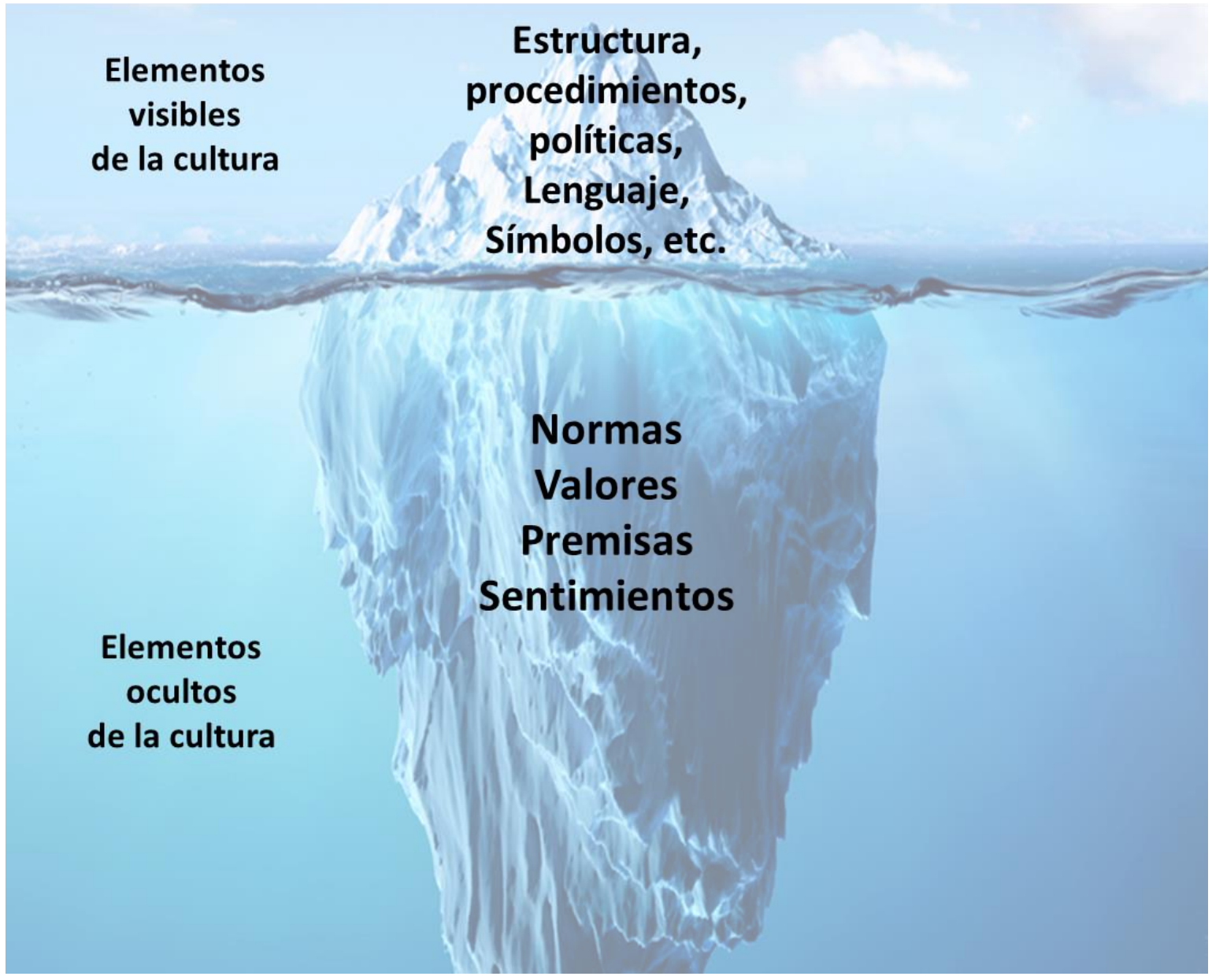

Elaboración propia

\footnotetext{
${ }^{20}$ Stephen P. Robbins.2004. Comportamiento Organizacional. Pearson Educación 10a. ed., México. P 525

${ }^{21}$ Castro Solano y otros. Obra ya citada, p 84
} 
Es importante destacar que también existen subculturas dentro de las organizaciones, éstas se presentan cuando los valores, las premisas y las normas son compartidas por algunos miembros de la organización, pero no por todos ${ }^{22}$.

Se generan cuando por ejemplo la organización es creada como resultado de una fusión, o porque los departamentos poseen normas y valores propios, o debido a que las instalaciones están ubicadas en otras zonas geográficas. También puede originarse porque existen diferentes fuerzas de trabajo que crean subculturas dentro de una misma institución.

Particularmente en las instituciones de salud, que son organizaciones donde conviven varios colectivos o grupos de poder (los diferentes profesionales, el personal administrativo, los técnicos, el personal de apoyo, los usuariospacientes, etc., como se explicará más adelante), puede observarse claramente cómo se entremezclan las diferentes subculturas dentro de la misma institución, lo que torna más complejo aún su funcionamiento y desarrollo.

Las distinciones en cuanto a las formas de sociabilización de varones y mujeres y las experiencias dispares en el trabajo son otras fuentes de subculturas en la organización. En muchas organizaciones, el género sigue aun representando un sesgo muy importante para la formación de subculturas.

Todas las nociones sobre lo femenino y lo masculino que integran la cultura de una institución están asentados en las percepciones y valoraciones que los miembros de una organización perciben e interpretan de cómo deben comportarse varones y mujeres. Estos conceptos inciden no solamente en las políticas, sino también en la forma en que se diseñan, estructuran y funcionan las organizaciones.

La valoración de los cargos está ligada a las diferentes valoraciones de los roles asignados a las mujeres (cuidado del hogar y la familia) y a los varones (a lo público o social, sustento del hogar). Se genera así lo que muchos autores denominan segregación ocupacional horizontal que refiere a la concentración de mujeres en sectores especificos, es decir, en ocupaciones identificadas como

\footnotetext{
${ }^{22}$ Hellriegel y otros. 2009. Administración. Un enfoque basado en competencias. 11 edición. CENGAGE Learning Editores SA. Cap. 18
} 
femeninas. ${ }^{23}$ Tradicionalmente la administración de los servicios de salud, uno de los pivotes centrales de la presente investigación, es considerada y calificada como ocupación masculina. Son organizaciones donde impera la cultura masculina y se espera que sus miembros en los altos mandos desplieguen características asociadas al género masculino lo que determina que las mujeres sufran más dificultades para desenvolverse efectivamente en esos contextos.

A su vez, la escala jerárquica en las organizaciones refleja las relaciones de subordinación mujer- varón. Los varones se concentran en las esferas de más alto nivel de dirección mientras que las mujeres suelen situarse en posiciones subordinadas. Este fenómeno que muchos autores denominan segregación ocupacional vertical genera que los varones que ocupan los puestos más altos están mejor remunerados.

En el sector de la salud, si bien en el área asistencial, se ha feminizado la fuerza de trabajo, lo que no significa que se logre la equidad de género, en la alta gerencia de estas organizaciones, siguen teniendo protagonismo los varones como administradores. Las mujeres se concentran en puestos de menor jerarquía, aunque posean igual calificación que sus pares masculinos.

En el mercado laboral en general, prevalece una sobre calificación femenina, es decir, una falta de correspondencia entre educación adquirida y calificación de la tarea que desarrollan las mujeres. Habitualmente se les asigna a las mujeres capacitadas trabajos de menor valor tanto en términos de calificación requerida como de remuneración. De este modo, ellas, terminan condenadas a convertirse en personal de apoyo de sus colegas masculinos, quienes ocupan posiciones superiores en la escala jerárquica de las organizaciones. Por lo expuesto, llegan a ocupar en general, empleos de los denominados "no estratégicos". ${ }^{24}$

"La regla empírica es siempre la siguiente: cuanto más alta es la jerarquía institucional, menos mujeres hay" (OIT 2004 Romper el Techo de Cristal, Las mujeres en puestos de dirección, p: 15)

\footnotetext{
${ }^{23}$ Programa de la Naciones Unidas para el Desarrollo (PNUD) 2011. Obra ya citada, p. 19

${ }^{24}$ Organización Internacional del trabajo OIT. 2004. ROMPER el techo de Cristal. Las mujeres en puestos de dirección. Ginebra p. 10
} 
Los estereotipos de género tradicionales conciben a las mujeres como pasivas, tímidas, sensibles, amigables, expresivas y preocupadas por los otros, en contraposición a las cualidades fundamentales para dirigir con éxito y que están ligadas a actitudes masculinas como son la determinación, control, racionalidad, agresividad, competitividad, sagacidad, asertividad, vigor, que se han formado en base a observar modelos exitosos históricos que han sido tradicionalmente dirigidos y conducidos por el género masculino. ${ }^{25}$ Tienen un impacto negativo para el óptimo aprovechamiento del recurso humano e Implican una barrera perjudicial para la libre movilidad laboral.

En tal sentido, los individuos tienden a creer que para poder ocupar puestos de dirección eficazmente es imprescindible desplegar cualidades masculinas, en base a observar modelos exitosos históricos, como ya se mencionó anteriormente. Dicha percepción ha presionado e influido en muchas mujeres a adoptar estilos de conducción masculinos a fin de ser consideradas y valoradas como más competentes para ocupar esos cargos en la cima gerencial ${ }^{26}$.

Esto conduce a examinar el término "techo de cristal," metáfora que tuvo su origen en la década de los 70 y que es concebida como las barreras invisibles, como el conjunto de normas no escritas o cultura de una organización que complican el acceso de las mujeres a determinados cargos directivos, es decir, permiten a las mujeres avanzar sólo hasta un estipulado nivel de la escala jerárquica. Cabe hacer una diferenciación con el término "techo de cemento" entendido como las barreras impuestas por autodeterminaciones personales tales como rechazar la promoción a puestos directivos más rígidos y exigentes.

Por otra parte, también pueden apreciarse barreras laterales denominadas "muros de cemento" o "paredes de cristal" que generan una segregación horizontal, concepto mencionado anteriormente.

Una importante barrera interna que enfrentan las mujeres, la cual demora y muchas veces impide su promoción y desarrollo profesional, se relaciona con asumir las responsabilidades familiares, cuidados filiales y tareas domésticas como propias, interiorizado como un deber asociado a su género, guiadas por

\footnotetext{
${ }^{25}$ Obra ya citada, p. 69

${ }^{26}$ Castro Solano y otros. Obra ya citada, p 83
} 
estereotipos aprendidos fruto de una cultura patriarcal, que generan un conflicto de repartos de tiempos y dedicación y la sensación de la denominada "doble jornada". Este fenómeno, que algunos autores denominan "suelo pegajoso," da cuenta de las pujas que mantienen a tantas mujeres atrapadas en la base de la pirámide organizacional.

Con relación a este tema, también en notorio observar las discontinuidades que se producen en las instituciones, coherentes con puntos cruciales del ciclo Vital $^{27}$ (casamiento, nacimiento del primer hijo, ingreso del menor al sistema escolar), y que se manifiestan con mayor frecuencia entre las mujeres, generando una importante barrera para el acceso y permanencia en los cargos de dirección.

Aquí, y siguiendo a Lidia Héller en su libro: "Mujeres... y varones en las organizaciones. Ambiciones y aspiraciones", se agrega el concepto de "laberinto" como concepto superador al término "techo de cristal", dado que dicha imagen refleja que existen salidas cuando se posee talento, perseverancia, inteligencia, actitud, pero también evidencia la existencia de ciertos obstáculos y complicaciones que demoran o frenan el acceso a la alta cúspide de las organizaciones.Otro término significativo y de interés para la presente investigación es el de los Costos personales entendido como todo aquello que una persona haya dejado de hacer o que haya repercutido negativamente como consecuencia de ocupar un cargo gerencial (por ejemplo, no contar con tiempo de ocio, conflictos con la familia, con la pareja, etc.)

En contraposición al término de los frenos y barreras, se conceptualiza en la presente investigación el término Impulsor como aquel elemento que facilita el desarrollo profesional y la conquista de un puesto de representación para la toma de decisiones en una organización.

Al hablar de impulsores es vital diferenciar entre los impulsores internos, aquellos que dependen o derivan de la propia personalidad, e impulsores externos, aquellos que están condicionados por componentes del ambiente social.

Específicamente, dentro de los impulsores internos puede distinguir un componente personal, conformado por las características de la personalidad, los valores y motivaciones propios de cada individuo y un componente profesional,

\footnotetext{
${ }^{27}$ Obra ya citada, p 73
} 
que tiene que ver con la formación profesional y la gestión del tiempo para alcanzar los puestos de representación.

Los valores se pueden concebir como aquellos principios y criterios, que definen lo que está bien y lo que está mal para una sociedad determinada; configuran las actitudes habituales de aprobación de lo que se considera deseable y de desaprobación de lo indeseable. ${ }^{28}$

Es importante destacar que la escala de valores cambia según el género, muchos de los valores que tradicionalmente han sido asignados a las mujeres (el cuidado, la escucha, el respeto, la ternura, el amor, etc.) siguen rigiendo aún hoy en la sociedad. En cambio, aquellos que las han conservado en situaciones de inferioridad respecto al varón y han supuesto prácticas denigrantes y ofensivas para ellas van desapareciendo, pues dejan de considerarse deseables y respetables por un amplio sector social (sumisión, obediencia, dependencia, etc.) De este modo, existen valores que permanecen y se van transmitiendo de generación en generación, mientras que otros van experimentando profundos cambios a nivel intergeneracional.

La motivación, otro impulsor interno, está compuesta por un cúmulo de estímulos personales que mueven a un individuo a realizar alguna actividad y persistir hasta su culminación. Las motivaciones pueden ser de origen interno y externo. Motivaciones de origen interno: satisfacción por el trabajo, logro de las metas fijadas, gusto por las actividades cambiantes y variadas.

Motivaciones de origen externo: búsqueda de beneficio social, valoración, reconocimiento y experiencia con nuevas personas y lugares.

La formación también interviene como un elemento impulsor en el desarrollo profesional, sin embargo, su elección genera y contribuye a la segregación horizontal.

Es importante aclarar que, en esta investigación, se utilizará un concepto más específico cuando se hable de formación. Aquí se referirá a la formación de posgrado en administración y gestión sanitaria dado que lo que se quiere exaltar es la formación de un recurso humano competente para actuar en el complejo escenario sanitario. Esto define un campo de aplicación profesional

\footnotetext{
${ }^{28}$ Economía Social con Perspectiva de Género. Obra ya citada, p.44
} 
específico que exige conocimientos, destrezas, comportamientos y actitudes especiales para el profesional que participe en la gestión de este tipo de organizaciones. Dicho de otro modo, se analizará aquí exclusivamente una formación de posgrado específica, que genere expertos en el gerenciamiento integral de organizaciones de salud, con habilidades y destrezas para la toma de decisiones en este específico tipo de instituciones.

\section{Management. Management Sanitario}

Girando el abordaje teórico hacia la segunda de las temáticas contempladas para esta investigación, el Management y el Management Sanitario, se adoptaron los siguientes conceptos siguiendo a Stephen P. Robbins "Los administradores hacen cosas a través de otras personas. Toman decisiones, asignan recursos y dirigen las actividades de los demás para conseguir metas" ${ }^{29}$ Ellos realizan su labor en una organización entendida como una unidad social coordinada deliberadamente y compuesta por dos o más personas, que funciona de manera más o menos continua para alcanzar una meta o unas metas comunes. Se entenderá aquí el término organización como sinónimo de empresa, establecimiento, institución o nosocomio.

Por su parte, en referencia a las organizaciones de salud, donde pone la mirada el presente trabajo de investigación, se entiende a las mismas siguiendo los lineamientos de Carlos Alberto Díaz en su libro "El Pequeño Gestión ilustrado. Servicios de Salud". Así, las organizaciones de salud son organizaciones complejas con múltiples dominios sociales y técnicos, donde coexisten saberes, objetivos y metas en una conformación sistémica. ${ }^{30}$ Son organizaciones mano de obra intensiva que se caracterizan por la interacción y la interdependencia de sus centros de responsabilidad, de sus servicios finales e intermedios, con los usuarios y su entorno social. Los servicios que ellas proporcionan son bienes de confianza que tratan de cubrir la asimetría de información entre el equipo sanitario y los usuarios ${ }^{31}$.

\footnotetext{
${ }^{29}$ Stephen P. Robbins.2004 Comportamiento Organizacional Pearson educación. 10a ed., p. 4

${ }^{30}$ Carlos Alberto Díaz 2005. El pequeño Gestión llustrado servicios de salud. Ediciones ISALUD

${ }^{31}$ Obra ya citada
} 
Del mismo modo, son organizaciones del conocimiento que se mueven en un entorno de permanente incertidumbre, en un medio hostil, caótico y de permanente cambio.

Es necesario mencionar que, cuando en la presente investigación se habla de instituciones prestadoras de salud privadas, se refiere a aquellas instituciones que cuentan con internación y prestación quirúrgica, de mediana y gran complejidad que poseen particularidades que merecen ser tomas en cuenta: son organizaciones sumamente complejas, que están conformadas por varias empresas en una; la médica, la hotelera, la de producción y la educativa. Son instituciones mano de obra intensiva donde coexisten diferentes grupos de poder con similar protagonismo. Son establecimientos dinámicos que conviven en ambientes caóticos y con cambios permanentes condicionados por múltiples factores. Existe asimetría de información entre los diferentes grupos de poder, principalmente entre el equipo sanitario y los usuarios (pacientes). Como toda organización, cuentan con recursos limitados, su principal acervo es el capital humano, son organizaciones que asumen una creciente demanda y tienen como rol vital garantizar por, sobre todo, la calidad de su servicio.

Por otra parte, retomando la noción seguida por Stephen P. Robbins se tomó el concepto de administradores como los encargados de supervisar las actividades de los demás en una organización y los responsables de conseguir las metas de esa organización. También se los conoce como gerentes o directores.

En el presente trabajo de investigación se optó por utilizar los términos, director, administrador, gerente o mánager indistintamente.

Un gerente es una persona que planea, organiza, dirige y controla la asignación de recursos humanos, financieros y de información para lograr los objetivos de la organización. ${ }^{32}$

Es el responsable por el esfuerzo de un grupo de personas que comparten un objetivo y el acceso a los recursos que el grupo emplea para lograr su objetivo.

Todo gerente que desee ser eficaz en la función gerencial debe desarrollar determinadas competencias gerenciales, entendidas como el conjunto de conocimientos, destrezas, comportamientos y actitudes que necesita una persona para ser eficiente en una amplia gama de labores gerenciales.

\footnotetext{
${ }^{32}$ Hellrieger Jackson, Slocum. Obra ya citada, p 7
} 
Básicamente, siguiendo a Hellriegel, Jackson y Slocum, los gerentes deben desarrollar seis competencias gerenciales:

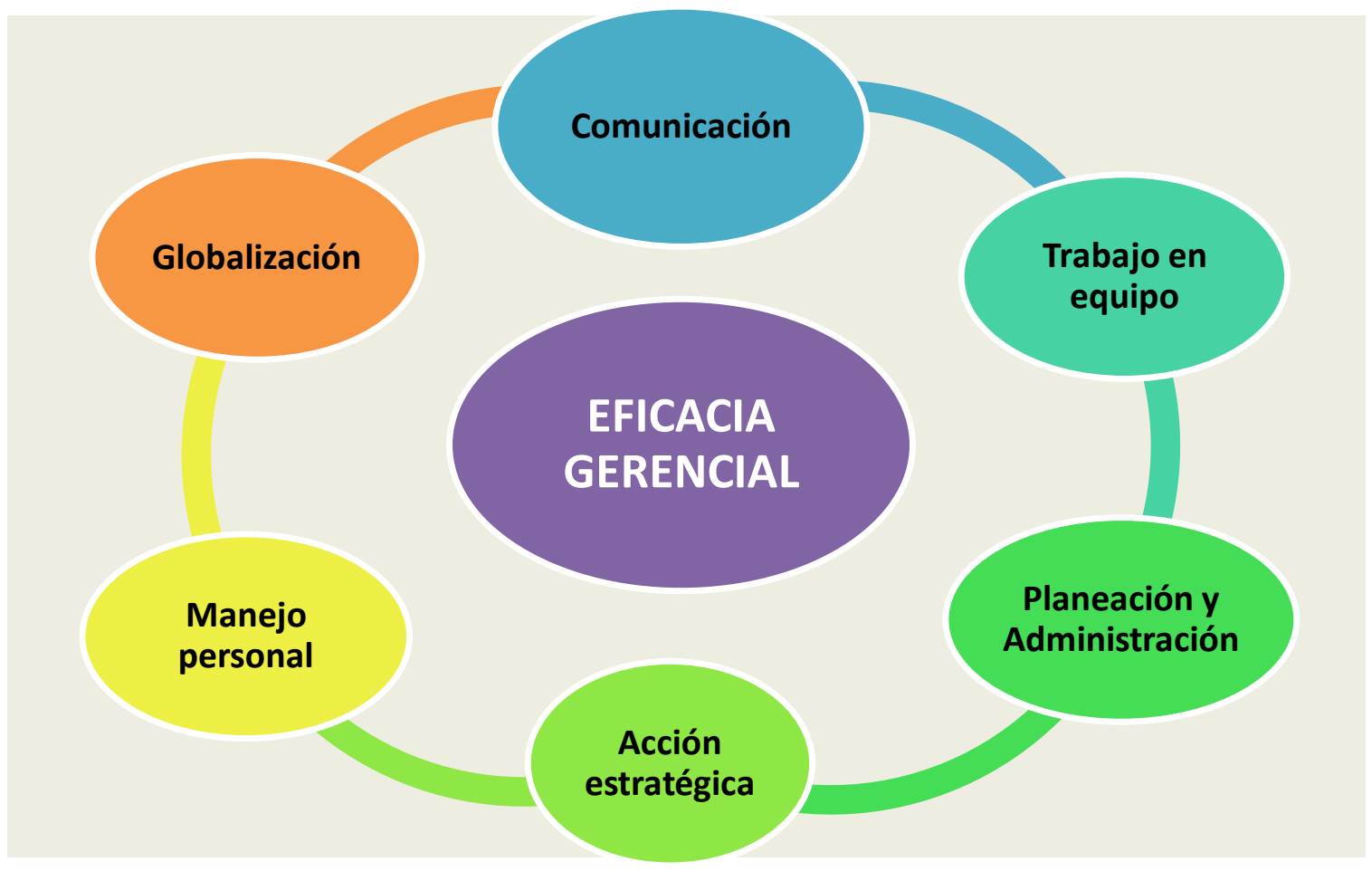

Elaboración propia

\section{Competencia en la Comunicación}

Se puede definir como la capacidad de saber transmitir e intercambiar eficazmente información con el resto de los individuos que se desempeñan en la institución. Comprende tanto la comunicación formal, informal y la negociación.

\section{Competencia para la planeación y administración}

Involucra decidir cuáles son las tareas a realizar y cómo llevarlas a cabo. A su vez también implica, asignar los recursos necesarios y supervisar la ejecución de las tareas a fin de corroborar su cumplimiento en tiempo y forma. Implica a su vez, recopilar y analizar información, resolver problemas, planear y organizar proyectos, administrar los tiempos, presupuestar y administrar las finanzas. 


\section{Competencia en el trabajo en equipo}

Un gerente necesita tener habilidades para planear los equipos en forma adecuada, generar un entorno de apoyo, conocer el manejo de las dinámicas de equipo, reconocer fortalezas y debilidades, y utilizarlas para potenciar y lograr los objetivos.

\section{Competencia en la acción estratégica}

Involucra comprender cuál es la misión y los valores generales de la organización para que las acciones que se lleven a cabo en la gerencia estén alineadas en la misma dirección con la organización. Implica también, conocer y entender cómo funciona la industria y aportar medidas estratégicas. Percibir todos los cambios que se generen en el ambiente de la organización aportando medidas estratégicas para hacer frente a esos cambios.

\section{Competencia para la globalización}

Implica que todo gerente no solo debe tener una comprensión cultural sino que debe estar abierto y ser sensible a las diferencias culturales para poder trabajar con personas de diferentes orígenes y formación.

\section{Competencia en el manejo personal}

Tiene que ver con la ética, con el carácter, con los principios, la motivación, los comportamientos.

Saber equilibrar las exigencias laborales y personales que muchas veces entran en conflicto, especialmente es el género femenino quien ha tenido grandes problemas para equilibrar esta puja entre lo personal y lo laboral a lo largo del tiempo.

En relación al tema de las competencias gerenciales, se considera acertado incluir en la presente investigación, una importante dimensión analizada por la autora Paula Molinari en su libro Turbulencia Generacional.

Ella destaca que dentro de las organizaciones conviven muchos individuos con diferentes mentalidades generacionales que deben compartir ideas, creencias, 
valores y comportamientos dentro de la institución. Molinari clasifica a esas diferentes mentalidades en cuatro, de acuerdo con las distintas épocas generacionales.

Según dicha autora, las mentalidades generacionales se forjan en base a los sucesos vividos por un grupo de personas como también a las consecuencias de esas experiencias. Las historias familiares, la relación con los pares, los eventos sucedidos, tanto regionalmente como a nivel mundial, en los diferentes momentos de la vida y primordialmente en la infancia, van moldeando y generando la forma de entender, interpretar y valorar el mundo. Esa mentalidad es la que delimitará el comportamiento de una persona configurando una personalidad generacional que no es estática, sino que se desarrolla, madura y se transforma, es decir, evoluciona. $^{33}$

De este modo Molinari establece cuatro categorías:

Los tradicionalistas, aquellos nacidos entre 1900 y 1945; los Baby Boomers, nacidos entre 1945 y 1964; la Generación X, nacidos entre 1964 y 1980 y la Generación Y o Millenials, entre 1981 y 2000

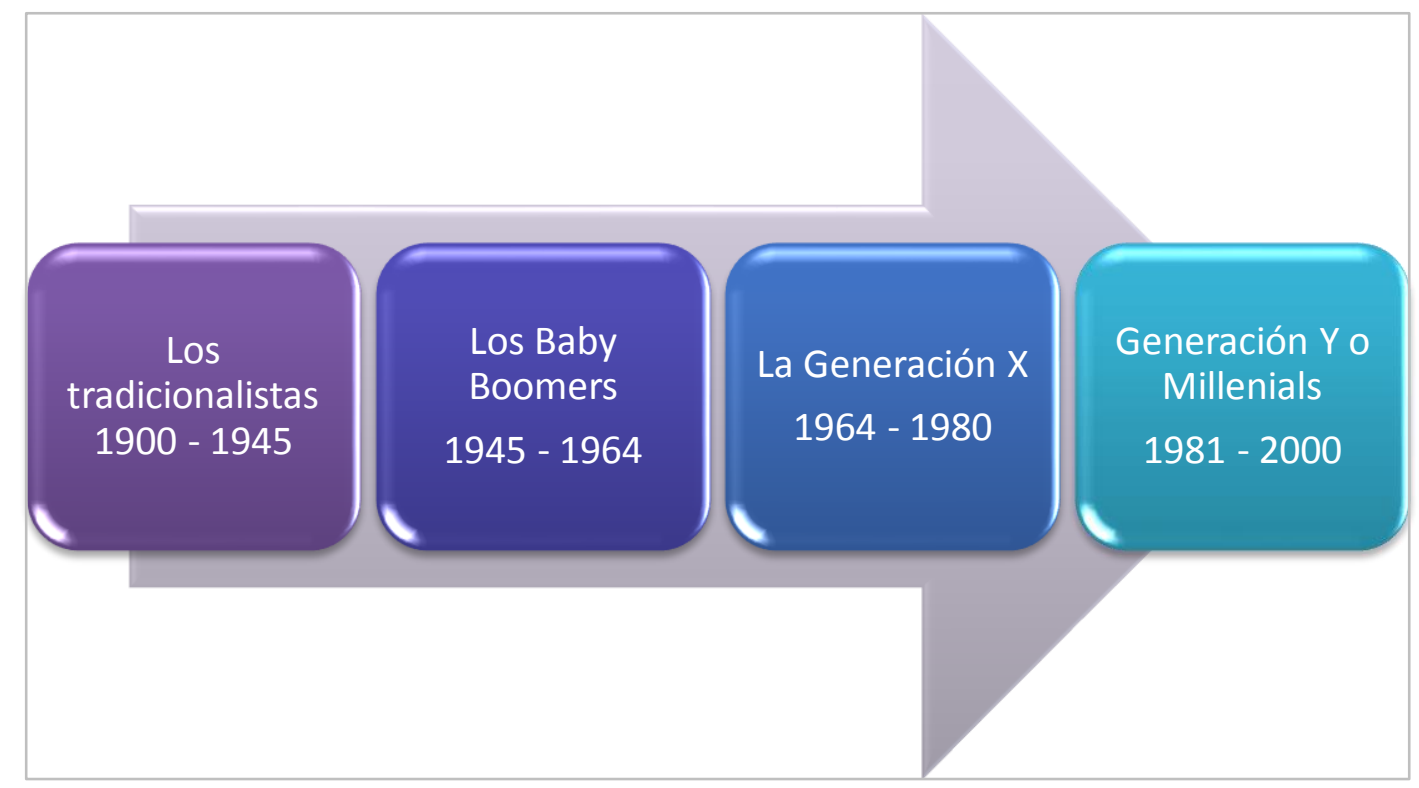

Elaboración propia

\footnotetext{
${ }^{33}$ Molinari, Paula. 2011. Turbulencia Generacional, 1ㅇed. Temas Grupo Editorial SRL. Buenos Aires.
} 
Los tradicionalistas $(1900-1945)$

Época en la que el mundo estaba en guerra (adversidad, escasez, y desempleo), Los valores eran el ahorro como base de la fortuna, el esfuerzo y el respeto a las instituciones.

Característica de esta generación: mentalidad austera, ahorrativa, alto compromiso y obediencia.

El management se basa en un estilo militar donde pocos deciden y muchos obedecen. Todo está establecido de antemano. Priman la ley, la lógica, la disciplina y el orden en las organizaciones tradicionalistas y se inhabilitan todos los pensamientos críticos para tomar decisiones.

\section{Los Baby Boomers (1945 - 1964)}

Una generación competitiva e idealista, como lo describe la autora. Nacidos en la posguerra con deseos de participación y protagonismo. Luchan por sus ideales.

Existe mayor libertad e informalidad en las relaciones, hay confianza en las instituciones y deseos de generar grandes cambios.

Esta generación accede a niveles superiores de educación. Valorizan el aprendizaje y la capacitación para crecer en sus carreras. No existe el balance entre vida laboral y privada. Hay un alto compromiso con la institución.

Las organizaciones comienzan a estructurarse por niveles. Es una generación que no piensa en el retiro y ve la jubilación como la oportunidad de encarar nuevos proyectos. Por otro lado esta generación comienza a enfrentarse con la realidad de la globalización, la racionalización y la reingeniería de las organizaciones.

\section{La Generación X (1964 - 1980)}

Definidos por la misma autora como desconfiados e individualistas. Se sienten defraudados por los efectos de la globalización. Observan la frustración de aquellos que tras años de dedicación quedan fuera del sistema o son pobremente recompensados por él. Generación con una cultura de la inmediatez, escépticos y sin fe en las instituciones, y mucho menos en la burocracia. Valoran su tiempo y todo lo que les genere placer fuera del trabajo. 
Los jefes de esta generación exigen logros, no presencia física y además valoran la informalidad.

\section{La Generación Y o Millenials (1981 -2000)}

Los aliens así apodados por la autora. Es la generación más numerosa de la historia. Crecidos en un entorno de valoración de sus capacidades, en un mundo hiper informado, interconectado y violento.

Características: son cortoplacistas, viven el presente y son los primeros nativos tecnológicos, piensan en simultáneo, detestan perder el tiempo, valoran los ambientes laborales donde tienen posibilidades de participar y de ser reconocidos, no toleran la injusticia. Para ellos, es importante una gestión con equidad interna y una estructura de premios y castigos en las organizaciones. Son eficientes, flexibles, resilentes, impacientes, innovadores, independientes, amantes de la justicia, de las buenas relaciones interpersonales y valoran la diversidad. Ellos demandan nuevas habilidades a los superiores que deseen retenerlos en las organizaciones ya que no temen abandonarla cuando algo no les agrada.

Ningún gerente en la actualidad debería evadir estas particularidades a la hora de manejar equipos de trabajo diversos.

En entornos tan complejos como son las organizaciones de salud, donde participan y conviven personas no sólo de múltiples disciplinas y saberes sino también de generaciones diferentes, es crucial que los gerentes, interpreten y comprendan la forma de entender el mundo de cada generación, especialmente teniendo en consideración que, según la autora Molinari, la generación Y será mayoría en el mundo del trabajo en los próximos 40 años. De modo que liderar equipos jóvenes requiere habilidades que no se requerían en modelos anteriores. Nuevamente siguiendo a Molinari, ella específica nuevos roles que deben asumir los gerentes: 


\section{Jefes desarrolladores:}

Para la generación $Y$ el nuevo gerente debe atreverse a abandonar su zona de confort, buscando desafíos propios ${ }^{34}$. Los gerentes deben saber generar procesos de aprendizaje asumiendo el rol de maestro y guía. Deben ser como un coach que acompañe permanentemente y genere mejoras en el equipo de trabajo. Debe conocer los intereses de sus empleados y brindar los espacios necesarios para el desarrollo de cada uno de ellos. Debe ser un soporte que enseñe y reconozca, que aconseje y auxilie.

\section{Jefes creadores de sentido:}

El gerente debe brindar sentido a quienes trabajan en su institución, demostrándoles lo importante que es para la organización cada contribución brindándole espacio y contacto con la alta dirección.

\section{Jefes que crean un contexto de familia:}

Se debe propiciar un buen clima laboral, con comunicaciones efectivas. Debe reconocer logros y forjar un contexto de libre expresión y buenas relaciones interpersonales.

Informalidad, espontaneidad y transparencia son requisitos para generar relaciones de confianza con el superior. Premiar y celebrar logros.

\section{Jefes que gestionen el desempeño:}

Deben recompensar de acuerdo con los resultados. Deben generar un feedback continúo de calidad y el reconocimiento no solo debe ser monetario, se deben generar oportunidades de aprendizaje, tiempo libre y premios simbólicos.

\section{Jefes con orientación a resultados:}

Los gerentes deben enfocarse en los resultados, establecer metas claras, definir prioridades y medir resultados con indicadores transparentes. Utilizar el tiempo eficientemente eliminando tareas inútiles. Incorporar tecnología para un mejor uso de los recursos.

\footnotetext{
34 Molinari, Paula. Obra ya citada
} 
Jefes que gestionan la diversidad:

Dejar atrás la uniformidad es decir, gestionar lo diferente con armonía y convivir con los conflictos tomándolos con oportunidades para innovar y crecer.

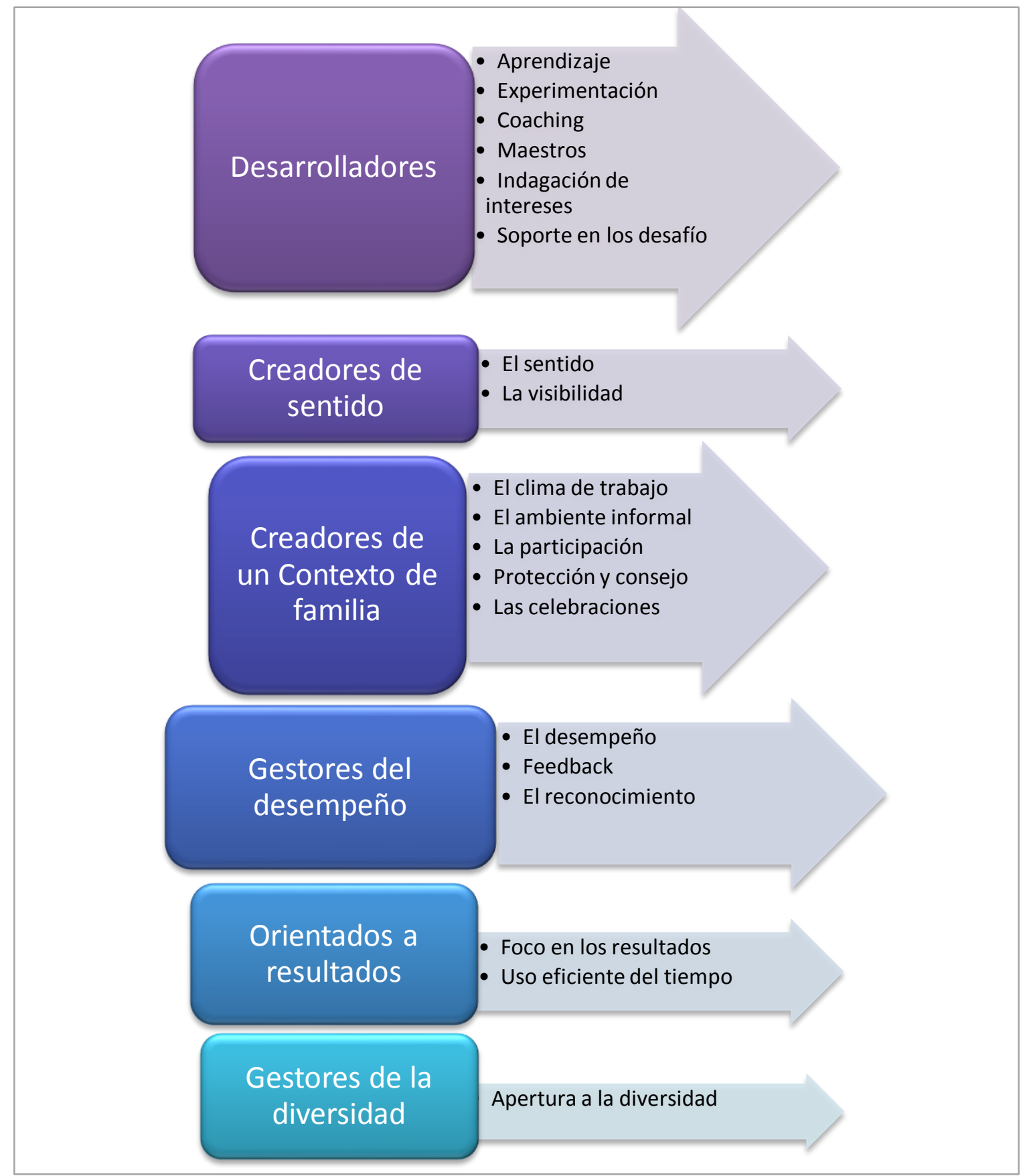

.Elaboración propia 


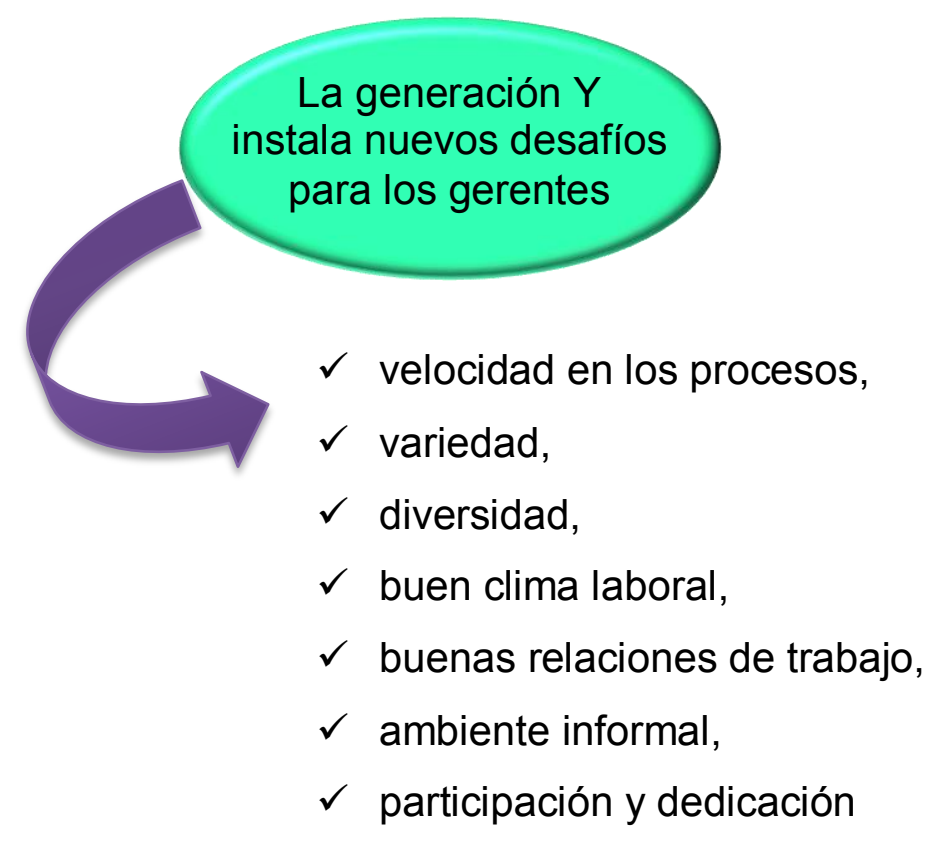

Por consiguiente, es preciso desarrollar nuevas competencias para el management del siglo XXI que permita dirigir con éxito las instituciones teniendo en cuenta todos estos elementos, los cuales generan entornos más complejos y con mayor cantidad de variables a analizar.

Por otra parte, siguiendo a los mismos autores, la función gerencial se evidencia en tres niveles fundamentales:

- Gerentes de primera línea: responsables directos de la producción de los bienes y servicios. Los empleados que le reportan realizan labores básicas de producción, los gerentes de primera línea requieren habilidades técnicas sólidas para enseñar a sus subordinados y supervisar sus trabajos.

- Gerente o administradores de mandos intermedios: coordinan las actividades de los empleados y reciben estrategias y políticas de la alta dirección

- Gerente o administradores de primer nivel: a cargo de la dirección general de la organización. ${ }^{35}$ Son quienes formulan los objetivos, políticas y estrategias de toda la organización y dirigen las actividades de esta. Representan a la organización y son el nexo con el medio exterior.

\footnotetext{
${ }^{35}$ Hellriegel, Jackson, Slocum. Obra ya citada, p. 10-12
} 
La presente indagación se focalizó principalmente en los gerentes de primer nivel, es decir en la alta gerencia, procurando evidenciar en qué medida influyen el género y la formación de posgrado específica, en la accesibilidad a la alta gerencia en las instituciones sanitarias locales.

Por otra parte, según Carlos Alberto Díaz, autor mencionado anteriormente, gestionar conlleva que las empresas cumplan los objetivos, con creatividad, preservando los valores institucionales y logrando objetivos ${ }^{36}$. Así entendido gestionar es un ciclo continuo que implica planificar, organizar, ejecutar, controlar y evaluar.

Sin embargo, gestionar significa ir más allá de administrar, que involucra a las funciones de planificar, organizar, ejecutar, controlar y evaluar. Gestionar incluye e involucra también las funciones de formar y negociar. En referencia a la función de formar se quiere expresar desarrollar a las personas, guiarla, cumplir la función de tutor, mientras que negociar significa vincular todas las partes de la organización entre si y a su vez enlazarlas con su entorno ${ }^{37}$

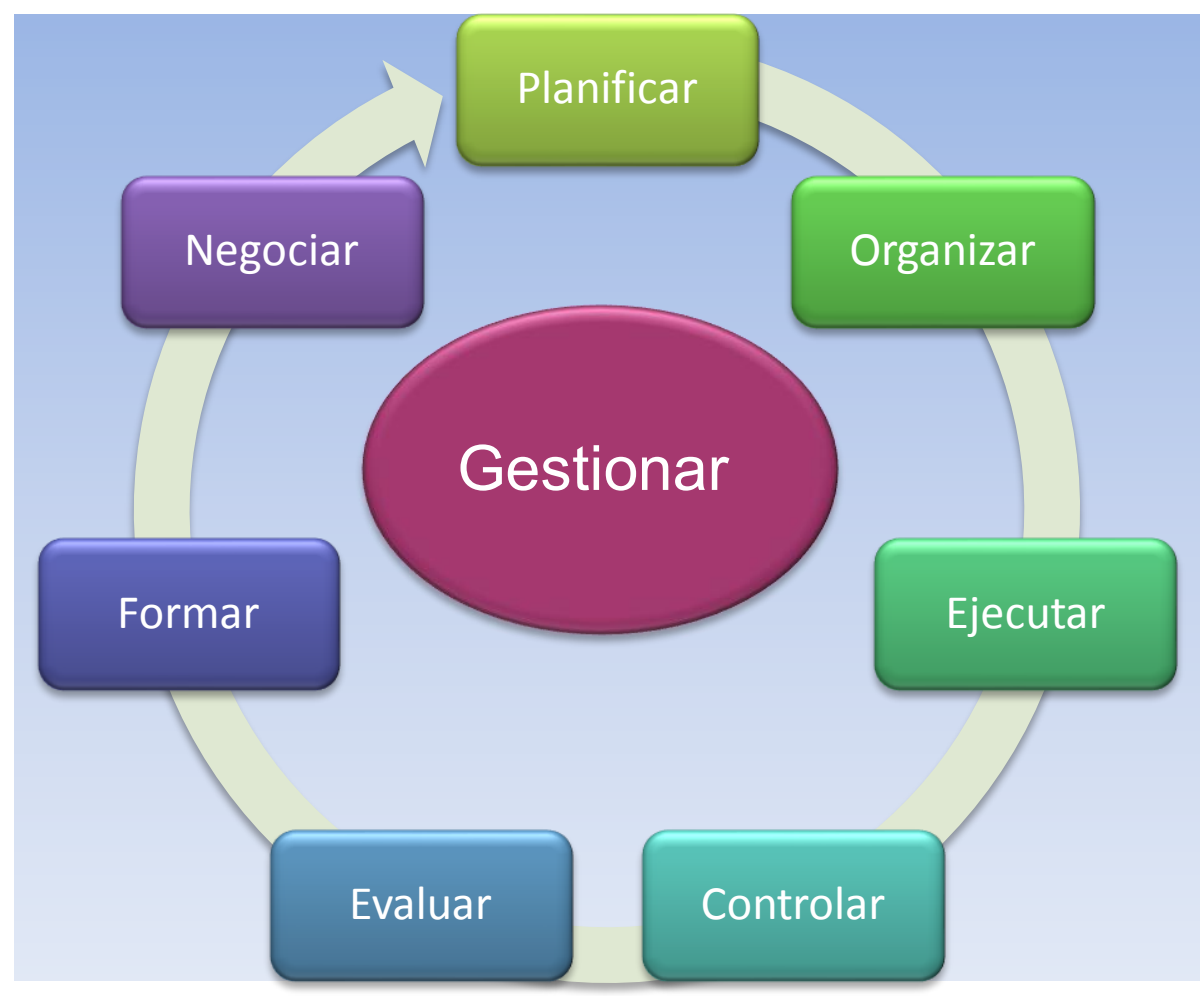

Elaboración propia

\footnotetext{
${ }^{36}$ Díaz, Carlos Alberto. Obra ya citada, p. 58

37 Ortiz, Mariel. 2012. El Gerente Sanitario. Distancias y confluencias de las competencias recomendadas, desarrolladas y manifiestas. Tesis de Maestría. FCE UNLP. La Plata.
} 
De este modo, en una organización de salud se gestionan básicamente varios componentes:

- La salud de las personas incluido el nacimiento y la muerte

- Los procesos productivos

- La gestión del conocimiento

- Interrelaciones personales

- Los intereses de los cinco colectivos que lo integran:

- Profesionales sanitarios (doctores, licenciados y diplomados universitarios)

- Personal en general

- Los gestores, administradores y directivos

- Los propietarios

- Los usuarios, ciudadanos aparentemente enfermos

- Un gran volumen de recursos económicos

- La praxis médica y la medicina defensiva

- La necesidad de objetivación de los intereses de los distintos colectivos y la lucha por el poder

\section{Gestión clínica}

Al hablar de gestión en salud se puede hacer alusión a tres niveles: a nivel macro se habla de gestión sanitaria, es el Estado quien interviene para corregir las fallas del mercado, mejorar el bienestar social y regular y establecer políticas sanitarias; el nivel meso se refiere a la gestión de centros, es decir donde operan diversas organizaciones, laboratorios, hospitales, aseguradoras, centros de salud; mientras que el nivel micro, hace referencia a la gestión clínica ${ }^{38}$., aquí principalmente el médico es quien conoce y plantea la realidad y toma las decisiones diagnósticas y terapéuticas sobre la cual el directivo no médico gestiona los recursos sanitarios disponibles y asigna prioridades.

La presente investigación se centrará en los aportes de la gestión clínica a las organizaciones de salud.

\footnotetext{
${ }^{38}$ Ortún, Vicente. Innovaciones en los Servicios de Salud. Innovación organizativa en sanidad. Departamento de Economía y Empresa. Universidad Pompeu Fabra. p160
} 


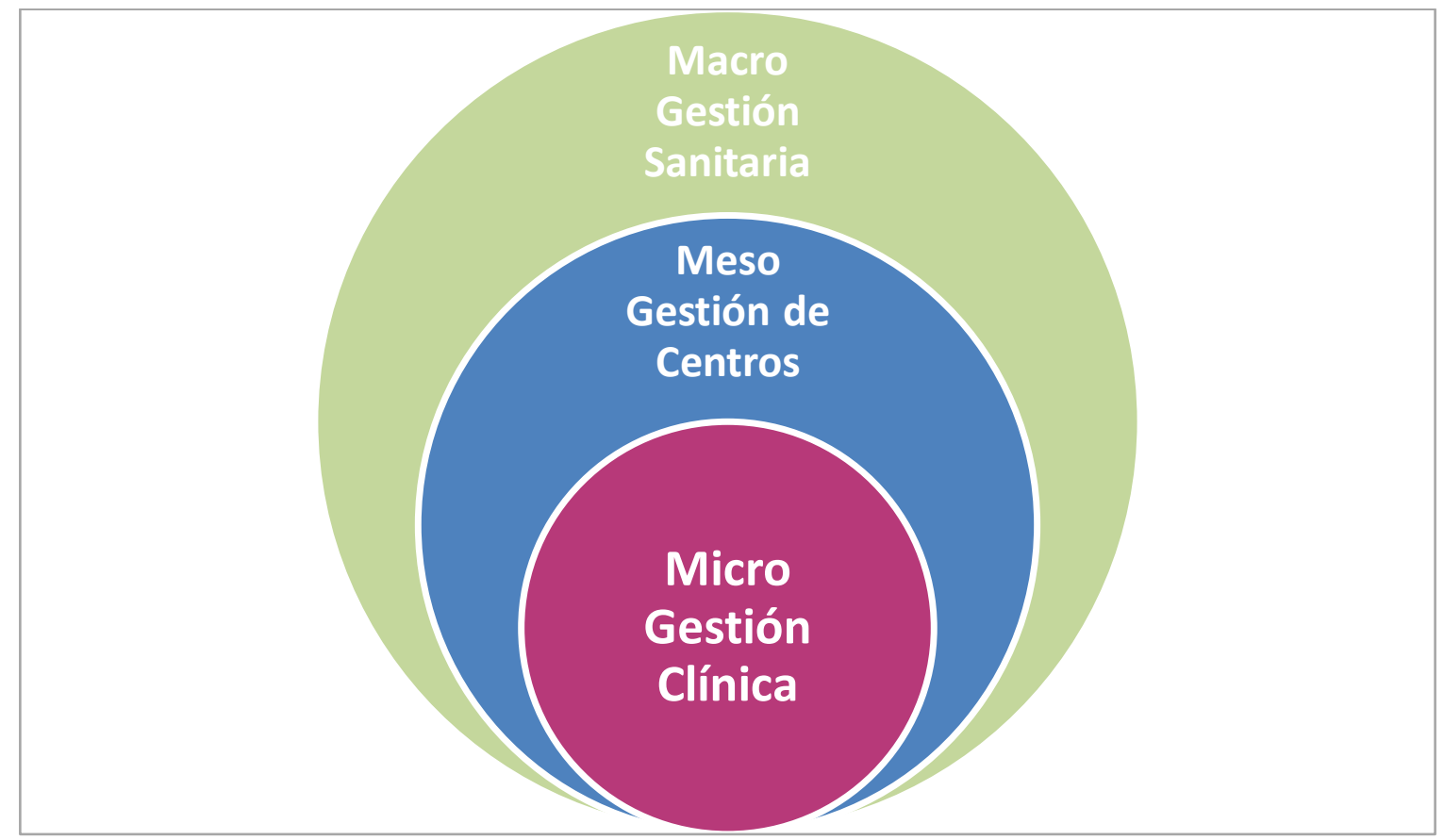

Fuente; Ortún, Vicente. Innovaciones en los Servicios de Salud. Innovación organizativa en sanidad. Departamento de Economía y Empresa. Universidad Pompeu Fabra. p160

\section{Enfoque médico}

Hasta hace algunas décadas este enfoque era el predominante en las instituciones de salud y se focalizaba exclusivamente en los aspectos que interesaban a los médicos respecto de sus pacientes (diagnóstico y tratamiento) sin contemplar los aspectos económicos (presupuestos, recursos, costos, etc.)

\section{Enfoque administrativo}

Al ser cada vez más reconocida la escasez de recursos, dado que estos siempre son menores a las necesidades, la visión fue cambiando hacia lo económico y aparece la visión que privilegia la administración. Surge el enfoque de ajuste donde se centra el esfuerzo en la facturación y en el recorte de gastos. El administrador desde este esquema olvida que los pacientes son seres humanos y que existen situaciones en las que se requiere excepciones a la regla.

\section{Enfoque de la Gestión Clínica}

Como enfoque superador a los anteriores, la Gestión Clínica representa un indiscutible modelo integrador dado que permite gerenciar servicios de salud a 
través del planeamiento, administración y control con base en la información clínica y en conjunto con la información económica permite comprender de manera cabal los procesos e identificar los productos por sus características clínicas, por su utilización de recursos y por su costo. ${ }^{39}$

La palabra Gestión, en sentido amplio, hace referencia a la utilización planificada, administrada y controlada de los recursos en una organización para el logro de sus objetivos, en tanto que el término Clínica refiere a la actividad médica específica dedicada al cuidado de los pacientes. Por lo dicho se podría explicar a la "Gestión Clínica» como la utilización eficiente de los recursos para la mejor atención de los pacientes. Esta definición implica que quienes toman decisiones diariamente, dentro de una institución de salud, que implican y comprometen recursos económicos, lo hagan en un marco de autoridad delegada y pactada con la Gerencia institucional asumiendo la responsabilidad de sus propias decisiones. ${ }^{40}$

Así, la gestión clínica permite la utilización de un lenguaje común y de interface entre los profesionales médicos y los administradores. Es un modelo integrador entre médicos y administradores que permite la construcción de un modelo de gestión.

\section{Ventajas o aportes de la gestión Clínica}

$\checkmark$ No precisa cambio normativo, es decir no precisa modificar la legislación

$\checkmark$ No concita rechazo político

$\checkmark$ Es un proceso paulatino y voluntario, los cambios organizativos y culturales paulatinos permiten optimizar los recursos y mejorar la calidad de forma progresiva. Se trata de una nueva manera de hacer las cosas dentro de la organización.

$\checkmark$ Conlleva autonomía de gestión lo que implica participación activa y responsable en las decisiones que se tomen dentro de la institución. Esto

\footnotetext{
${ }^{39}$ Giraldo, Alicia. Junio 2012 Economía de la Salud. Cuadernillo del Módulo Economía de la Salud, Maestría en Economía de la Salud y Administración de Organizaciones de Salud. FCE UNLP

${ }^{40}$ Temes, José, Parra Blanca y Keller Rebellón. Gestión Clínica: Ventajas e inconvenientes; en Temes José, Parra Blanca

"Gestión Clínica" Mc Graw Hill - Interamericana Bs. As.
} 
agiliza la capacidad de respuesta de la organización, las unidades de gestión clínica son más flexibles y rápidas al momento de tomar decisiones y de adaptarse a nuevas situaciones que el conjunto del nosocomio

$\checkmark$ Mejora la relación profesional paciente

$\checkmark$ Mejora la motivación del personal dado que los objetivos son pactados por ellos y dependen de ellos.

$\checkmark$ Proporciona mejor y más información que estimula a generar líneas de acción y mejora en los resultados

Hasta aquí todos los conceptos y autores citados han servido de sustento y apoyo teórico para fundamentar y respaldar el presente trabajo de investigación. 


\section{Propósito y objetivos específicos}

\section{Objetivo General}

Identificar, describir y analizar, la incidencia de los factores formación académica de posgrado en gestión sanitaria, y género como determinantes de las posibilidades de acceso a puestos en la alta gerencia de los establecimientos prestadores sanitarios privados del Gran La Plata.

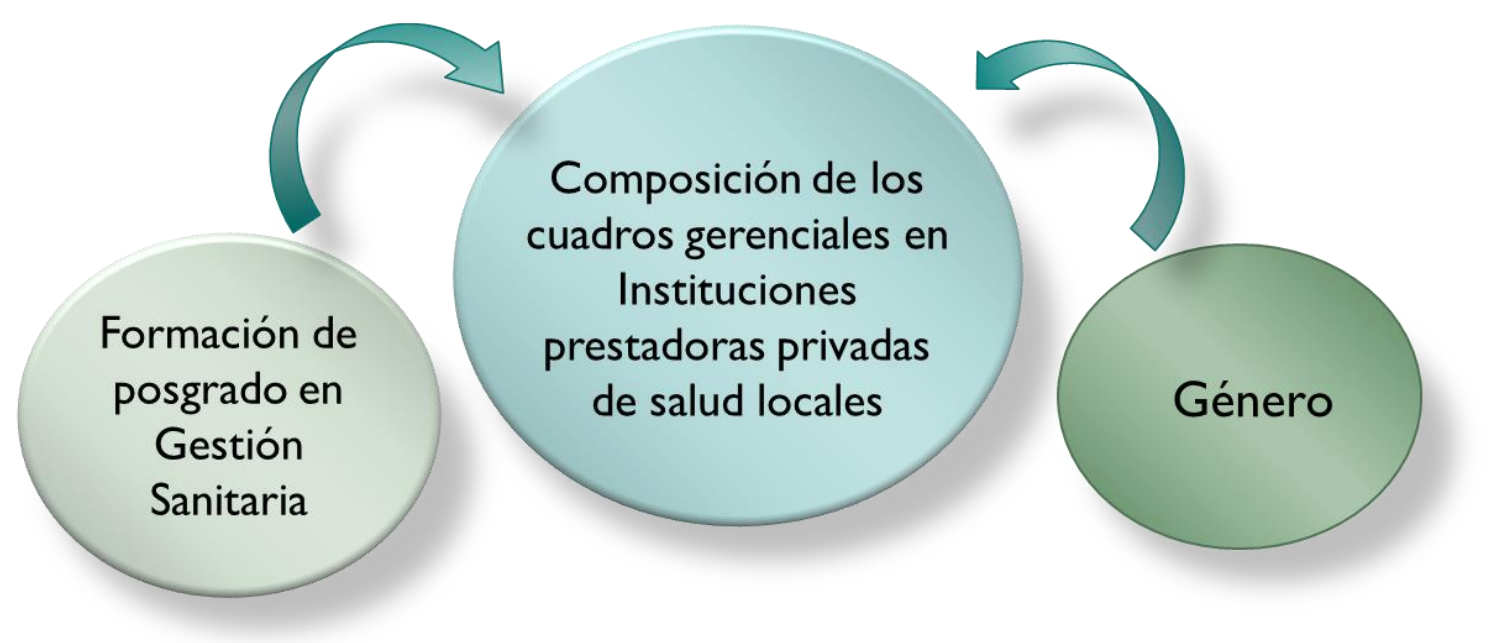

\section{Objetivos específicos}

1. Comprobar la existencia de una prevalencia de género en el actual mapa gerencial de los establecimientos prestadores privados de salud del Gran La Plata.

2. Determinar el nivel de formación académica alcanzado en el actual mapa gerencial de los establecimientos prestadores privados de salud del Gran La Plata.

3. Describir la realidad a nivel local, en el período 1996 - 2015, de la relación varón- mujer en las matrículas y graduaciones de posgrado en la disciplina gestión sanitaria.

4. Identificar si el factor género actúa como una variable influyente para acceder a puestos de alta gerencia. 
5. Comprobar si el factor formación académica de posgrado en gestión sanitaria actúa como variable impulsora para el acceso a cargos de alta gerencia.

6. Identificar otras barreras y/o propulsores que cada género percibe para alcanzar posiciones de poder formal en las instituciones prestadoras privadas de salud del Gran La Plata. 


\section{Proceso metodológico}

En esta sección se mencionan aquellos aspectos y técnicas metodológicas que se consideraron para abordar la temática a investigar.

\section{Tipo de tesis}

El presente trabajo se define como una investigación de tipo descriptivo.

\section{Descripción del trabajo de campo}

Este trabajo Involucra el uso de diferentes herramientas para la recopilación de datos; consultando fuentes primarias y secundarias. El desarrollo metodológico se apoya en tres grandes ejes de análisis con criterios de recortes particulares para cada uno.

\section{Primer eje de investigación}

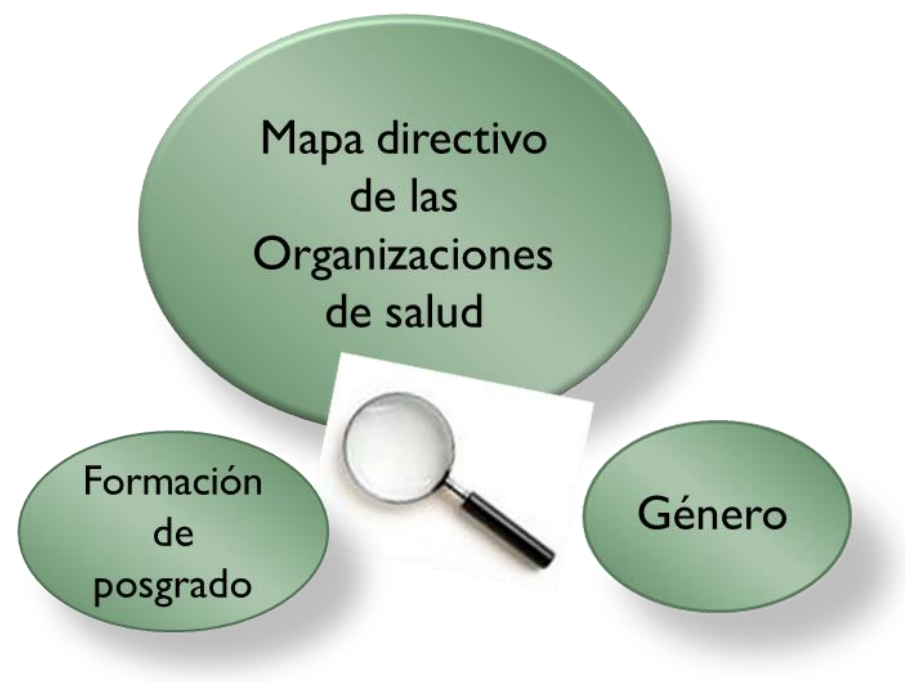

Está centrado en el diagnóstico del mapa directivo de las organizaciones de salud por medio de la lupa del género y de la formación de posgrado 


\section{Criterios de recorte para este eje de estudio:}

Del universo de instituciones de salud locales se tomaron para la muestra las organizaciones privadas prestadoras de servicios de salud con internación y prestación quirúrgica, polivalentes, según Decreto 448/14, nucleadas en FECLIBA ${ }^{41}$ y ACLIBA $1^{42}$, ubicados en el Gran La Plata, entendiéndose por Gran La Plata los partidos de La Plata, Berisso y Ensenada.

Concretamente, la muestra de análisis es de 20 establecimientos sanitarios de los cuales 11 están asociados a FECLIBA y 9 están nucleados en ACLIBA 1.

Quedaron excluidos del análisis del presente trabajo de investigación, las instituciones públicas de la región, los establecimientos ambulatorios y aquellos con internación y prestación quirúrgica monovalentes asociados a FECLIBA y ACLIBA1. Asimismo, aquellos que por su ubicación geográfica se encontraban fuera del área de alcance de la presente investigación.

En parte, dicha exclusión se fundamentó en que pareciera, según afirman algunos autores, que cuanto más complejas son las organizaciones, más difícil es para las mujeres acceder a los altos mandos gerenciales.

Seguidamente se expone el detalle de las instituciones analizadas

Cuadro 6

\begin{tabular}{|c|}
\hline $\begin{array}{c}\text { Instituciones privadas prestadoras de } \\
\text { servicios de salud Gran La Plata }\end{array}$ \\
\hline $\begin{array}{c}\text { C/ internación y prestación quirúrgica, } \\
\text { polivalentes }\end{array}$ \\
\hline Asociadas a FECLIBA \\
\hline Nucleadas a ACLIBA 1 \\
\hline Total
\end{tabular}

${ }^{41}$ FECLIBA: Federación de Clínicas de la Provincia de Buenos Aires

${ }^{42}$ ACLIBA 1: Asociación de hospitales, clínicas y establecimientos de alta complejidad de La Plata 


\begin{tabular}{|c|}
\hline Nucleados en FECLIBA \\
\hline $\begin{array}{c}\text { C/ internación y prestación quirúrgica, } \\
\text { polivalentes }\end{array}$ \\
\hline INSTITUTO MEDICO ARGENTINO DE BERISSO S.A. \\
\hline CLINICA PRIVADA ENRIQUE MOSCONI S.A. \\
\hline SANATORIO ARGENTINO DEL PLATA S.A. \\
\hline INSTITUTO MEDICO MATER DEI S.A. \\
\hline INSTITUTO CENTRAL DE MEDICINA S.A. \\
\hline CLINICA PRIVADA DR.J.J. VACCARINI \\
\hline CLINICA PRIVADA DEL CENTRO \\
\hline SANATORIO SAN JOSE DE VILLA ELISA S.A. \\
\hline CLINICA BELGRANO \\
\hline SANATORIO MEDICO LOS TILOS \\
\hline CLINICA DE LA COMUNIDAD Polivalente de Ensenada \\
\hline Establecimientos agrupados en ACLIBA 1 \\
\hline $\begin{array}{c}\text { C/ internación y prestación quirúrgica, } \\
\text { polivalentes }\end{array}$ \\
\hline CLINICA INSTITUTO MEDICO DE LA RIBERA S.A. \\
\hline HOSPITAL ESPAÑOL \\
\hline HOSPITAL ITALIANO \\
\hline HOSPITAL PRIVADO SUDAMERICANO \\
\hline INSTITUTO MEDICO PLATENSE \\
\hline IPENSA \\
\hline INSTITUTO DE DIAGNÓSTICO DE LA PLATA SA \\
\hline NUEVA CLÍNICA DEL NIÑO DE LA PLATA SA \\
\hline CLÍNICA CITY BELL SA \\
\hline
\end{tabular}

Este segmento del estudio se materializó mediante el análisis documental de: Organigramas y Nóminas de Autoridades, ya sea mediante visitas virtuales en el caso de aquellas instituciones que contaban con páginas web; en su defecto se apeló a llamados telefónicos y/o visitas personales a los nosocomios.

Para el caso de las instituciones nucleadas en FECLIBA, que en su gran mayoría no contaban con página web, se logró plasmar el estudio solicitando a dicho 
organismo, datos relativos al género y profesión de los actuales gerentes generales o administradores en las instituciones asociadas a éste.

Con la información obtenida en esta primera fase de la investigación, se confeccionó una matriz de trabajo que permitió desplegar las variables Género y Nivel de formación, en categorías, lo que habilitó luego su análisis.

De este modo, la variable Género se depuró en las categorías: mujeres y varones, mientras que la variable Nivel de formación, se desagregó en nivel secundario, nivel universitario de grado y nivel universitario de posgrado. Esta última variable también se estudió por áreas disciplinares, diferenciando a los gerentes generales cuyo nivel de formación provenía de las ciencias económicas de aquellos provenientes de las ciencias de la salud.

Los datos clasificados y depurados permitieron el análisis y la determinación de conclusiones para este primer eje de análisis.

En el capítulo siguiente se exponen los resultados de los datos recogidos y analizados para esta primera línea de investigación. 


\section{Segunda línea de análisis}

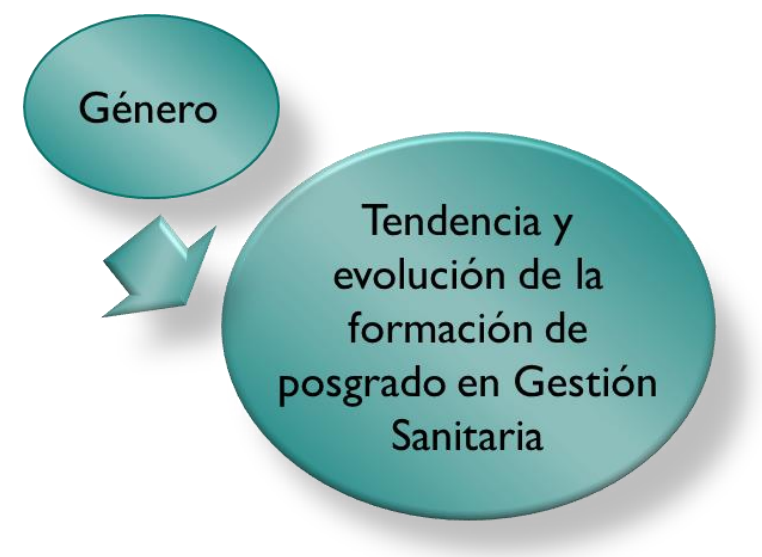

Comprende el análisis de la composición de género en las matrículas de posgrados específicos en Gestión Sanitaria.

El propósito del abordaje es mostrar la tendencia y evolución a través del tiempo de la composición por género, ya sea de los ingresos como de las graduaciones. Esta misma población de datos, se estudia en forma enriquecida incluyendo la mirada de las disciplinas correspondientes a la formación de grado de los estudiantes de posgrado.

\section{Recortes temporal y espacial establecidos}

Se realiza exploración, a nivel local de los datos estadísticos facilitados por las unidades académicas de la UNLP que ofrecen posgrados específicos referidos a la temática de interés en el período 1996- 2015.

De dicha exploración resulta que las dos únicas unidades académicas que poseen posgrados específicos referidos a la temática de estudio son

1- La Facultad de Ciencias Económicas (FCE) de la UNLP, a través de la Escuela de Posgrado de Gestión de Organizaciones de Salud (EGSalud), que ha desarrollado dos carreras de posgrado relacionadas a esta temática específica.

La primera es la Maestría en Economía de la Salud y Administración de Organizaciones de Salud (MES), que tiene en su haber 14 cohortes editadas en forma continua e inició su primera edición en el año 1996. Dicha carrera posee una nómina de inscriptos de 323 alumnos. Desde el año 2012 se encuentra interrumpida. 
La segunda carrera que ofrece esta unidad académica es la Especialización en Gestión de Organizaciones de Salud (ESAL), la cual lleva desarrolladas 5 cohortes completas hasta el momento en que se analizó la información. Comenzó su primera edición en al año 2007 y aún hoy continúa desarrollándose, la cantidad de alumnos inscriptos al momento de realizar esta investigación fue de 89 personas. Actualmente se encuentra en vigencia.

2- La segunda es la Facultad de Ciencias Médicas de la UNLP que ofrece una única carrera de posgrado relacionada a la administración y gestión de organizaciones de salud: la Maestría en Salud Pública que cuenta con tres orientaciones: en Establecimientos y Servicios de Atención Médica; en Sistemas de Salud y en Sistemas Municipales de Salud.

La totalidad de alumnos inscriptos en dicha carrera contabilizó un total de 234 matriculados desde el año 2003, año que comenzó a editarse la primera edición, hasta el año 2015, período de corte que te tomó de realizar esta investigación.

Cabe destacar que este recorte se consideró el más apropiado en primera instancia, debido a la posibilidad de acceso a la información. En segundo lugar, las particularidades y complejidades que presentan las Organizaciones de Salud por sus propias dinámicas de funcionamiento y por el contexto de incertidumbre permanente en el que se desenvuelven, requieren por parte de quienes tienen la responsabilidad de su conducción, contar con características y capacidades particulares, con habilidades gerenciales específicas y fundamentalmente con conocimiento. Este último ítem solo puede ser externamente enriquecido con una formación de posgrado específica que ofrezca las herramientas necesarias para generar un recurso humano experto en gestión sanitaria, imprescindible para asegurar en buena medida la supervivencia y el desarrollo de este tipo tan particular de organización.

Una vez obtenidos los datos brindados por ambas unidades académicas y definidas las variables a estudiar (género; alumnos posgrados en gestión sanitaria; profesión; disciplina de procedencia), se confeccionaron distintas matrices de trabajo que permitieron el refinamiento y unificación de datos. 
Se analizó en primera medida la variable género, filtrando y separando en la dimensión femenina, masculina.

A la variable profesión, otra de las variables relevantes de este análisis, se la filtró por disciplina de formación de procedencia en tres grandes grupos: Ciencias de la Salud, Ciencias Económicas y Otras Ciencias.

A la variable alumnos posgrados gestión sanitaria se la clasificó en inscriptos posgrados en gestión sanitaria y graduados posgrado gestión sanitaria

En esta instancia, resultó transcendental describir la relación o asociación entre las variables de análisis. Se generaron así, tablas para poder contrastar la asociación o relación entre estas variables.

En el capítulo siguiente se exponen los resultados de su análisis. 


\section{Tercer eje de estudio}

\section{Matriz de puestos \\ de alta gerencia en \\ Organizaciones de \\ Salud Locales}

Indaga la percepción de profesionales respecto a los factores facilitadores y retractores para el acceso a los cuadros de alta gerencia de las instituciones sanitarias.

\section{Recorte temporal y espacial de este eje de estudio}

Para cumplir el propósito de este eje, la muestra integra a 13 profesionales posgraduados y 102 ex alumnos de posgrados de Gestión en Salud.

Por su parte la estrategia metodológica se apoya en encuestas diseñadas especialmente. Se utiliza un cuestionario web construido exclusivamente para este relevamiento, que consta de dos variables de control (edad y género) y 6 preguntas; combinando preguntas abiertas, cerradas y de selección múltiple de opciones de respuesta.

Dicho cuestionario estuvo dirigido a:

I. Graduados de la Maestría en Economía de la Salud y Administración de Organizaciones de Salud (13 graduados)

II. Ex alumnos de la carrera de posgrado Maestría en Economía de la Salud y Administración de organizaciones de Salud (17 ex alumnos)

III. Ex alumnos de la carrera de posgrado Especialización en Gestión de Organizaciones de Salud (85 ex alumnos) 
Todos pertenecientes a la Escuela de Gestión de Organizaciones de Salud, FCE de la UNLP.

Cabe aclarar que dicha decisión fue tomada por motivos de acceso a la información de contacto. Por la misma razón, se emplea como recorte temporal el segmento de graduados y ex alumnos que hayan cursado en el período (20102017) en las carreras de posgrado de la Escuela de Gestión de Organizaciones de salud,

En la sección donde se muestran los resultados de este tercer eje, se expone con mayor nivel de detalle lo antedicho. 


\section{Análisis de la información}

Considerando que el objetivo de la presente investigación fue Identificar, describir y analizar, la incidencia de los factores formación académica en posgrado en Gestión Sanitaria y Género, como determinantes de las posibilidades de acceso a puestos de alta gerencia de los establecimientos prestadores sanitarios privados del Gran La Plata, seguidamente se procedió a analizar los datos obtenidos en cada uno de los ejes de estudio planteados.

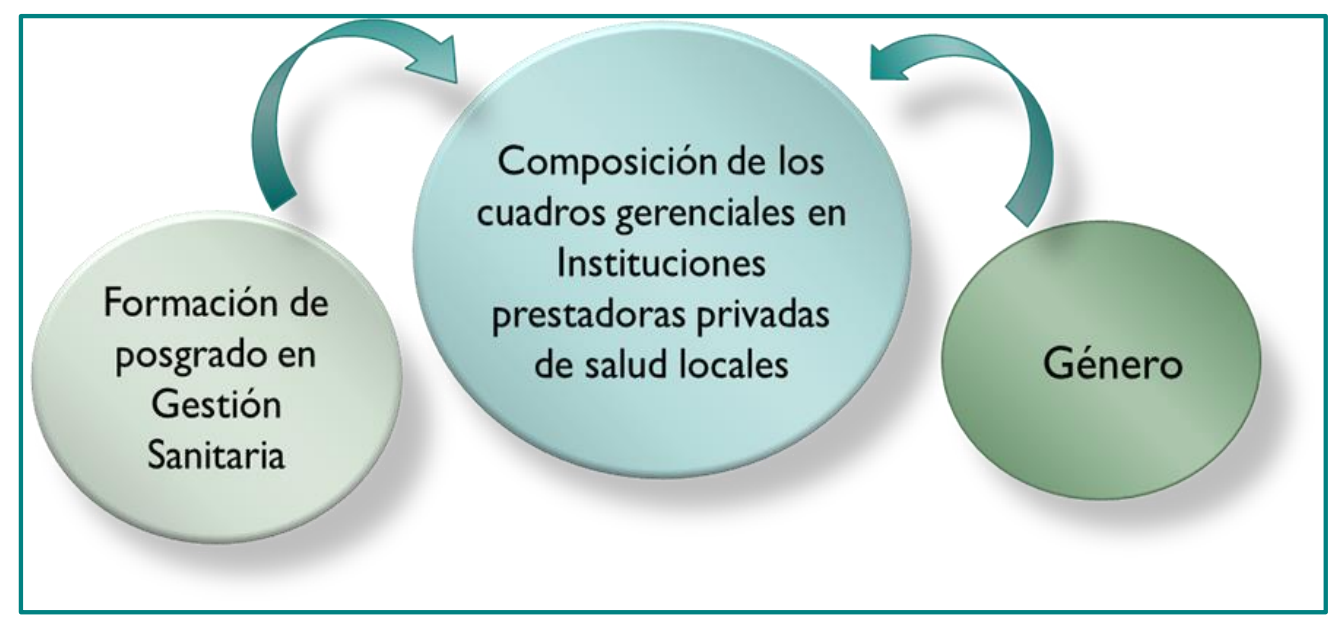

\section{Resultados del primer eje de estudio}

Partiendo de un primer eje de análisis, enfocado en el estudio del mapa directivo de las organizaciones de salud por medio de la lupa del género y de la formación de posgrado, seguidamente se exponen los resultados alcanzados a partir de los datos obtenidos a través de los diferentes canales ya detallados en apartado anterior.

De un total de 20 instituciones incluidas en este análisis, se pudo obtener información del $100 \%$ de ellas. (Ver anexo 3 pág.100)

De este modo, tomando la totalidad de establecimientos asistenciales privados de mediana y alta complejidad según la clasificación del decreto 448/14, modificatorio del decreto 3280/90: con internación y prestación quirúrgica, polivalentes, ubicados en el Gran La Plata (La Plata, Berisso y Ensenada), se pudo contabilizar que sólo en el $20 \%$ de los casos, las mujeres ocupaban el cargo de gerente general o administrador, mientras que el $80 \%$ de las instituciones 
contaban en sus altos cuadros gerenciales con representantes varones. Lo narrado puede observarse en detalle en el cuadro 6 adjunto:

\section{Cuadro 6}

\begin{tabular}{|c|c|c|}
\hline \multicolumn{2}{|c|}{$\begin{array}{c}\text { Relación varones - mujeres, en los cuadros gerenciales de los establecimientos sanitarios } \\
\text { privados, con internación y prestación quirúrgica, polivalentes asociados a FECLIBA y ACLIBA1 } \\
\text { del Gran La Plata. }\end{array}$} \\
\hline Gerentes Varones & Gerentes Mujeres & Total \\
\hline 16 & 4 & 20 \\
\hline $80 \%$ & $20 \%$ & $100 \%$ \\
\hline
\end{tabular}

Por otra parte, poniendo el foco en la variable, nivel de formación alcanzada, surge del análisis que el $50 \%$ de los actuales gerentes de estas instituciones contaban con título universitario de grado, mientras que el $50 \%$ restante carecía de dicho título.

Más evidente es aún que ninguno de los gerentes implicados en la muestra contara con título universitario de Posgrado. En este último ítem, es necesario distinguir que dichos gerentes sí poseen estudios de posgrados, pero en todos los casos no han completado sus tesis de graduación.

Por otra parte, los datos obtenidos permitieron a su vez, obtener conclusiones contundentes sobre cuáles eran las disciplinas de procedencia de los actuales gerentes sanitarios en este segmento analizado. El $50 \%$ de los gerentes que poseían título de grado universitario, provenían de las ciencias de la salud y en su totalidad eran médicos, mientras que el $50 \%$ restante provenían de las ciencias económicas. De estos últimos, el $80 \%$ poseían título de contador y el $20 \%$ de Licenciado en Administración. Dicha información se detalla en cuadro 7 adjunto: 
Cuadro 7

\begin{tabular}{|c|c|c|c|c|c|}
\hline \multirow{2}{*}{$\begin{array}{c}\text { Nivel de } \\
\text { formación } \\
\text { alcanzada de } \\
\text { los gerentes } \\
\text { analizados }\end{array}$} & $\begin{array}{c}\text { Proveniente de Cs de } \\
\text { la Salud }\end{array}$ & $\begin{array}{c}\text { Tŕtulo universitario de grado } \\
\text { Proveniente de las } \\
\text { Cs Económicos }\end{array}$ & $\begin{array}{c}\text { No posee } \\
\text { título } \\
\text { universitario }\end{array}$ & $\begin{array}{c}\text { Título } \\
\text { universitario } \\
\text { de Posgrado }\end{array}$ & Totales \\
\hline $\begin{array}{c}\text { Cantidad de } \\
\text { gerentes } \\
\text { analizados }\end{array}$ & 5 & 5 & 10 & 0 & 20 \\
\cline { 2 - 5 } & $\mathbf{2 5 \%}$ & $\mathbf{2 5 \%}$ & $\mathbf{5 0 \%}$ & $\mathbf{0}$ & $\mathbf{1 0 0 \%}$ \\
\hline
\end{tabular}

A su vez, tanto del subgrupo de gerentes que poseen título de grado universitario provenientes de las ciencias de la salud, como del subgrupo proveniente de las ciencias económicas, el $80 \%$ pertenece al género masculino y el $20 \%$ al género femenino, tal como se detalla en cuadro 8 y 9 :

Cuadro 8

\begin{tabular}{|c|c|c|c|}
\hline \multirow{2}{*}{ Profesión de Base } & \multicolumn{3}{|c|}{$\begin{array}{c}\text { Gerentes con título universitario de grado } \\
\text { proveniente de Cs de la Salud }\end{array}$} \\
\cline { 2 - 4 } & Mujer & Varón & Total \\
\hline \multirow{2}{*}{ Médicos } & 1 & 4 & 5 \\
\cline { 2 - 4 } & $\mathbf{2 0 \%}$ & $\mathbf{8 0}$ & $\mathbf{1 0 0 \%}$ \\
\hline
\end{tabular}

Cuadro 9

\begin{tabular}{|c|c|c|c|}
\hline \multirow{2}{*}{ Profesión de base } & \multicolumn{3}{|c|}{$\begin{array}{c}\text { Gerentes con Título Universitario de } \\
\text { Grado proveniente de las Cs } \\
\text { Económicas }\end{array}$} \\
\cline { 2 - 4 } & Mujer & Varón & Total \\
\hline Contador & 1 & 3 & 4 \\
\hline Lic. en Administración & 0 & 1 & 1 \\
\hline \multirow{2}{*}{ Total } & 1 & 4 & 5 \\
\cline { 2 - 4 } & $\mathbf{2 0 \%}$ & $\mathbf{8 0 \%}$ & $\mathbf{1 0 0 \%}$ \\
\hline
\end{tabular}




\section{Resultados del segundo eje de análisis}

Tomando en cuenta el segundo eje de estudio que analiza la composición de género, mostrando su tendencia y evolución a través del tiempo tanto en las matrículas de posgrados específicos en Gestión Sanitaria como de las graduaciones a continuación, se enuncian los resultados arrojados luego del análisis de los datos obtenidos de ambas unidades académicas, objeto de análisis en el presente eje de estudio.

\section{Total de unidades académicas estudiadas}

En primer lugar, se observa un claro corte temporal de la receptividad de la propuesta de posgrado en gestión sanitaria dado que en los primeros 6 años los varones lideraron las inscripciones en las carreras disponibles. (46\% mujeres54\% varones). Posteriormente, a partir del año 2003 la situación se revierte, mostrando una prevalencia del género femenino en los posgrados en gestión sanitaria. (63\% mujeres - 37\% varones). Por su parte, desde el año 2007 se refuerza la evidencia ya que, continúa la prevalencia de las mujeres en las matrículas de posgrado, pero ahora la brecha entre varones y mujeres es levemente más profunda ( $65 \%$ mujeres $-35 \%$ varones). Así puede apreciarse en detalle en el cuadro 10 y gráfico $10 a, 10 b$ y 10c adjuntos:

Cuadro 10

\begin{tabular}{|c|c|c|c|}
\hline \multicolumn{4}{|c|}{ Carreras de posgrado en Gestión Sanitaria en la UNLP } \\
\hline Períodos & $\begin{array}{c}\text { Mujeres } \\
\text { Inscriptas }\end{array}$ & $\begin{array}{c}\text { Varones } \\
\text { Inscriptos }\end{array}$ & $\begin{array}{c}\text { Total, } \\
\text { Inscriptos }\end{array}$ \\
\hline \multirow{2}{*}{1996 a 2002} & 67 & 78 & 145 \\
\cline { 2 - 4 } & $46 \%$ & $54 \%$ & $100 \%$ \\
\hline \multirow{2}{*}{2003 a 2015} & 318 & 183 & 501 \\
\hline \multirow{2}{*}{2007 a 2015} & $63 \%$ & $37 \%$ & $100 \%$ \\
\hline & 236 & 129 & 365 \\
\hline
\end{tabular}


Gráfico 10a

Composición por género. Inscripciones carreras de posgrado en Gestión Sanitaria UNLP - Período 1996- 2002

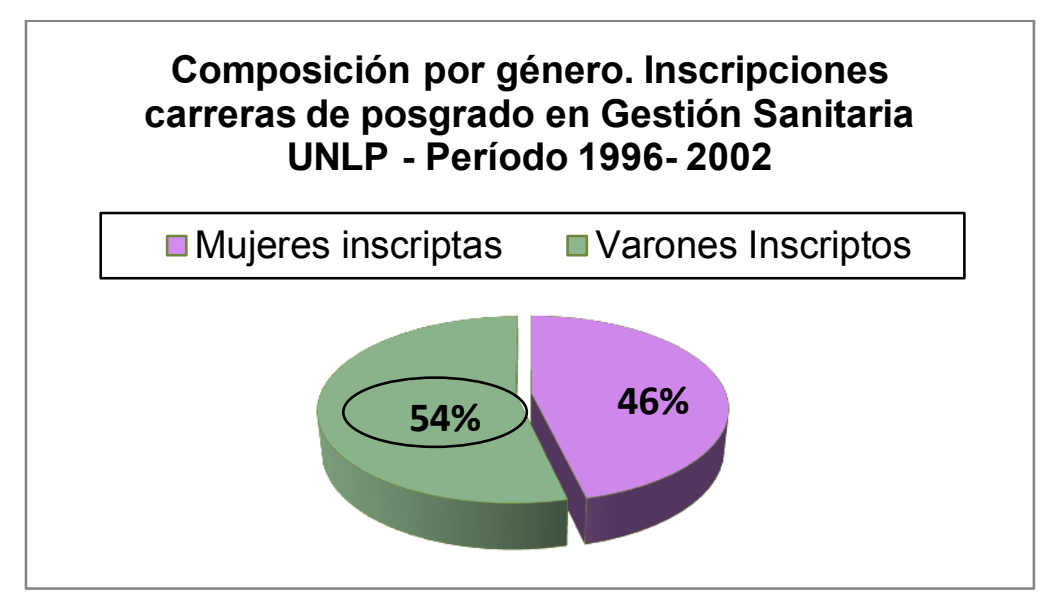

Gráfico 10b

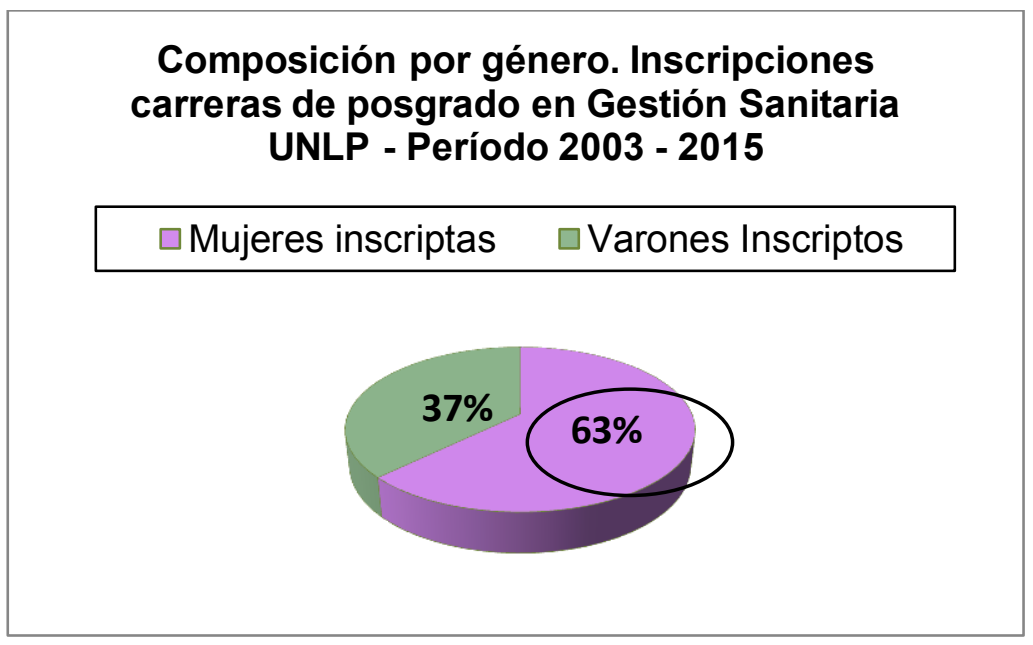

Gráfico 10c

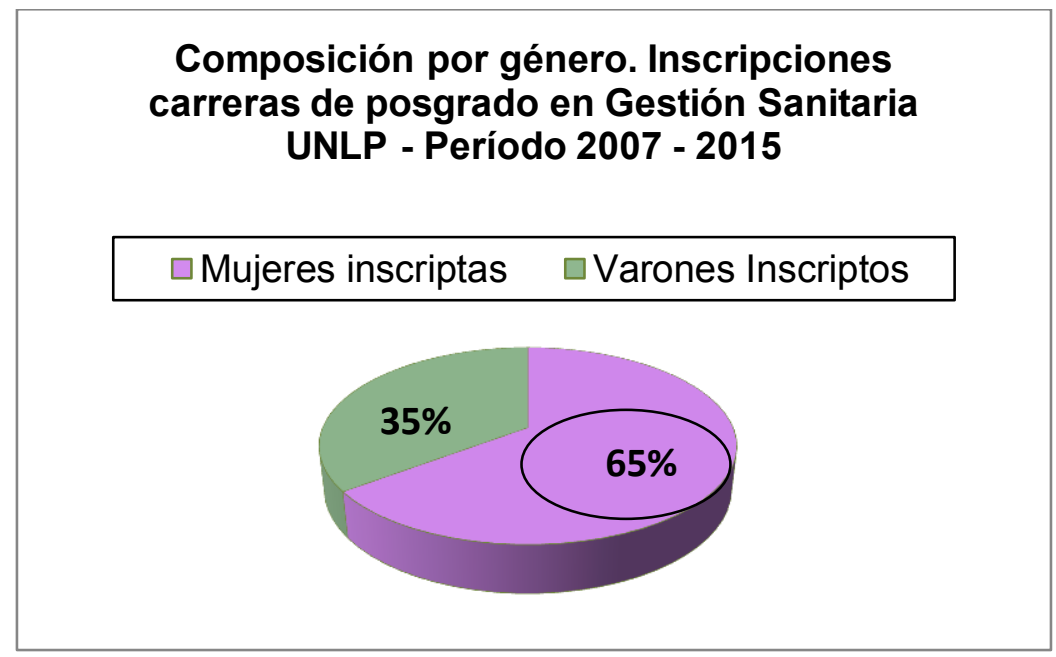

Ver información adicional en (Anexo 9 Cuadros 1 a 4 en pág. 119 - 120) 
Examinando las inscripciones en los posgrados en gestión sanitaria, haciendo un desglose por género y por disciplina de procedencia se observa que en todos los casos las mujeres superan en número las inscripciones tal como puede observarse en cuadro y gráfico 11.

Cuadro 11

Inscriptos en los posgrados de Gestión Sanitaria

\begin{tabular}{|rrrrrr} 
Género & $\begin{array}{c}\text { Provenientes } \\
\text { de las Ciencias } \\
\text { de la salud }\end{array}$ & $\begin{array}{c}\text { Provenientes } \\
\text { de las } \\
\text { Ciencias } \\
\text { Económicas }\end{array}$ & $\begin{array}{c}\text { Provenientes } \\
\text { de otras áreas } \\
\text { disciplinares }\end{array}$ & Sin datos & Total \\
\hline Femeninos & 217 & 88 & 50 & 30 & 385 \\
\hline Masculinos & 167 & 65 & 22 & 7 & 261 \\
\hline Total & 384 & 153 & 72 & 37 & 646
\end{tabular}

Gráfico 11

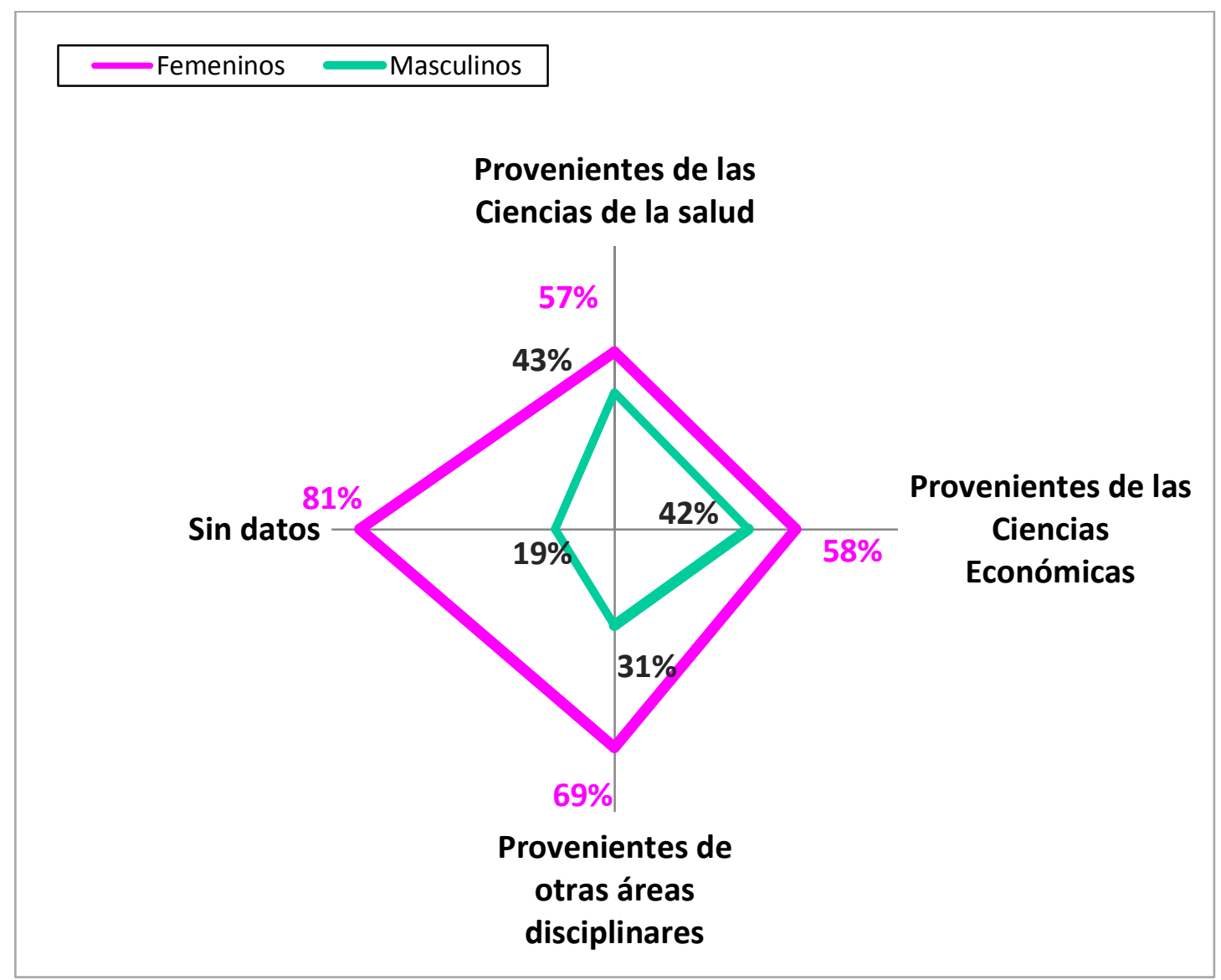


Cambiando el rumbo del análisis hacia las tasas de graduación en posgrados de gestión sanitaria, se puede observar una fuerte presencia de la mujer (65\% mujeres $-35 \%$ varones), lo que permite inferir una mejor performance femenina en las carreras de posgrado, tal como puede apreciarse en el Cuadro 12.

Cuadro 12

\begin{tabular}{|c|c|c|}
\hline \multicolumn{3}{|c|}{$\begin{array}{c}\text { Total, graduados en las carreras de posgrado } \\
\text { en Gestión Sanitaria }\end{array}$} \\
\hline $\begin{array}{c}\text { Varones } \\
\text { Graduados }\end{array}$ & $\begin{array}{c}\text { Mujeres } \\
\text { Graduadas }\end{array}$ & $\begin{array}{c}\text { Total, } \\
\text { Graduados }\end{array}$ \\
\hline 12 & 22 & 34 \\
\hline $35 \%$ & $65 \%$ & $100 \%$ \\
\hline
\end{tabular}

Ver más información en (Anexo 7. Cuadro 4 pág. 111) y en (Anexo 8. Cuadro 2 pág.116)

Por otra parte, si el análisis se enfoca en contrastar, por género, las graduaciones con las inscripciones entonces los datos revelan que la brecha entre géneros se sostiene, ya que la mujer sigue manteniendo un leve predominio sobre los varones al completar su formación de posgrado; el 7\% de las mujeres inscriptas se gradúan, mientras que en el caso de los varones la tasa es del $5 \%$. Dicha información se visualiza en el Gráfico 12.

Gráfico 12

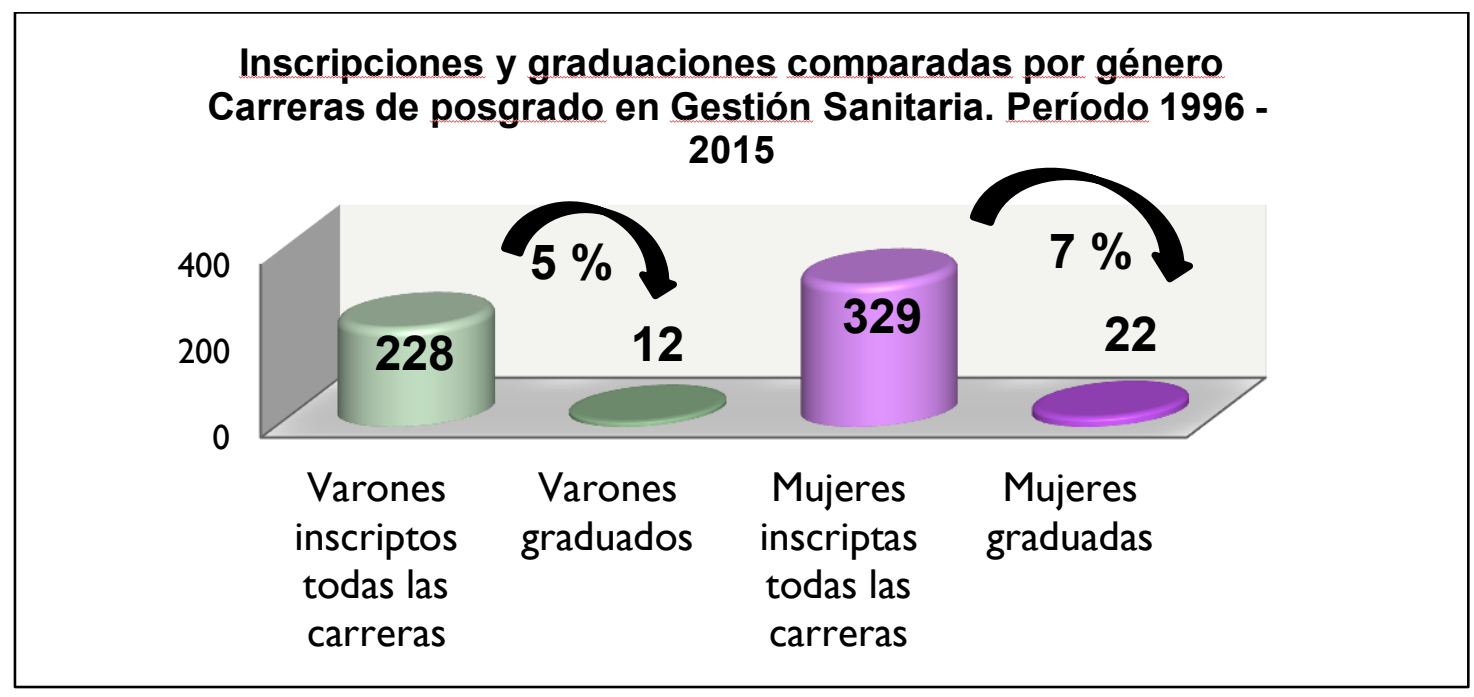


Para este análisis se contabilizaron solo los inscriptos de las carreras que contaban con graduados hasta el momento de realizar la investigación. Se dejó fuera del estudio a los inscriptos en la carrera ESAL, dado que hasta ese momento no acreditaba graduaciones.

Ver más detalles en (Anexo 7. Cuadro 3 pág. 111) (Anexo 8. Gráfico 2 pág. 115)

Graduaciones de posgrado en gestión sanitaria desagregadas por disciplina de procedencia

- Las mujeres, cualquiera sea su área disciplinar de procedencia, superan en número las graduaciones de posgrado en gestión sanitaria

En detalle puede observarse un $57 \%$ de mujeres entre los graduados en Gestión Sanitaria cuyas profesiones de base provienen de las Ciencias de la Salud.

Más notorio es que, entre los graduados que provienen de las Ciencias Económicas, las mujeres superan las graduaciones en un 83 \%. Situación similar ocurre cuando se analiza el resto de las áreas disciplinares, el porcentaje de mujeres también es superior con un $80 \%$ de graduadas con respecto a los varones.

Cuadro 13

\begin{tabular}{|c|c|c|c|c|}
\hline Género & $\begin{array}{c}\text { Total } \\
\text { graduados - } \\
\text { Posgrados en } \\
\text { Gestión } \\
\text { Sanitaria }\end{array}$ & $\begin{array}{c}\text { Provenientes } \\
\text { de las } \\
\text { Ciencias de la } \\
\text { salud }\end{array}$ & $\begin{array}{c}\text { Provenientes } \\
\text { de las } \\
\text { Ciencias } \\
\text { Económicas }\end{array}$ & $\begin{array}{l}\text { Provenientes de } \\
\text { otras áreas } \\
\text { disciplinares }\end{array}$ \\
\hline Femeninos & 22 & 13 & 5 & 4 \\
\hline Masculinos & 12 & 10 & 1 & 1 \\
\hline Total & 34 & 23 & 6 & 5 \\
\hline $\begin{array}{c}\% \\
\text { Graduaciones } \\
\text { Femeninas }\end{array}$ & $65 \%$ & $57 \%$ & $83 \%$ & $80 \%$ \\
\hline $\begin{array}{c}\% \\
\text { Graduaciones } \\
\text { Masculinas }\end{array}$ & $35 \%$ & $43 \%$ & $17 \%$ & $20 \%$ \\
\hline
\end{tabular}


- Sólida concentración de profesionales provenientes de las ciencias de la salud entre de graduados de posgrado en gestión sanitaria

\section{Gráfico 13}

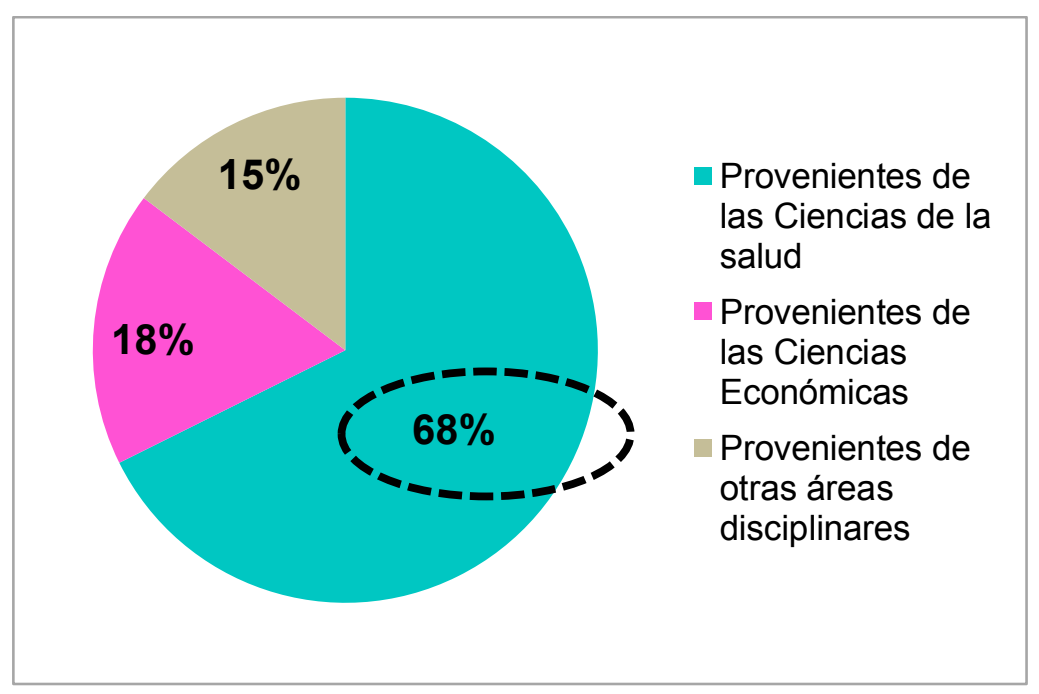

Graduaciones de posgrados en gestión sanitaria diferenciadas por género y profesión de procedencia

- Marcado predominio de médicos entre los varones (75\%)

- Amplio abanico de disciplinas profesionales entre las mujeres, mostrando mayoría Licenciadas en Administración (23\%) seguidas por Médicas y Licenciadas en enfermería (18\%) 
Grafico 14

Profesión de base de los varones graduados de posgrado en gestión sanitaria

\section{$8 \% \quad 9 \%$}

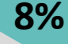

(a)

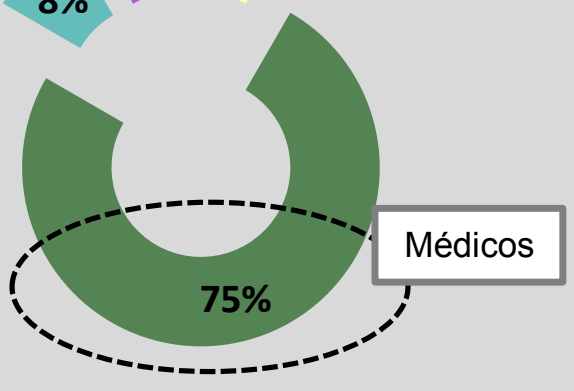

Lic en economía

Médicos

Psicólogo

Fisioterapeuta

Grafico 15

Profesión de base de las mujeres graduadas de posgrados en gestión sanitaria

Licenciadas en Enfermería

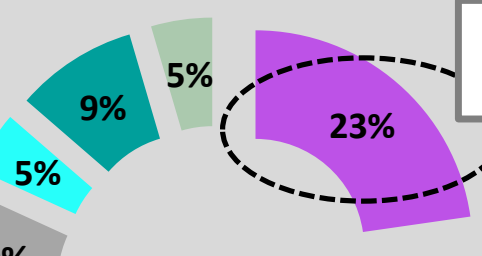
Licenciadas en Administración

$5 \%$

$9 \%$

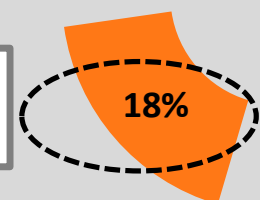

$9 \%$

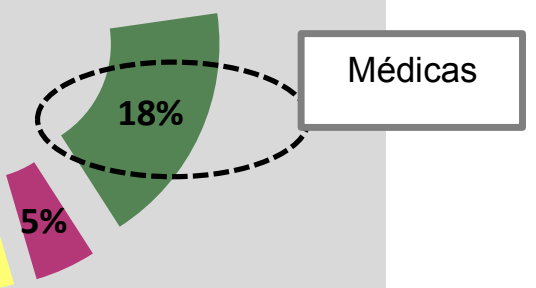
Lic. En adm
Medico
Lic en Biología
Lic terapia ocupacional
Lic. En efermería Bioquímica 


\section{Resultados del tercer eje de análisis}

Para el tercer eje de análisis, que se centró en el nexo formación académica de posgrados en Gestión Sanitaria - posibilidades de acceso a puestos de alta gerencia en las organizaciones privadas de salud del Gran La Plata, a continuación, se exponen los resultados obtenidos de los datos recabados mediante encuestas realizadas a ex alumnos y graduados de las carreras de la EGSalud de la FCE de la UNLP. (Ver modelos de encuestas en Anexo 10 pág. 120 a 128)

En primera instancia, para poder cumplir con este objetivo se realizaron 115 encuestas a graduados y ex alumnos que hayan cursado en el período (20102017) en las carreras de posgrado de la Escuela de Gestión de Organizaciones de salud, recorte que fue tomado por motivos de acceso a la información.

Detalle de los encuestados:

Cuadro 14

\begin{tabular}{|cccc|}
\hline Encuestados & $\begin{array}{c}\text { Mujeres } \\
\text { encuestadas }\end{array}$ & $\begin{array}{c}\text { Varones } \\
\text { encuestados }\end{array}$ & $\begin{array}{c}\text { Total } \\
\text { encuestados }\end{array}$ \\
\hline $\begin{array}{c}\text { Graduados de la Maestría en Economía } \\
\text { de la Salud y Administración de } \\
\text { Organizaciones de Salud }\end{array}$ & 10 & 3 & 13 \\
$\begin{array}{c}\text { Ex alumnos Maestría de Economía de la } \\
\text { Salud y Administración de Organizaciones } \\
\text { de Salud }\end{array}$ & 11 & 6 & 17 \\
\hline $\begin{array}{c}\text { Ex alumnos Especialización en Gestión de } \\
\text { Organizaciones de salud }\end{array}$ & 53 & 32 & 85 \\
\hline Total & 74 & 41 & 115 \\
\hline
\end{tabular}


Gráfico 16

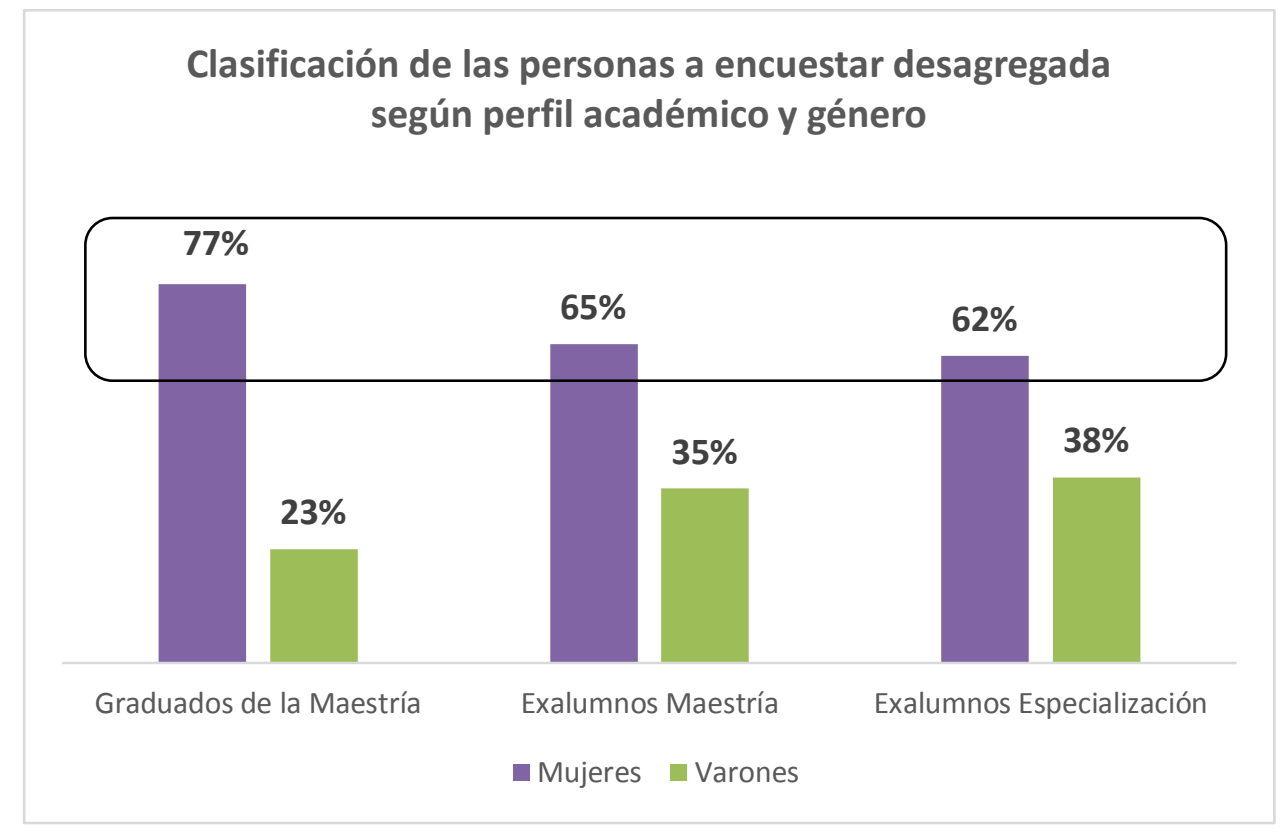

De un total de 115 encuestas enviadas tanto a ex alumnos de la Especialización en Gestión de Organizaciones de Salud, como a ex alumnos y graduados de la Maestría en Economía de la Salud y Administración de Organizaciones de Salud, se han recogido un total de 67 respuestas, lo cual significa un índice de adhesión a la consulta del $58 \%$. (Ver cuadro 15 )

Cuadro 15

\begin{tabular}{r|rr}
\multicolumn{1}{c|}{$\begin{array}{c}\text { Total, } \\
\text { encuestados }\end{array}$} & $\begin{array}{c}\text { Totales } \\
\text { encuestas c/ } \\
\text { respuestas }\end{array}$ & $\begin{array}{c}\text { Totales } \\
\text { encuestas s/ } \\
\text { respuesta }\end{array}$ \\
115 & 67 & 48 \\
\hline $100 \%$ & $58 \%$ & $\mathbf{4 2 \%}$ \\
\hline
\end{tabular}

Una primera apreciación de la información recogida muestra que el $70 \%$ de las respuestas fueron materializadas por mujeres, mientras que el $30 \%$ fueron realizadas por el género masculino. Esto parecería una obviedad si se considera que, del total de encuestados, el $64 \%$ son mujeres y el $35 \%$ pertenecen al género masculino. Sin embargo, si se confrontan los datos según el género, se comprueba que la tasa de respuesta femenina es del $64 \%$, es decir 47 mujeres respondieron la encuesta sobre un total de 74 mujeres encuestadas, mientras que 
la tasa de respuesta masculina es del $49 \%$ (20 varones respondieron sobre un total de 41 encuestados), lo que permitiría suponer que las mujeres parecerían más predispuestas a responder encuestas que los varones. (Ver cuadros 16 y 17)

Cuadro 16

\begin{tabular}{rrr}
$\begin{array}{c}\text { Total, de } \\
\text { respuestas } \\
\text { recibidas }\end{array}$ & \multicolumn{1}{l}{ Varones } & \multicolumn{1}{c}{ Mujeres } \\
67 & 20 & 47 \\
$\%$ & $30 \%$ & $70 \%$ \\
\hline
\end{tabular}

Cuadro 17

\begin{tabular}{c|cc}
$\begin{array}{c}\text { Total, } \\
\text { Mujeres } \\
\text { encuestadas }\end{array}$ & $\begin{array}{c}\text { Mujeres que } \\
\text { respondieron } \\
\text { afirmativamente }\end{array}$ & $\begin{array}{c}\text { Porcentaje de } \\
\text { respuesta }\end{array}$ \\
\hline 74 & 47 & $64 \%$ \\
\hline $\begin{array}{c}\text { Total, } \\
\text { Varones } \\
\text { encuestados }\end{array}$ & $\begin{array}{c}\text { Varones que } \\
\text { respondieron } \\
\text { afirmativamente }\end{array}$ & $\begin{array}{c}\text { Porcentaje de } \\
\text { respuesta }\end{array}$ \\
\hline 1 & 20 & $49 \%$ \\
\hline
\end{tabular}

Tomando en consideración los rangos de edad de los respondientes, los resultados arrojan los siguientes valores:

Total, de respuestas desagregadas por rango de edad y género

Cuadro 18

\begin{tabular}{ccccc}
$\begin{array}{c}\text { Total, } \\
\text { respuestas } \\
\text { recibidas }\end{array}$ & $\begin{array}{c}\text { Menores } \\
\text { de } \mathbf{3 0} \text { años }\end{array}$ & $\begin{array}{c}\text { Entre } \mathbf{3 0 y} \\
\mathbf{3 9} \text { años }\end{array}$ & $\begin{array}{c}\text { Entre } \mathbf{4 0} \text { y } \\
\mathbf{4 9} \text { años }\end{array}$ & $\begin{array}{c}\text { Entre } \mathbf{5 0} \mathbf{y} \\
\mathbf{5 9} \text { años }\end{array}$ \\
\hline $\begin{array}{c}\text { Mujeres } \\
47\end{array}$ & 7 & 21 & 17 & 2 \\
\hline & $15 \%$ & $45 \%$ & $36 \%$ & $4 \%$ \\
\hline $\begin{array}{c}\text { Total, } \\
\text { respuestas } \\
\text { recibidas }\end{array}$ & $\begin{array}{c}\text { Menores } \\
\text { de } \mathbf{3 0} \text { años }\end{array}$ & $\begin{array}{c}\text { Entre } \mathbf{3 0} \mathbf{y} \\
\mathbf{3 9} \text { años }\end{array}$ & $\begin{array}{c}\text { Entre } \mathbf{4 0} \mathbf{y} \\
\mathbf{4 9} \text { añ }\end{array}$ & $\begin{array}{c}\text { Entre } \mathbf{5 0} \mathbf{y} \\
\mathbf{5 9} \text { años }\end{array}$ \\
\hline $\begin{array}{c}\text { Varones } \\
20\end{array}$ & 0 & 6 & 9 & 5 \\
\hline
\end{tabular}




\begin{tabular}{ccccc}
$\begin{array}{c}\text { Total, } \\
\text { respuestas } \\
\text { recibidas }\end{array}$ & $\begin{array}{c}\text { Menores } \\
\text { de } \mathbf{3 0} \text { años }\end{array}$ & $\begin{array}{c}\text { Entre } \mathbf{3 0} \mathbf{y} \\
\mathbf{3 9} \text { años }\end{array}$ & $\begin{array}{c}\text { Entre } \mathbf{4 0} \text { y } \\
\mathbf{4 9} \text { años }\end{array}$ & $\begin{array}{c}\text { Entre } \mathbf{5 0} \mathbf{y} \\
\mathbf{5 9} \text { años }\end{array}$ \\
\hline 67 & 7 & 27 & 26 & 7 \\
\hline $100 \%$ & $10 \%$ & $40 \%$ & $39 \%$ & $10 \%$ \\
\hline
\end{tabular}

En el caso de las mujeres, el mayor porcentaje de respuestas se obtuvo en el rango de edad que va desde los 30 a 39 años, mientras que para el caso de los varones el mayor porcentaje se ubica en la escala comprendida entre los 40 y 49 años. Disminuyendo el porcentaje de respuesta para el último rango de edad (50 a 59 años) para ambos géneros, siendo mayor la brecha para el género femenino. Resumiendo, entre los 30 y 49 años, los encuestados se mostraron más predispuestos a responder la encuesta

\section{Resultados obtenidos de la primera parte de la encuesta (preguntas 1 a 4)}

Trazando un análisis de los resultados con la mirada puesta en el género, se pueden observar los siguientes rasgos en relación con el género femenino:

De las mujeres encuestadas, más del $50 \%$ ocupaban algún cargo de gestión en organizaciones sanitarias antes de comenzar el posgrado. Sin embargo, dichos cargos, salvo en un solo caso, pertenecen al nivel medio en la escala jerárquica de las organizaciones sanitarias, no así a la alta gerencia donde pone el foco la presente investigación.

Cuadro 19

$\begin{gathered}\text { Ocupaban algún cargo de gestión antes } \\ \text { del posgrado (gestión media) }\end{gathered}$
SI

Del 51 \% sólo 1 caso ocupa cargo en la alta gerencia (empresa familiar), 
En cuanto al valor que las mujeres le dan a la formación de posgrado específica, más del $80 \%$ reconoce como necesaria una capacitación de posgrado y de ese porcentaje, el $19 \%$ la considera absolutamente esencial.

Cuadro 20

\begin{tabular}{|c|c|c|c|c|c|}
\hline \multicolumn{5}{|c|}{ Importancia que le dan a la formación } & \\
\hline Esencial & $\begin{array}{c}\text { Absolutamente } \\
\text { esencial }\end{array}$ & Nada esencial & $\begin{array}{c}\text { Poco } \\
\text { esencial }\end{array}$ & Total & \multirow{3}{*}{$\begin{array}{c}\text { El } 83 \% \text { considera } \\
\text { necesaria la capacitación } \\
\text { de posgrado }\end{array}$} \\
\hline 30 & 9 & 1 & 7 & 47 & \\
\hline$\overline{64 \%}$ & $19 \%$ & $2 \%$ & $15 \%$ & $100 \%$ & \\
\hline
\end{tabular}

Cuando se les preguntó a las mujeres si actualmente ocupaban algún cargo en la gestión, resultó llamativo que una vez finalizado el posgrado mas del $60 \%$ no trabajaran ni en la alta gerencia ni en la gestión media.

\section{Cuadro 21}

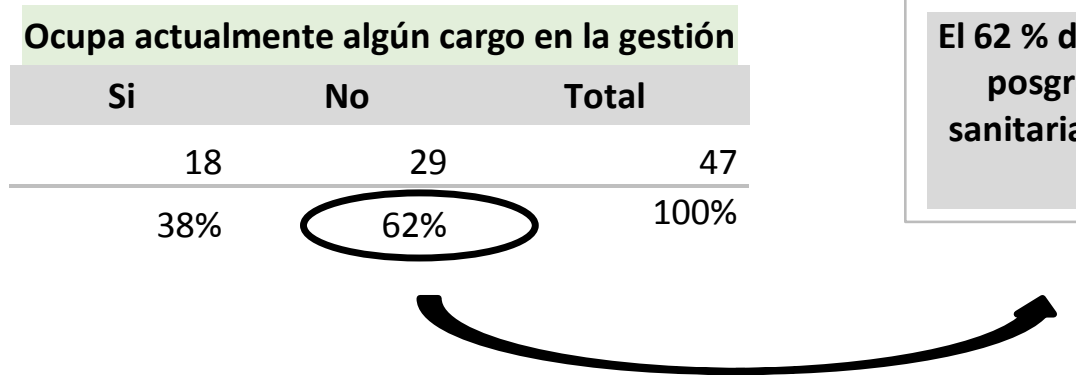

Por lo que podría adelantarse como una primera conclusión, que la formación de posgrado en forma aislada, para el caso femenino, no actuaría como factor directo, determinante, para acceder a cargos en la alta gestión.

Ahora bien, fijando la mirada en el género masculino, se pueden observar los siguientes elementos característicos: 
Cuadro 22

\begin{tabular}{cccc}
$\begin{array}{c}\text { Total, } \\
\text { respuestas } \\
\text { recibidas }\end{array}$ & $\begin{array}{c}\text { Entre } \mathbf{3 0} \text { y } \\
\mathbf{3 9} \text { años }\end{array}$ & $\begin{array}{c}\text { Entre } \mathbf{4 0 y} \text { y } \\
\mathbf{4 9} \text { años }\end{array}$ & $\begin{array}{c}\text { Entre } \mathbf{5 0} y \\
\mathbf{5 9} \text { años }\end{array}$ \\
\hline $\begin{array}{c}\text { Varones } \\
20\end{array}$ & 6 & 9 & 5 \\
\hline
\end{tabular}

Como ya se había expuesto, el mayor porcentaje de varones que han accedido a responder la encuesta se encuentran en el rango de 40 a 49 años

En relación con la primera consulta, "ocupaba algún cargo de gestión antes de realizar el posgrado", aquí es visiblemente superior el porcentaje de varones que desempeñaban funciones de gestión antes de realizar el posgrado (65\%) en comparación al género femenino $(51 \%)$ mencionado anteriormente.

Cuadro 23

\section{Ocupaban algún cargo de gestión antes del} posgrado (gestión media) SI NO Total

\begin{tabular}{rrr}
13 & 7 & 20 \\
\hline $65 \%$ & $35 \%$ & $100 \%$ \\
\hline
\end{tabular}

Los varones, al igual que sus pares femeninas, consideran también necesaria la formación de posgrado. Aquí los valores difieren muy poco a lo indicado por el género femenino. Así, el 55\% lo cree esencial, mientras que el $20 \%$ lo define como absolutamente esencial.

Cuadro 24

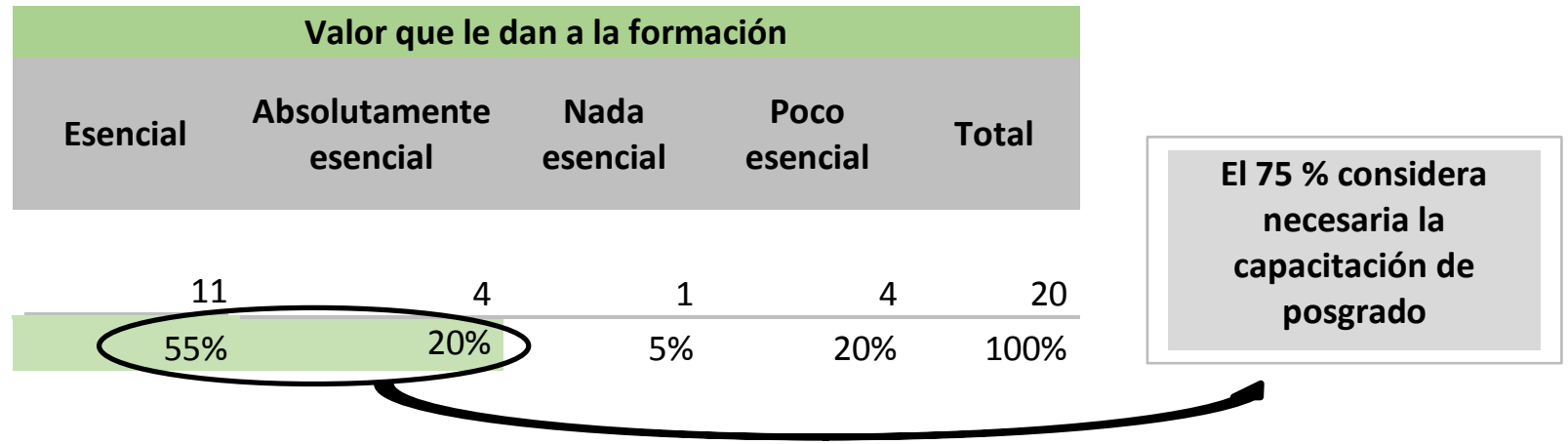


Por otra parte, analizando la pregunta: "ocupa actualmente ${ }^{43}$ algún cargo en la gestión", nuevamente llaman la atención los resultados arrojados; mientras que el $65 \%$ ocupaba cargos de gestión antes de realizar el posgrado, luego de la formación, el porcentaje es del $60 \%$. Nuevamente esto hace suponer que, analizando la formación de posgrado en forma aislada, ésta no actuaría como un factor directo y único para acceder a cargos de gestión en las organizaciones sanitarias.

\section{Cuadro 25}

\begin{tabular}{|c|c|c|}
\hline \multicolumn{3}{|c|}{ Ocupa actualmente algún cargo en la gestión } \\
\hline Si & No & Total \\
\hline 12 & 8 & 20 \\
\hline $60 \%$ & $40 \%$ & $100 \%$ \\
\hline
\end{tabular}

Profundizando el análisis y tomando en consideración comparativamente las respuestas femeninas y masculinas desagregadas por rangos de edad se pueden observar las siguientes apreciaciones:

Existe un mayor porcentaje de mujeres que ocupaban cargos de gestión en las organizaciones sanitarias antes de realizar el posgrado, en los primeros rangos de edad, aunque como ya se aclaró anteriormente, esos puestos no se corresponden con la alta gerencia, sino que pertenecen a la gerencia media.

Aquí es necesario hacer una salvedad dado que para el primer rango de edad (menores de 30) no se cuenta con datos del género masculino dado que del total de repuestas recibidas masculinas ninguno pertenecía a este rango de edad.

Sin embargo, para los últimos tramos de edad, desde los 40 años en adelante, es notoria la ventaja que llevan los varones frente a las mujeres. Ellos ocupan cargos de gestión aún antes de capacitarse en un porcentaje mucho mayor que las mujeres para esos mismos rangos de edad.

Adicionalmente a ello, es importante resaltar que algunos varones encuestados ocupan cargos en la alta gerencia no siendo así para el caso de las mujeres.

\footnotetext{
${ }^{43}$ Actualmente, entendido como después de realizar el posgrado
} 
En detalle:

Cuadro 26

\begin{tabular}{|c|c|c|c|}
\hline \multirow{3}{*}{ Rango de edad } & \multicolumn{3}{|c|}{ Mujeres } \\
\hline & \multicolumn{3}{|c|}{$\begin{array}{l}\text { Ocupaban algún cargo de gestión } \\
\text { antes del posgrado (gestión media) }\end{array}$} \\
\hline & Si & No & Total \\
\hline Menores de 30 & $43 \%$ & $57 \%$ & $100 \%$ \\
\hline Entre 30 y 39 años & $52 \%$ & $48 \%$ & $100 \%$ \\
\hline Entre 40 y 49 años & $53 \%$ & $47 \%$ & $100 \%$ \\
\hline Entre 50 y 59 años & $50 \%$ & $50 \%$ & $100 \%$ \\
\hline
\end{tabular}

Cuadro 27

\begin{tabular}{|c|ccr|}
\hline & \multicolumn{3}{c|}{ Varones } \\
\hline Rango de edad & $\begin{array}{c}\text { Ocupaban algún cargo de gestión antes } \\
\text { del posgrado (gestión media) }\end{array}$ \\
\hline Menores de $\mathbf{3 0}$ & $\mathbf{S i}$ & No & Total \\
\hline Entre $\mathbf{3 0}$ y $\mathbf{3 9}$ años & $17 \%$ & $83 \%$ & $100 \%$ \\
\hline Entre $\mathbf{4 0}$ y $\mathbf{4 9}$ años & $89 \%$ & $11 \%$ & $100 \%$ \\
\hline Entre $\mathbf{5 0}$ y $\mathbf{5 9}$ años & $80 \%$ & $20 \%$ & $100 \%$ \\
\hline
\end{tabular}

En cuanto a la valoración que le dan a la formación de posgrado ambos géneros, aquí puede apreciarse que tanto las mujeres como los varones perciben como muy necesaria la formación de posgrado específica, mostrando un mayor porcentaje de valoración a medida que avanzan en rangos de edad. Así puede verse en los cuadros y gráficos siguientes: 
Cuadro 28

\begin{tabular}{|c|c|c|c|c|c|}
\hline \multirow{3}{*}{ Rango de edad } & \multicolumn{5}{|c|}{ Mujeres } \\
\hline & \multicolumn{5}{|c|}{ Importancia que le dan a la formación } \\
\hline & $\begin{array}{c}\text { Muy } \\
\text { esencial }\end{array}$ & Esencial & $\begin{array}{c}\text { Poco } \\
\text { esencial }\end{array}$ & $\begin{array}{c}\text { Nada } \\
\text { esencial }\end{array}$ & Total \\
\hline Menores de 30 & $14 \%$ & $71 \%$ & $14 \%$ & $0 \%$ & $100 \%$ \\
\hline Entre 30 y 39 & & & & & \\
\hline años & $19 \%$ & $52 \%$ & $24 \%$ & $5 \%$ & $100 \%$ \\
\hline $\begin{array}{c}\text { Entre } 40 \text { y } 49 \\
\text { años }\end{array}$ & $24 \%$ & $65 \%$ & $12 \%$ & $0 \%$ & $100 \%$ \\
\hline $\begin{array}{l}\text { Entre } 50 \text { y } 59 \\
\text { años }\end{array}$ & $0 \%$ & $100 \%$ & $0 \%$ & $0 \%$ & $100 \%$ \\
\hline
\end{tabular}

Cuadro 29

\begin{tabular}{|c|c|c|c|c|c|}
\hline \multirow{3}{*}{ Rango de edad } & \multicolumn{5}{|c|}{ Varones } \\
\hline & \multicolumn{5}{|c|}{ Importancia que le dan a la formación } \\
\hline & $\begin{array}{c}\text { Muy } \\
\text { esencial }\end{array}$ & Esencial & $\begin{array}{c}\text { Poco } \\
\text { esencial }\end{array}$ & $\begin{array}{c}\text { Nada } \\
\text { esencial }\end{array}$ & Total \\
\hline Menores de 30 & $0 \%$ & $0 \%$ & $0 \%$ & $0 \%$ & $0 \%$ \\
\hline Entre 30 y 39 años & $0 \%$ & $50 \%$ & $33 \%$ & $17 \%$ & $100 \%$ \\
\hline Entre 40 y 49 años & $22 \%$ & $67 \%$ & $11 \%$ & $0 \%$ & $100 \%$ \\
\hline Entre 50 y 59 años & $40 \%$ & $40 \%$ & $20 \%$ & $0 \%$ & $100 \%$ \\
\hline
\end{tabular}

En relación con los porcentajes de quienes ocupan cargos de gestión, tanto antes como después de realizar el posgrado, la evidencia muestra que a medida que se avanza en los rangos de edad, la discrepancia entre géneros se hace más profunda.

Luego de la capacitación de posgrado, el género femenino no muestra un aumento en el acceso a cargos de gestión para el tramo de edad más joven, mostrando a su vez, para los tramos de edad de 30 a 49 años, una disminución de presencia en los cargos de gestión después del posgrado.

De lo anterior se podría interpretar que existen otros factores externos, que evidentemente afectan los resultados, entre ellos, por ejemplo, la maternidad. 
Por otra parte, para el último rango de edad, no existen diferencias en el acceso a cargos de gestión antes y después del posgrado en ambos géneros. Aquí nuevamente puede inferirse que existirían otros factores que influirían más directamente en el acceso a cargos de gestión que la formación de posgrado.

En los rangos de edad de 40 a 59 años se observan más notoriamente las discrepancias que se producen entre géneros, dado que, si bien ambos perciben de manera similar la valoración de la formación de posgrado, es el género masculino quien logra acceder a puestos de gestión en mayor proporción que el género femenino, tanto antes de la formación como después de ella.

Cuadro 30

\begin{tabular}{|c|c|c|c|}
\hline \multirow{3}{*}{ Rango de edad } & \multicolumn{3}{|c|}{ Mujeres } \\
\hline & \multicolumn{3}{|c|}{$\begin{array}{l}\text { Ocupan después del posgrado algún } \\
\text { cargo en la gestión }\end{array}$} \\
\hline & Si & No & Total \\
\hline Menores de 30 & $43 \%$ & $57 \%$ & $0 \%$ \\
\hline Entre 30 y 39 años & $38 \%$ & $62 \%$ & $0 \%$ \\
\hline Entre 40 y 49 años & $35 \%$ & $65 \%$ & $0 \%$ \\
\hline Entre 50 y 59 años & $50 \%$ & $50 \%$ & $0 \%$ \\
\hline
\end{tabular}

Cuadro 31

\begin{tabular}{|c|c|c|c|}
\hline \multirow{3}{*}{ Rango de edad } & \multicolumn{3}{|c|}{ Varones } \\
\hline & \multicolumn{3}{|c|}{$\begin{array}{c}\text { Ocupan después del posgrado algún } \\
\text { cargo en la gestión }\end{array}$} \\
\hline & $\mathrm{Si}$ & No & Total \\
\hline Menores de 30 & $0 \%$ & $0 \%$ & $0 \%$ \\
\hline Entre 30 y 39 años & $33 \%$ & $67 \%$ & $100 \%$ \\
\hline Entre 40 y 49 años & $67 \%$ & $33 \%$ & $100 \%$ \\
\hline Entre 50 y 59 años & $80 \%$ & $20 \%$ & $100 \%$ \\
\hline
\end{tabular}

Sintetizando, los resultados arrojados en esta primera parte del relevamiento se podrían resumir así: 
$\checkmark$ Existe una notoria diferencia en cuanto a la ocupación de cargos gerenciales entre mujeres y varones. El género masculino accede en mayor escala a los cargos gerenciales que las mujeres, aún antes de capacitarse y esa diferencia porcentual es mayor a medida que se avanza en el rango de edad.

$\checkmark$ Tanto las mujeres como los varones perciben como muy necesaria la formación de posgrado específica, mostrando un mayor porcentaje de importancia a medida que avanzan en rangos de edad.

$\checkmark$ Por los datos expuestos y analizando el factor formación de posgrado en forma aislada, la evidencia demuestra que este último no tiene un impacto directo en el acceso a los cargos de gestión de las organizaciones de salud.

\section{Resultados de la segunda parte del trabajo de campo (preguntas 5 y 6 )}

Continuando con el análisis, en las encuestas se indagó, además, sobre el impacto que tienen en la accesibilidad a la alta gerencia los factores:

$\checkmark$ Género,

$\checkmark$ Aptitudes personales,

$\checkmark$ Formación de Posgrado,

$\checkmark$ Aspirante con o sin hijos,

$\checkmark$ Cultura de la Organización,

$\checkmark$ Experiencia en cargos de Gestión.

Desagregando las respuestas obtenidas por género se puede observar cuál fue el nivel de impacto que ambos le otorgan a cada factor mencionado en la encuesta. Así puede verse en detalle: 


\section{Cuadro 32}

Impacto en la accesibilidad a

la alta gerencia (en valores relativos) - Mujeres

\begin{tabular}{|c|c|c|c|c|c|c|}
\hline Categorías & Género & $\begin{array}{l}\text { Aptitudes } \\
\text { personales }\end{array}$ & $\begin{array}{l}\text { Formación } \\
\text { de } \\
\text { posgrado }\end{array}$ & $\begin{array}{l}\text { Aspirante } \\
\text { con o sin } \\
\text { hijos }\end{array}$ & $\begin{array}{c}\text { Cultura de } \\
\text { la } \\
\text { organización }\end{array}$ & $\begin{array}{c}\text { Experiencia } \\
\text { en cargos } \\
\text { de gestión }\end{array}$ \\
\hline $\begin{array}{l}\text { extremadamente } \\
\text { influyente }\end{array}$ & $9 \%$ & $23 \%$ & $6 \%$ & $6 \%$ & $34 \%$ & $23 \%$ \\
\hline influyente & $55 \%$ & $66 \%$ & $49 \%$ & $38 \%$ & $53 \%$ & $51 \%$ \\
\hline Poco influyente & $34 \%$ & $9 \%$ & $40 \%$ & $45 \%$ & $13 \%$ & $19 \%$ \\
\hline Nada influyente & $2 \%$ & $2 \%$ & $4 \%$ & $11 \%$ & $0 \%$ & $6 \%$ \\
\hline Total & $100 \%$ & $100 \%$ & $100 \%$ & $100 \%$ & $100 \%$ & $100 \%$ \\
\hline
\end{tabular}

Para una mejor visualización se complementa la información con:

Gráfico 17

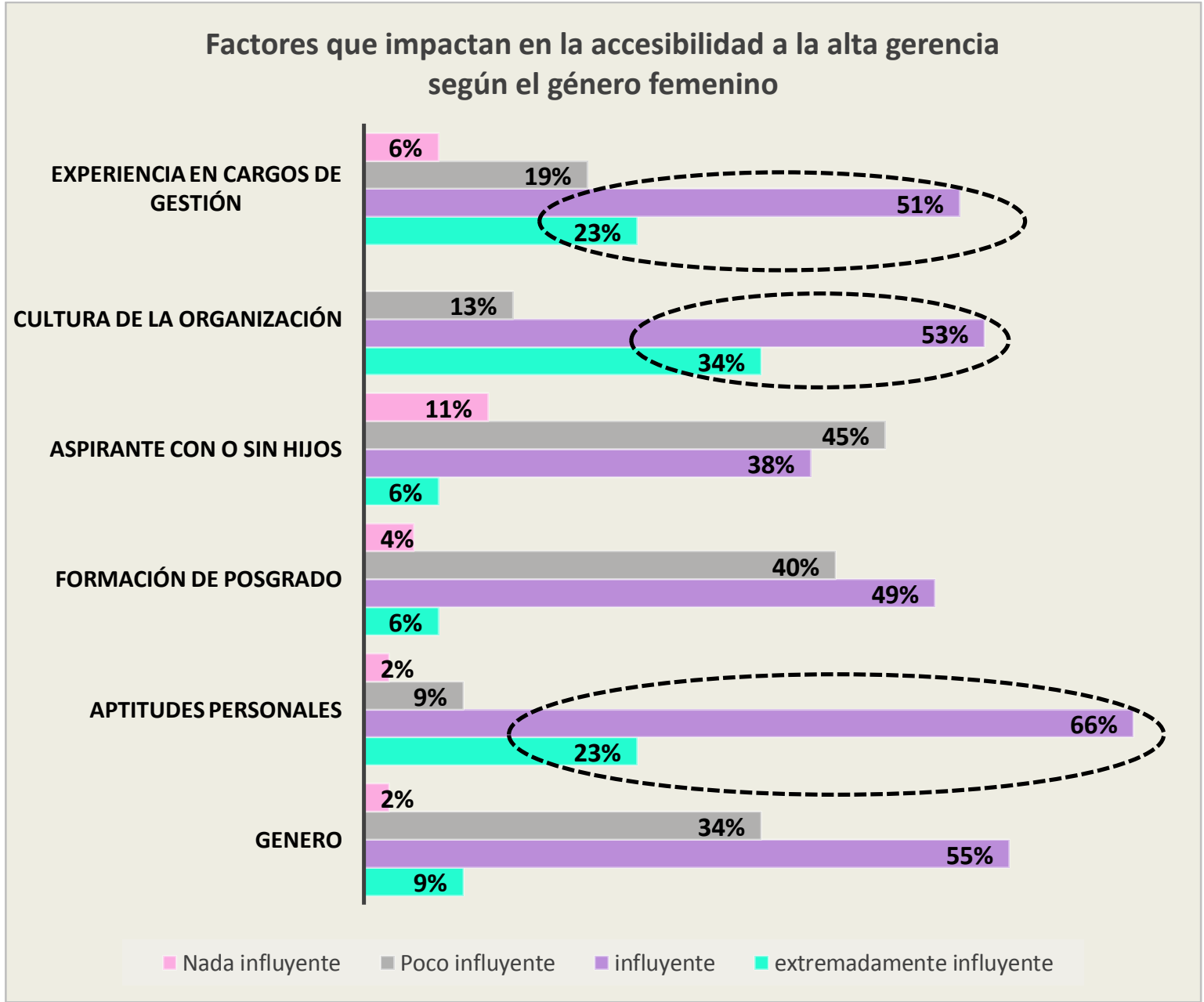




\section{Cuadro 33}

Impacto en la accesibilidad a la alta gerencia (en valores relativos) -Varones

\begin{tabular}{|c|c|c|c|c|c|c|}
\hline Categorías & Género & $\begin{array}{l}\text { Aptitudes } \\
\text { personales }\end{array}$ & $\begin{array}{l}\text { Formación } \\
\text { de } \\
\text { posgrado }\end{array}$ & $\begin{array}{l}\text { Aspirante } \\
\text { con o sin } \\
\text { hijos }\end{array}$ & $\begin{array}{c}\text { Cultura de } \\
\text { la } \\
\text { organización }\end{array}$ & $\begin{array}{c}\text { Experiencia } \\
\text { en cargos de } \\
\text { gestión }\end{array}$ \\
\hline $\begin{array}{l}\text { extremadamente } \\
\text { influyente }\end{array}$ & $5 \%$ & $40 \%$ & $20 \%$ & $0 \%$ & $30 \%$ & $20 \%$ \\
\hline influyente & $30 \%$ & $50 \%$ & $55 \%$ & $5 \%$ & $60 \%$ & $60 \%$ \\
\hline Poco influyente & $35 \%$ & $10 \%$ & $20 \%$ & $55 \%$ & $5 \%$ & $15 \%$ \\
\hline Nada influyente & $30 \%$ & $0 \%$ & $5 \%$ & $40 \%$ & $5 \%$ & $5 \%$ \\
\hline Total & $100 \%$ & $100 \%$ & $100 \%$ & $100 \%$ & $100 \%$ & $100 \%$ \\
\hline
\end{tabular}

Para una mejor visualización se complementa la información con:

Gráfico 18

Ponderación de los factores que impactan en la accesibilidad a los altos cargos directivos según el género masculino

Experiencia en cargos de gestión

Cultura de la organización

Aspirante con o sin hijos

Formación de posgrado

Aptitudes personales

Genero

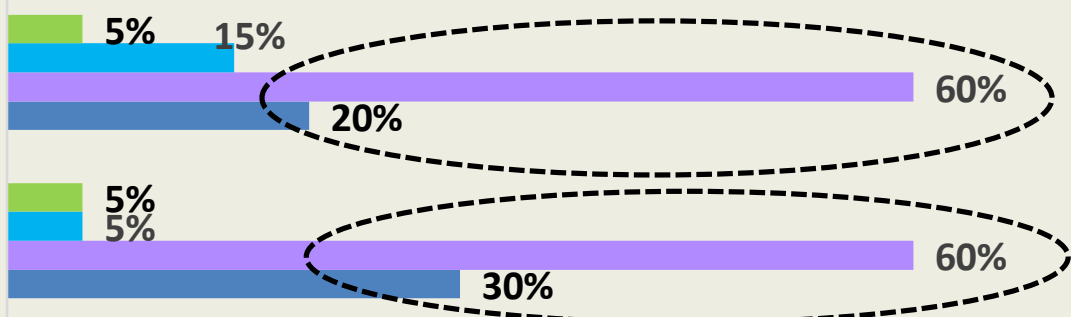

$40 \%$

$55 \%$

$55 \%$

$20 \%$

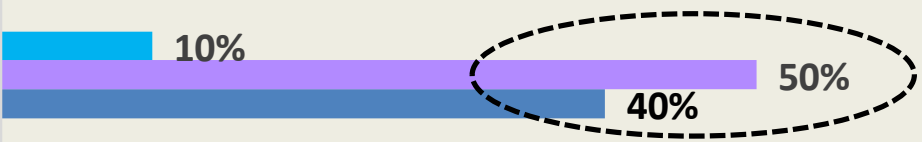

$30 \%$ 35\% 
Es importante destacar que, de la ponderación de los factores mencionados tanto para las mujeres como para los varones, el orden de prioridades de cada componente es similar, salvo para el caso de los factores género y formación de posgrado, donde se observan diferencias según sea la percepción de mujeres o de varones.

\section{Cuadro 34}

Impacto en la accesibilidad a la alta gerencia (en valores relativos) Mujeres

\begin{tabular}{l|rrrrrr} 
Categorías & Genero & $\begin{array}{c}\text { Aptitudes } \\
\text { personales }\end{array}$ & $\begin{array}{c}\text { Formación } \\
\text { de } \\
\text { posgrado }\end{array}$ & $\begin{array}{c}\text { Aspirante } \\
\text { con o sin } \\
\text { hijos }\end{array}$ & $\begin{array}{c}\text { Cultura de } \\
\text { la } \\
\text { organización }\end{array}$ & $\begin{array}{c}\text { Experiencia } \\
\text { en cargos } \\
\text { de gestión }\end{array}$ \\
Impacta & $64 \%$ & $89 \%$ & $55 \%$ & $45 \%$ & $87 \%$ & $74 \%$ \\
\hline
\end{tabular}

Cuadro 35

Impacto en la accesibilidad a la alta gerencia (en valores relativos) Varones

\begin{tabular}{l|rrrrrr} 
Categorías & Genero & $\begin{array}{c}\text { Aptitudes } \\
\text { personales }\end{array}$ & $\begin{array}{c}\text { Formación } \\
\text { de } \\
\text { posgrado }\end{array}$ & $\begin{array}{c}\text { Aspirante } \\
\text { con o sin } \\
\text { hijos }\end{array}$ & $\begin{array}{c}\text { Cultura de } \\
\text { la } \\
\text { organización }\end{array}$ & $\begin{array}{c}\text { Experiencia } \\
\text { en cargos } \\
\text { de gestión }\end{array}$ \\
Impacta & $35 \%$ & $90 \%$ & $75 \%$ & $5 \%$ & $90 \%$ & $80 \%$ \\
\hline
\end{tabular}

Analizando los datos obtenidos en cuanto al impacto que genera en la accesibilidad a la alta gerencia lo que perciben las mujeres, los resultados arrojan el siguiente orden de prioridad:

1. Actitudes personales $89 \%$

2. Cultura organizacional $87 \%$

3. Experiencia en cargos de gestión $74 \%$

4. Género $64 \%$

5. Formación de Posgrado 55\%

6. Aspirante con o $\sin$ hijos $45 \%$ 
Para el caso de los varones, la ponderación resulta en el siguiente orden de prioridades:

1. Actitudes personales $90 \%$

2. Cultura organizacional $90 \%$

3. Experiencia en cargos de gestión $80 \%$

\section{Formación de Posgrado $75 \%$ \\ 5. Género $35 \%$}

6. Aspirante con o sin hijos $5 \%$

Puede concluirse de acuerdo con los resultados arrojados, que las mujeres perciben el factor género como un determinante con mayor peso que la formación de posgrado, para acceder a los cargos de alta gerencia. A su vez, para ellas el factor género es un elemento mucho más influyente que para los varones. (Mujeres 64\%, varones $35 \%$ ).

Por el contrario, los varones atribuyen mayores porcentajes a la formación de posgrado (75\%) que sus pares femeninas (55\%), aunque en la práctica sean estas últimas las que predominan en las matrículas de posgrado específico en gestión sanitaria. 


\section{Conclusiones emergentes y desafíos pendientes}

En primer lugar se presenta una síntesis de los resultados a los que se arribó en cada uno de los ejes de estudio.

Luego se exponen las conclusiones pertinentes a cada eje de análisis; lo cual permite culminar con una reflexión integral sobre la problemática investigada.

Finalmente, se plantean algunos desafíos o interrogantes a ser abordados en el futuro y se sugieren posibles líneas de investigación para profundizarlos.

\section{Primer eje de estudio}

- De un total de 20 establecimientos asistenciales privados de mediana y alta complejidad con internación y prestación quirúrgica, polivalentes, ubicados en el Gran La Plata (La Plata, Berisso y Ensenada), solo en el $20 \%$ de los casos, las mujeres ocupaban el cargo de gerente general o administrador, mientras que el $80 \%$ de las instituciones contaban en sus altos cuadros gerenciales con representantes varones.

- El $50 \%$ de los actuales gerentes de estas instituciones contaban con título universitario de grado, mientras que el $50 \%$ restante carecía de dicho título.

- Ninguno de los gerentes implicados en la muestra poseía título universitario de Posgrado. Sin embargo afirmaron haber cursado estudios de posgrado, pero en todos los casos sin haber realizado sus tesis de graduación.

- El $50 \%$ de los gerentes que poseían título de grado universitario, provenían de las ciencias de la salud y en su totalidad eran médicos, mientras que el $50 \%$ restante provenían de las ciencias económicas. De estos últimos, el $80 \%$ poseían título de contador y el $20 \%$ de Licenciado en Administración.

De acuerdo con los resultados de este primer eje de análisis, y dando respuesta a los dos primeros objetivos trazados en esta investigación, se puede exponer como primera conclusión, que existe una clara prevalencia del género masculino en las 
instituciones sanitarias privadas de salud del Gran La Plata ( $80 \%$ varones; $20 \%$ mujeres).

Por otra parte, como lo demuestra la evidencia exhibida en la presente investigación, la mitad de quienes ocupan cargos en la cima organizacional no necesitaron de títulos universitarios de grado y posgrado para acceder a los mismos, lo que deja entrever que pesan más otros factores a la hora de acceder a estos puestos estratégicos de poder.

Aún continúa vigente la fuerza de la imagen del médico a cargo de la gestión integral de instituciones sanitarias. Si bien es aceptado que las Instituciones de salud, particularmente las privadas, han surgido gracias al impulso e iniciativa de profesionales de la salud, lo cual ha dado lugar a que desde sus comienzos estuviesen manejadas estratégicamente por dichos profesionales; en la actualidad existe prueba suficiente para reflexionar acerca de si los médicos, dada su formación de base, cuentan con las habilidades y capacidades necesarias para gerenciar este tipo tan particular de organizaciones o se necesitan especialistas en gestión con conocimientos y capacidades determinadas.

\section{Segundo eje de análisis}

- Analizando el período 1996 - 2015, en las carreras de posgrado en Gestión sanitaria de la UNLP, se observa un claro corte temporal de la receptividad de la propuesta de posgrado dado que en los primeros 6 años los varones lideraron las inscripciones en las carreras disponibles. (46\% mujeres- 54\% varones). A partir del año 2003 la situación se revierte, mostrando una prevalencia del género femenino en los posgrados en gestión sanitaria. (63\% mujeres - 37\% varones). Desde el año 2007 se refuerza la evidencia ya que, continúa la prevalencia de las mujeres en las matrículas de posgrado, pero ahora la brecha entre varones y mujeres es levemente más profunda (65\% mujeres - 35\% varones).

- Las tasas de graduación en posgrados de gestión sanitaria permiten vislumbrar una fuerte presencia de la mujer (65\% mujeres - 35\% varones), lo que admite inferir una mejor performance femenina en estas carreras de 
posgrado. La mujer mantiene el predominio sobre los varones al completar su formación de posgrado; el $7 \%$ de las mujeres inscriptas se gradúan, mientras que en el caso de los varones la tasa es del $5 \%$.

- En detalle puede observarse un $57 \%$ de mujeres entre los graduados en Gestión Sanitaria cuyas profesiones de base provienen de las Ciencias de la Salud. Más notorio es que, entre los graduados que provienen de las Ciencias Económicas, las mujeres superan las graduaciones en un $83 \%$. Situación similar ocurre cuando se analiza el resto de las áreas disciplinares, el porcentaje de mujeres también es superior con un $80 \%$ de graduadas con respecto a los varones.

- Otra contemplación de las graduaciones de posgrados en gestión sanitaria. Existe un marcado predominio de médicos entre los varones (75\%); y un amplio abanico de disciplinas profesionales entre las mujeres, mostrando mayoría Licenciadas en Administración (23\%) seguidas por médicas y Licenciadas en enfermería (18\%).

Dado que uno de los objetivos de la presente investigación consiste en describir la realidad a nivel local de la relación varón- mujer en las matrículas y graduaciones de posgrado en la disciplina gestión sanitaria entre los años 1996 -2015; los resultados arribados en este eje de estudio permitieron detallar la composición de género tanto en las matrículas como en las graduaciones de los posgrados específicos de gestión sanitaria locales.

Adicionalmente, se profundizó la exploración mostrando la composición de las disciplinas de base desagregadas por género.

Así, se corrobora la hipótesis implícita de que las mujeres son cada vez más, las que ganan terreno año a año en las aulas universitarias de los posgrados específicos a la gestión sanitaria.

\section{Tercer eje de estudio}

Analizando el nexo formación académica - posibilidades de acceso a cargos en la alta gestión de organizaciones de salud, los resultados de las encuestas realizadas muestran: 
- Notoria diferencia en cuanto a la ocupación de cargos gerenciales entre mujeres y varones. El género masculino accede en mayor escala a los cargos gerenciales que las mujeres, aún antes de capacitarse. Esa diferencia se incrementa a medida que se avanza en los rangos de edad (mayor edad, mayor la brecha entre géneros)

- Tanto las mujeres como los varones consideran muy necesaria la formación de posgrado específica, mostrando un mayor porcentaje de importancia a medida que avanzan en rangos de edad.

- Las mujeres perciben el factor género como un determinante con mayor peso que la formación de posgrado, para acceder a los cargos de alta gerencia.

- Las mujeres conceden mayores porcentajes al factor género, como elemento influyente $(64 \%)$ en relación con los varones (35\%) para acceder a la cima organizacional.

- A su vez, los varones otorgan mayores porcentajes a la formación de posgrado $(75 \%)$ como elemento influyente en relación con otros factores, frente a las mujeres $(55 \%)$, aunque en la práctica sean estas últimas las que predominan en las matrículas de posgrado específico en gestión sanitaria.

Los resultados proporcionan una clara evidencia de que el factor género es percibido por las mujeres como un importante factor retractor (65\%) para acceder a los cargos de poder en las organizaciones de salud privadas locales, no siendo percibido del mismo modo por el género masculino $(35 \%)$, quienes lo conciben como uno de los menos influyentes, de un abanico de 6 factores analizados en el estudio.

En cuanto al factor formación de posgrado, si bien es percibido por los encuestados como un elemento impulsor, se le otorga menos trascendencia que a otros componentes como las aptitudes personales y la cultura organizacional, que llevan con marcada diferencia la vanguardia. También queda expuesto que el género masculino valoriza más la formación de posgrado $(75 \%)$ que el género 
femenino (55\%) pese a que, como ya se mencionó, sean las mujeres las que ganan en número en los posgrados, tanto en matriculación como en graduación.

Por último, para este eje de estudio se pudo comprobar que existen otros factores como las aptitudes personales, la cultura de la organización y la experiencia profesional, que influyen más directa y marcadamente en el acceso a cargos de poder en las instituciones bajo estudio.

Un punto que merece atención resulta de observar el factor "aspirante con o sin hijos"; si bien para ambos géneros se ubica en el último lugar de las posiciones estudiadas, las mujeres le otorgaron un porcentaje mucho mayor en relación con los varones (mujeres 45\%, varones 5\%). Queda demostrada así, la influencia que tienen los estereotipos de género y la cultura patriarcal en el inconsciente de mujeres y varones. Son las mujeres quienes culturalmente, en mayor medida han tenido que hacerse cargo del cuidado y crianza de los hijos a lo largo de los años y esos patrones son difíciles de romper y son uno de los desafíos de este nuevo siglo. 


\section{Conclusiones globales y nuevos desafíos}

En las organizaciones sanitarias privadas de salud locales, tal como lo demuestra la teoría y la evidencia expuesta en la presente investigación, la gran mayoría de las mujeres llega en condiciones similares de igualdad con sus pares masculinos hasta las gerencias medias, pero se queda en el camino a la hora de aspirar a posiciones máximas en las jerarquías directivas, es decir a los niveles de poder real en dichas instituciones.

Esta situación, tal como lo advierten autores citados en el marco teórico de la presente investigación, permitiría suponer que, como la permanencia en la cima gerencial es poco amigable con los tiempos personales, las mujeres priorizarían otros intereses. En otras ocasiones, existirían factores externos a las propias mujeres, como la cultura propia de cada organización, que como también se mencionó en el marco teórico, generarían barreras difíciles de derribar.

Las organizaciones de salud hoy están gerenciadas en gran parte por la generación de los Baby Boomers (1945 - 1964), una generación que, como lo definió la propia autora Paula Molinari, mencionada en el marco teórico de esta investigación, es una generación competitiva e idealista que le resulta sumamente complejo manejar un balance entre vida laboral y privada y familiar. Éste es uno de los puntos cruciales que le genera especialmente a las mujeres, cuantiosas dificultades para acceder y permanecer en estos cargos. Pero a la vez, origina enormes desafíos para quienes buscan encontrar la paridad en la cima gerencial.

Actualmente, se está abordando un cambio de paradigma que ansía eliminar la transmisión de los roles de género y estereotipos a las nuevas generaciones y erradicar los valores patriarcales que siguen aún presentes en la sociedad.

Este cambio demandará mucho tiempo, lo que implica que no se logrará ni en el corto ni en el mediano plazo y será de vital importancia, involucrar a todos los actores sociales: individuos, familias, instituciones y Estado, es decir a la sociedad en su conjunto para lograrlo. 
La formación de posgrado cada vez más debería ser una de las principales herramientas que encuentren varones y mujeres para aspirar ascender en la escala jerárquica de toda organización. Sin embargo, como la evidencia lo demuestra en esta investigación, esto por sí solo no alcanza; existen otros factores como las aptitudes personales y la cultura de la organización que llevan por mucho la delantera. El género sigue siendo un influyente factor para lograr escalar puestos de poder en las organizaciones y son especialmente las mujeres quienes lo perciben como un factor retractor y con más peso a diferencia de los varones.

Actualmente, desde distintas corrientes se busca concientizar a la sociedad en su conjunto y en especial a las organizaciones en temas como son la flexibilidad horaria, de modo que, tanto varones como mujeres, con o sin hijos/as, puedan distribuir y equilibrar el uso de sus tiempos.

De Igual manera, dichas corrientes reclaman poder adaptar la jornada de trabajo de acuerdo con la etapa del ciclo vital de cada persona y mediar por lo que algunos autores denominan "flexibilidad bien entendida" que implicaría horarios flexibles donde se prioricen la responsabilidad y el trabajo por objetivos. Se podría inferir aquí que a medida que las nuevas generaciones vayan asumiendo la conducción de las instituciones, estos modelos que hoy parecieran utopías lleguen a cristalizarse, dado que ellas priorizan el balance entre vida personal y laboral.

Estas acciones hoy están modestamente comenzando a pensarse en las cúspides de las instituciones sanitarias y, si bien podrían contribuir a generar condiciones de acceso más equitativas para ambos géneros en las organizaciones, todavía existen muchas barreras que derribar, no sólo culturales. Aún hoy, hay que desaprender muchos mandatos que colisionan con las nuevas realidades, hay que desterrar mitos que se formaron en base a viejos paradigmas. Únicamente desaprendiendo esas viejas prácticas y descubriendo nuevos modelos para llevar a cabo la función gerencial, que incluya una perspectiva de género, podría achicarse la brecha estudiada en estas instituciones. 


\section{Desafíos pendientes y líneas de investigación para seguir investigando}

Es relevante dejar abiertas posibles líneas de estudio para profundizar el análisis y poder examinar otros aspectos no incluidos en la presente investigación.

$\checkmark$ Una posible línea sería continuar estudiando las variables analizadas en la presente investigación, continuando con la actualización de los datos para examinar cómo se comportan esas variables en el tiempo, qué cambios sufren, etc.

$\checkmark$ Indagar acerca de cuáles son las percepciones de quienes han llegado a la cima organizacional dentro de las propias organizaciones de salud, haciendo un estudio de la ruta de vida de cada uno para encontrar factores comunes si los hay.

$\checkmark$ Identificar y estudiar las competencias gerenciales manifiestas diferenciadas por género.

Para ello, sería interesante además indagar el aporte que están ofreciendo las neurociencias en el campo del neurománagement. Las cuales han demostrado que existen procesos cerebrales que determinan y definen la toma de decisiones y que tanto varones como mujeres gozan de una plataforma neurobiológica con enormes semejanzas, pero a su vez con distinciones que influyen concluyentemente en la conducta de cada uno.

El Dr. Braidot en su libro "Neuromanagement" ha expuesto las diferencias biológicas que existen entre cerebros masculinos y femeninos que podrían explicar por qué por ejemplo las mujeres tienen una visión más amplia de una situación determinada y los varones una visión más focalizada. Esto permitiría reflexionar acerca de la importancia de incluir en una posible y futura línea de investigación, el uso de las neurociencias y sus herramientas para potenciar el estudio y optimización de las habilidades y competencias, tanto innatas como adquiridas de los gerentes en general y especialmente en los gerentes sanitarios, haciendo foco en el género, para hacer más eficiente su gestión. 


\section{Bibliografía utilizada}

$\checkmark$ Aspiazu, Eliana. 2016. Heterogeneidad y desigualdad de género en el sector salud: entre las estadísticas y las percepciones sobre las condiciones de trabajo. Revista Pilquen. Sección ciencias Sociales. Vol. 19 $\mathrm{N}^{\circ} 1$ p60 2016SSN 1851-3123 http://www.curza.net/revistapilquen/index.php/Sociales

$\checkmark$ Barberá Rivera, Teresa y otros. September 2nd- 4th 2009. Obstáculos en la promoción profesional de las mujeres: El Techo de Cristal. $3^{\circ}$ Conferencia Internacional de Industria - XIII Congreso de Ingeniería. Barcelona Terrassa

$\checkmark$ Barberá, Ester y otros "Rompiendo el techo de cristal: Los beneficios de la diversidad de género en los equipos de dirección" Universitat de Valência- Estudi General

$\checkmark$ Braidot, Néstor. 2008. Neuromanagement: cómo utilizar a pleno el cerebro en la conducción de organizaciones. $1^{\circ}$ ed. Ediciones Granica SA. Buenos Aires 488p

$\checkmark$ Burin, Mabel. 2004. Género Femenino, Familia y Carrera Laboral: Conflictos Vigentes. Universidad de Ciencias Empresariales y Sociales (UCES). Subjetividad y Procesos Cognitivos, p 48- 77

$\checkmark$ Castro Solano y otros. 2007. Teoría y Evaluación del Liderazgo $1^{\circ}$ edición. Paidós. Buenos Aires

$\checkmark$ Chinchilla, Nuria y otros. Mayo 2006. Frenos e Impulsores en la trayectoria profesional de las mujeres directivas. Centro Internacional Trabajo y Familia. Universidad de Navarra, DI No 632, Barcelona, España

$\checkmark$ Díaz, Carlos Alberto. 2005. El pequeño Gestión llustrado Servicios de Salud. Instituto Universitario ISALUD

$\checkmark$ Dirección General de Economía Social y Emprendedores. Economía Social con Perspectiva de Género. Análisis de Techo de Cristal y establecimiento de un modelo equitativo de Gestión empresarial. CEPES- Andalucía, Confederación de entidades para la Economía Social. Sevilla 
$\checkmark$ Fundación Friedrich Ebert. Julio 2018. Aportes de la Economía Feminista desde Argentina. Análisis No 27

$\checkmark$ Gasparini, Leonardo y Marchionni, Mariana. 2015. ¿Brechas que se cierran? Aumento y desaceleración de la participación laboral femenina en América Latina Resumen Ejecutivo CEDLAS Centro de Estudios Distributivos Laborales y Sociales FCE UNLP

$\checkmark$ Héller, Lidia. 2015. Mujeres... y varones en las organizaciones. Ambiciones y aspiraciones $1^{\circ}$ ed. Pluma Digital Ediciones. Ciudad Autónoma de Buenos Aires. $180 \mathrm{p}$

$\checkmark$ Hellriegel, Jackson, Slocum. 2009. Administración: Un enfoque basado en Competencias $11^{\circ}$ ed. Cengage Learning Editores SA.

$\checkmark$ Marchionni, Mariana. Diciembre 2018. Los desafíos de la igualdad de Género en revista ECONO- FCE- UNLP. No 17. Año 9 p15-17

$\checkmark$ Molinari, Paula. 2011. Turbulencia Generacional $1^{\circ}$ ed. Temas Grupo Editorial SRL. Buenos Aires.

$\checkmark$ Oficina Internacional del Trabajo. 2004. ROMPER el techo de cristal. Las mujeres en puestos de dirección. Ginebra 75 p

$\checkmark$ Organización Internacional del Trabajo - Programa de Naciones Unidas para el Desarrollo OIT- PNUD. 2009. Trabajo y Familia: Hacia nuevas formas de conciliación con responsabilidad social " 2 ed. Ginebra

$\checkmark$ Organización Internacional del trabajo OIT. 2008. ABC de los derechos de los trabajadores y la igualdad de género": $2^{\circ}$ ed. Ginebra

$\checkmark$ Organización Internacional del Trabajo OIT. 2015. La mujer en la gestión empresarial: Cobrando impulso. Versión resumida del Informe mundial Oficina internacional del trabajo, Ginebra

$\checkmark$ Ortiz, Mariel. 2012. El Gerente Sanitario. Distancias y Confluencias de las competencias recomendadas, desarrolladas y manifiestas. Tesis de graduación Maestría en Economía de la Salud y Administración de Organizaciones de Salud. FCE UNLP. La Plata

$\checkmark$ Ortún, Vicente. Innovaciones en los Servicios de Salud. Innovación organizativa en sanidad. Departamento de Economía y Empresa. Universidad Pompeu Fabra. p160 
$\checkmark$ Programa de las Naciones Unidas para el Desarrollo PNUD. 2018. Aportes para el desarrollo humano en Argentina 2018. Género en el sector salud: feminización y brechas laborales. $1^{\text {a }}$ ed. Buenos Aires:

$\checkmark$ Programa Naciones Unidas para el desarrollo PNUD. 2014. Género en el Trabajo. Brechas en el acceso a puestos de decisión. Número 8.

$\checkmark$ Robbins, Stephen P. 2004. Comportamiento Organizacional $10^{\circ}$ ed. Pearson Educación. México

$\checkmark$ Temes Montes, José, Parra Vásquez, Blanca y Keller Rebellón, Isabel. 2000. Gestión Clínica: Ventajas e inconvenientes; en Temes J., Parra B., "Gestión Clínica" $1^{\circ}$ ed. Mc Graw Hill - Interamericana Bs. As.

Wainerman, Catalina. 2007. Conyugalidad y paternidad ¿Una Revolución Estancada? En publicación: Género, familias y trabajo: rupturas y continuidades. Desafíos para la investigación política. Gutiérrez María Alicia. CLACSO Consejo Latinoamericano de Ciencias Sociales, Buenos Aires. Disponible en: http://bibliotecavirtual.clacso.org.ar/ar/libros/grupos/gutierrez/09wainerm an.pdf 
Anexos 


\section{Anexo 1.}

Nota remitida a las autoridades de FECLIBA solicitando: nombre, apellido y profesión de la persona que ocupa cargo de gerente o administrador general en las clínicas asociadas a FECLIBA

\section{Sr. Presidente FECLIBA}

La Plata, 6 de abril de 2018.-

Lic. Néstor Porras

Su Despacho:

En mi calidad de director de la Maestría en Economía de la Salud y Administración de Organizaciones de Salud de la Facultad de Ciencias Económicas de la UNLP, tengo el agrado de dirigirme a Usted a fin de solicitarle tenga a bien proporcionarle a la Lic. Mastropietro Andrea Lorena, DNI 23.353.288, alumna del posgrado mencionado, la información que se detalla seguidamente, la cual resulta sumamente valiosa para incorporar en su trabajo de Tesis de graduación.

Motiva el pedido la necesidad de contar con datos fehacientes y actuales que servirán de soporte para dicho trabajo.

El detalle de los datos solicitados es el siguiente:

$\square \quad$ Nombre, apellido y profesión de la persona que ocupa actualmente el cargo de gerente o administrador general de las siguientes clínicas asociadas a FECLIBA

\begin{tabular}{|l|}
\hline Instituciones con internación y prestación quirúrgica \\
\hline INSTITUTO MEDICO ARGENTINO DE BERISSO S.A. \\
\hline CLINICA PRIVADA ENRIQUE MOSCONI S.A. \\
\hline SANATORIO ARGENTINO DEL PLATA S.A. \\
\hline INSTITUTO MEDICO MATER DEI S.A. \\
\hline INSTITUTO CENTRAL DE MEDICINA S.A. \\
\hline ALTHEA CLINICA PRIVADA (EX CLÍNICA DR.J.J. VACCARINI) \\
\hline CLINICA PRIVADA DEL CENTRO \\
\hline SANATORIO SAN JOSE DE VILLA ELISA S.A. \\
\hline CLINICA BELGRANO \\
\hline SANATORIO MEDICO LOS TILOS \\
\hline CLINICA DE LA COMUNIDAD Polivalente de Ensenada \\
\hline
\end{tabular}

Agradeciendo desde ya toda la información que le pueda facilitar a la Licenciada Mastropietro, me despido muy atentamente.

Datos de contacto de la alumna:

Lic. Héctor Ángel Calvo

Director de la Escuela de Gestión de Organizaciones de Salud

Mastropietro, Andrea Lorena Licenciada en Administración UNLP andrea.mastropietro@econo.unlp.edu.ar Teléfono de contacto 0221 419-1404 


\section{Anexo 2.}

Nota recibida de FECLIBA en respuesta a información solicitada en anexo 1

La Plata, 11 de abril de 2018.

Lic. En Administración

UNLP

Mastropietro Andrea Lorena

S I D

Tengo el agrado de dirigirme a Usted, dando respuesta a lo solicitado mediante Nota del día 06 de Abril del corriente. En el cuadro se detalla con Nombre y Apellido los respectivos Gerentes 0 Administradores, como así también, profesión de cada uno de ellos.

\begin{tabular}{|l|l|l|l|}
\hline \multicolumn{1}{|c|}{ Establecimiento } & \multicolumn{1}{c|}{ Nombre y Apellido } & \multicolumn{1}{c|}{ Profesión } & \multicolumn{1}{c|}{ Cargo } \\
\hline $\begin{array}{l}\text { INST. MCO. ARG. DE BERISSO } \\
\text { S.A. }\end{array}$ & $\begin{array}{l}\text { JUAN MANUEL DE } \\
\text { ROSA }\end{array}$ & MÉDICO & GERENTE GENERAL \\
\hline CL. PRIV. MOSCONI S.A. & $\begin{array}{l}\text { SALVADOR } \\
\text { ESPÓSITO }\end{array}$ & & GERENTE GENERAL \\
\hline SANATORIO ARGENTINO S.A. & JOSÉ GIMENEZ & CONTADOR & GERENTE \\
\hline INST. MCO. MATER DEI S.A. & $\begin{array}{l}\text { ENRIQUE CALVO } \\
\text { GAINZA }\end{array}$ & MÉDICO & GERENTE GENERAL \\
\hline $\begin{array}{l}\text { INST. CENTRAL DE MEDICINA } \\
\text { S.A. }\end{array}$ & NICOLÁS SALAS & & ADMINISTRADOR \\
\hline ALTHEA CLINICA PRIVADA & LABRIOLA JOSÉ & & GERENTE \\
\hline CL. PRIV. DEL CENTRO & ORDONEEZ RAÚL & MÉDICO & GERENTE \\
\hline SANAT. SAN JOSÉ VILLA ELISA & JOAQUÍN ROSENDE & & GERENTE GENERAL \\
\hline CLÍNICA BELGRANO & $\begin{array}{l}\text { HONORIA } \\
\text { TAMBURRINI }\end{array}$ & & ADMINISTRADORA \\
\hline SANATORIO MÉDICO LOS TILOS & SILVIA ARZUAGA & & GERENTE GENERAL \\
\hline CL. DE LA COMUNIDAD & $\begin{array}{l}\text { JUAN MANUEL DE } \\
\text { ROSA }\end{array}$ & MÉDICO & GERENTE GENERAL \\
\hline
\end{tabular}

Sin más, y deseando que la información brindada le resulte valiosa para la incorporación en su trabajo de Tesis de graduación, saludo a Ud. muy atentamente. 


\section{Anexo 3.}

Tabla con detalle de las personas que están a cargo de la gerencia en las instituciones prestadoras privadas del Gran La Plata nucleadas en ACLIBA 1 y FECLIBA y de su máximo nivel académico alcanzado.

ACLIBA I

\begin{tabular}{|c|c|c|c|}
\hline Establecimiento & Nombre y Apellido & Título de grado & Genero \\
\hline CLINICA INSTITUTO MEDICO DE LA RIBERA S.A. & Elida Casal & Contadora & Femenino \\
\hline HOSPITAL ESPAÑOL & Daniel Reija & Contador & Masculino \\
\hline HOSPITAL ITALIANO & $\begin{array}{l}\text { Luciano } \\
\text { Erramuspe }\end{array}$ & Contador & Masculino \\
\hline HOSPITAL PRIVADO SUDAMERICANO & Gisela Siquilof & Médica & Femenino \\
\hline INSTITUTO MEDICO PLATENSE & Daniel Gómez & No posee & Masculino \\
\hline IPENSA & Atilio Gobbini & No posee & Masculino \\
\hline INSTITUTO DE DIAGNÓSTICO DE LA PLATA S.A & Norberto Morbelli & No posee & Masculino \\
\hline NUEVA CLÍNICA DEL NIÑO DE LA PLATA S.A & Nicolás Fernández & No posee & Masculino \\
\hline CLÍNICA CITY BELL S.A & Cristian Calvo & $\begin{array}{l}\text { Lic. En } \\
\text { Administración }\end{array}$ & Masculino \\
\hline
\end{tabular}

FECLIBA

\begin{tabular}{|l|l|l|l|}
\hline \multicolumn{1}{|c|}{ Establecimiento } & \multicolumn{1}{c|}{ Nombre y Apellido } & \multicolumn{1}{c|}{ Título de grado } & \multicolumn{1}{c|}{ Genero } \\
\hline INST. MCO. ARG. DE BERISSO S.A. & JUAN MANUEL DE ROSA & Médico & Masculino \\
\hline CL. PRIV. MOSCONI S.A. & SALVADOR ESPÓSITO & No posee & Masculino \\
\hline SANATORIO ARGENTINO S.A. & JOSÉ GIMENEZ & Contador & Masculino \\
\hline INST. MCO. MATER DEI S.A. & ENRIQUE CALVO GAINZA & Médico & Masculino \\
\hline INST. CENTRAL DE MEDICINA S.A. & NICOLÁS SALAS & No posee & Masculino \\
\hline ALTHEA CLINICA PRIVADA & LABRIOLA JOSÉ & No posee & Masculino \\
\hline CL. PRIV. DEL CENTRO & ORDOÑEZ RAÚL & Médico & Masculino \\
\hline SANAT. SAN JOSÉ VILLA ELISA & JOAQUÍN ROSENDE & No posee & Masculino \\
\hline CLÍNICA BELGRANO & HONORIA TAMBURRINI & No posee & Femenino \\
\hline SANATORIO MÉDICO LOS TILOS & SILVIA ARZUAGA & No posee & Femenino \\
\hline CL. DE LA COMUNIDAD & JUAN MANUEL DE ROSA & Médico & Masculino \\
\hline
\end{tabular}


Anexo 4.

Cuadro con la clasificación establecida por el Decreto 448/14. Elaboración Propia

\section{Decreto 448/14}

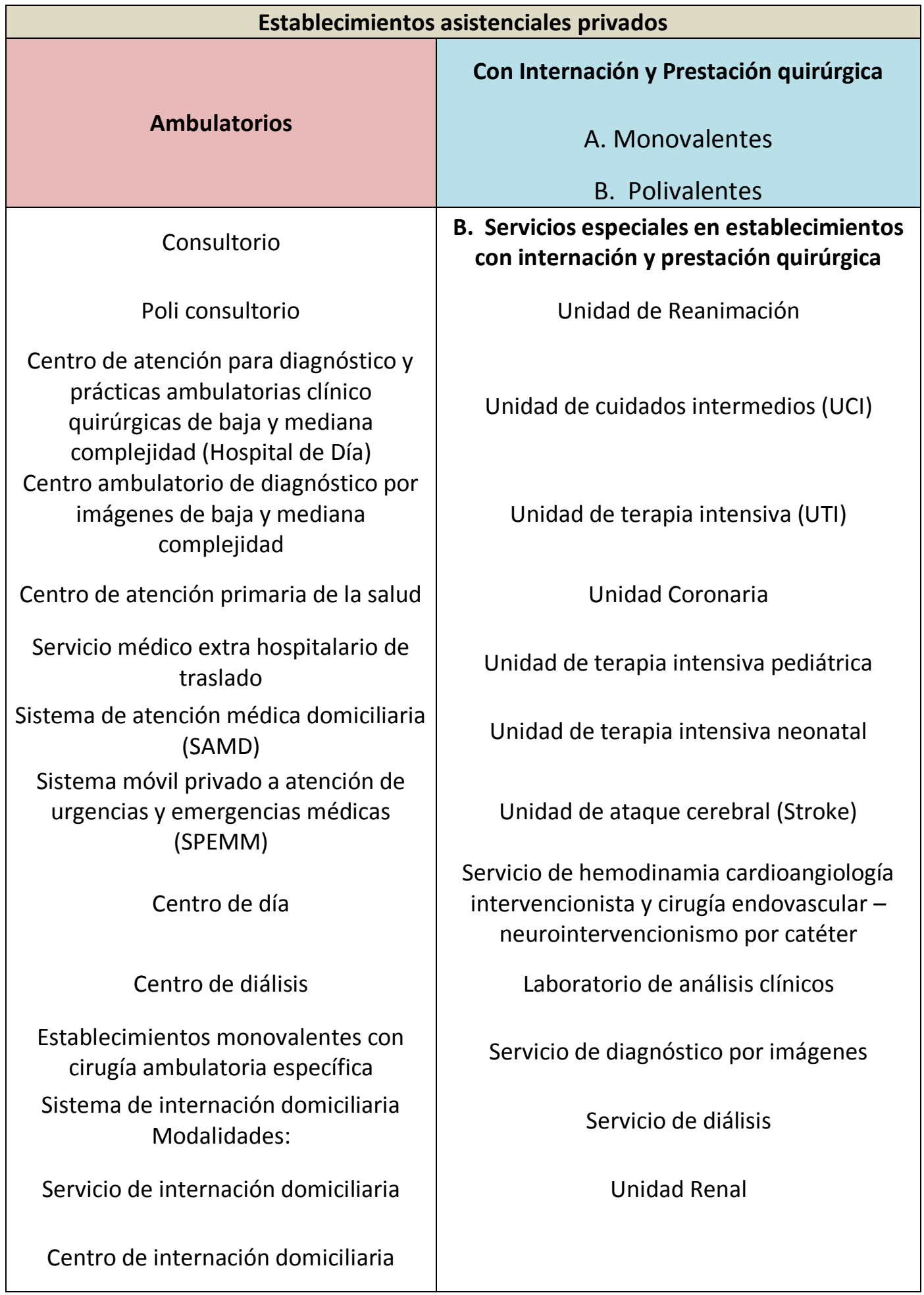




\section{Anexo 5.}

Nota remitida al director del CeSPI- UNLP solicitando información desagregada por género de la oferta académica de grado y posgrado de esa casa de estudios

La Plata, 14 de Julio de 2017.-

Señor Director General Científico y Técnico

CeSPI - UNLP

Lic. Francisco Javier Díaz

Su Despacho:

En mi calidad de director de la Maestría en Economía de la Salud y Administración de Organizaciones de Salud de la Facultad de Ciencias Económicas de la UNLP, tengo el agrado de dirigirme a Usted a fin de solicitarle tenga a bien proporcionarle a la Lic. Mastropietro Andrea Lorena DNI 23.353.288, alumna del posgrado mencionado, la información que se detalla seguidamente, la cual resulta sumamente valiosa para incorporar en su trabajo de Tesis de graduación.

Motiva el pedido la necesidad de contar con datos fehacientes y actuales que servirán de soporte para dicho trabajo.

El detalle de los datos solicitados es el siguiente:

- Cantidad de inscriptos en todas las ofertas académicas de grado y posgrado de la UNLP desagregadas por género y por facultad

- Cantidad de graduados en todas las carreras de grado de la UNLP segmentados por género y desagregadas por facultad

- Cantidad de graduados en todas las carreras de posgrado de la UNLP agrupados por género y por facultad

Agradeciendo desde ya toda la información que le pueda facilitar a la Licenciada Mastropietro, me despido muy atentamente.

Lic. Héctor Ángel Calvo

Director de la Escuela de Gestión

de Organizaciones de Salud

Datos de contacto de la alumna:

Mastropietro, Andrea Lorena

Licenciada en Administración UNLP

andrea.mastropietro@econo.unlp.edu.ar 


\title{
Anexo 6.
}

Nota remitida a la Secretaría de Asuntos Académicos- UNLP solicitando información desagregada por género de la oferta académica de grado y posgrado de esa casa de estudios

La Plata, 14 de agosto de 2017.-

Sra. Secretaria de Asuntos Académicos

De la Universidad Nacional de La Plata

Dra. María Mercedes Medina

Su Despacho:

En mi calidad de director de la Maestría en Economía de la Salud y Administración de Organizaciones de Salud de la Facultad de Ciencias Económicas de la UNLP, tengo el agrado de dirigirme a Usted a fin de solicitarle tenga a bien proporcionarle a la Lic. Mastropietro Andrea Lorena, DNI 23.353.288, alumna del posgrado mencionado, la información que se detalla seguidamente, la cual resulta sumamente valiosa para incorporar en su trabajo de Tesis de graduación.

Motiva el pedido la necesidad de contar con datos fehacientes y actuales que servirán de soporte para dicho trabajo.

El detalle de los datos solicitados es el siguiente:

- Cantidad de inscriptos en todas las ofertas académicas de grado y posgrado de la UNLP desagregadas por género y por facultad en el año 2016

- Cantidad de graduados en todas las carreras de grado de la UNLP segmentados por género y desagregadas por facultad en el año 2016

- Cantidad de graduados en todas las carreras de posgrado de la UNLP agrupados por género y por facultad en el año 2016

Agradeciendo desde ya toda la información que le pueda facilitar a la Licenciada Mastropietro, me despido muy atentamente.

\author{
Lic. Héctor Ángel Calvo \\ Director de la Escuela de Gestión \\ de Organizaciones de Salud
}

Datos de contacto de la alumna:

Mastropietro, Andrea Lorena

Licenciada en Administración UNLP

andrea.mastropietro@econo.unlp.edu.ar

Teléfono de contacto 0221 419-1404 


\section{Anexo 7.}

Análisis de la información recogida por cada carrera de la unidad académica FCE UNLP (EGSalud)

\section{Datos relevados de la FCE UNLP- Escuela de Gestión de Organizaciones de Salud}

La EGSalud, según los datos a los que se accedió para la presente investigación, ofrece dos carreras de posgrado relacionadas con el tema que es objeto de estudio de la presente investigación:

- La Maestría en Economía de la Salud y Administración de Organizaciones de Salud (MES) que tiene en su haber 14 cohortes editadas en forma continua e inició su primera edición en el año 1996. Dicha carrera posee una nómina de inscriptos de 323 alumnos. Desde el año 2012 se encuentra discontinuada.

- La Especialización en Gestión de Organizaciones de Salud (ESAL) la cual lleva desarrolladas 5 cohortes completas hasta el momento en que se analizó la información, comenzó su primera edición en al año 2007 y aún hoy continúa desarrollándose, la cantidad de alumnos inscriptos al momento de realizar esta investigación fue de 89 personas.

En la Maestría en Economía de la Salud y Administración de Organizaciones de Salud el volumen de inscriptos contabilizó un total de 323 alumnos de los cuales, efectuando una desagregación por género, según se detalla en el gráfico siguiente, el $54 \%$ pertenece al femenino, mientras que el $46 \%$ corresponde al género masculino. 
Anexo 7 - Grafico 1

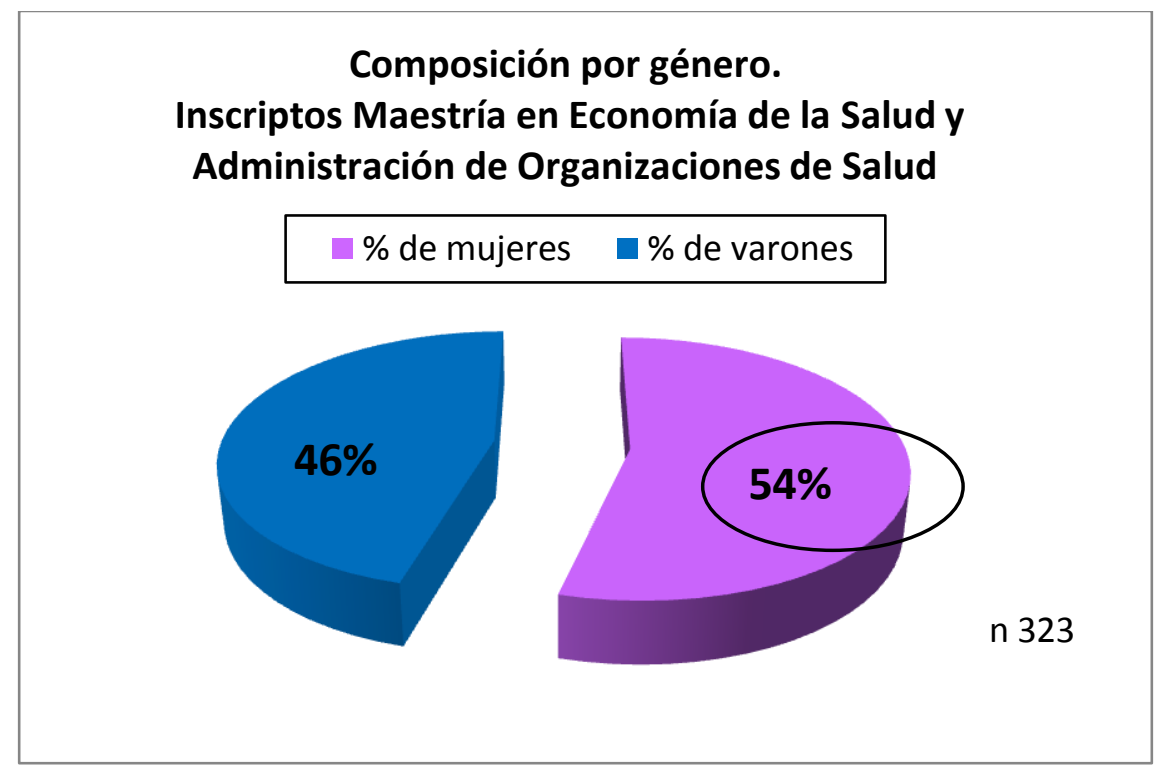

Es importante resaltar que la carrera, en sus primeras cohortes, se caracterizó por contar en su mayoría con un público masculino, situación que se fue revirtiendo con el transcurso de los años, perfilándose ya para el año 2007 una importante mayoría femenina, con el $70 \%$ de las mujeres sobre un $30 \%$ de los hombres. Esta tendencia persistió hasta la última edición que abarcó los años 2011- 2013.

Según estos datos, podría demostrarse que la carrera, que en sus primeras cuatro ediciones computaba una mayoría del género masculino, con el correr de los años se fue feminizando, pasando a exhibir en las sucesivas ediciones una preponderancia del género femenino sobre el masculino.

Esta situación se puede visualizar en detalle en los cuadros 1 de este anexo y gráfico 2 adjuntos: 
Anexo 7 - Cuadro 1

\begin{tabular}{|c|c|c|c|c|c|c|}
\hline \multicolumn{7}{|c|}{$\begin{array}{r}\text { Maestría en Economía de la Salud y Adm } \\
\text { Salud }\end{array}$} \\
\hline \multirow[b]{2}{*}{ Edición } & \multirow{2}{*}{$\begin{array}{l}\text { Año de } \\
\text { comienzo }\end{array}$} & \multicolumn{5}{|c|}{ Alumnos Inscriptos discriminados por género } \\
\hline & & Femenino & Masculino & Totales & $\begin{array}{c}\% \\
\text { femenino }\end{array}$ & $\begin{array}{c}\% \\
\text { masculino }\end{array}$ \\
\hline $1^{\circ}$ & 1996 & 10 & 13 & 23 & $43,48 \%$ & $56,52 \%$ \\
\hline $2^{\circ}$ & 1997 & 11 & 15 & 26 & $42,31 \%$ & $57,69 \%$ \\
\hline $3^{\circ}$ & 1999 & 14 & 15 & 29 & $48,28 \%$ & $51,72 \%$ \\
\hline $4^{\circ}$ & 2000 & 11 & 14 & 25 & $44,00 \%$ & $56,00 \%$ \\
\hline $5^{\circ}$ & 2001 & 14 & 11 & 25 & $56,00 \%$ & $44,00 \%$ \\
\hline $6^{\circ}$ & 2002 & 7 & 10 & 17 & $41,18 \%$ & $58,82 \%$ \\
\hline $7^{\circ}$ & 2003 & 13 & 8 & 21 & $61,90 \%$ & $38,10 \%$ \\
\hline $8^{\circ}$ & 2005 & 15 & 9 & 24 & $62,50 \%$ & $37,50 \%$ \\
\hline $9^{\circ}$ & 2006 & 6 & 12 & 18 & $33,33 \%$ & $66,67 \%$ \\
\hline $10^{\circ}$ & 2007 & 14 & 6 & 20 & $70,00 \%$ & $30,00 \%$ \\
\hline $11^{\circ}$ & 2008 & 22 & 12 & 34 & $64,71 \%$ & $35,29 \%$ \\
\hline $12^{\circ}$ & 2009 & 15 & 10 & 25 & $60,00 \%$ & $40,00 \%$ \\
\hline $13^{\circ}$ & 2010 & 10 & 5 & 15 & $66,67 \%$ & $33,33 \%$ \\
\hline $14^{\circ}$ & 2011 & 13 & 8 & 21 & $61,90 \%$ & $38,10 \%$ \\
\hline \multirow{2}{*}{\multicolumn{2}{|c|}{ Total }} & 175 & 148 & 323 & & \\
\hline & & $54 \%$ & $46 \%$ & $100 \%$ & & \\
\hline
\end{tabular}


Anexo 7. Gráfico 2

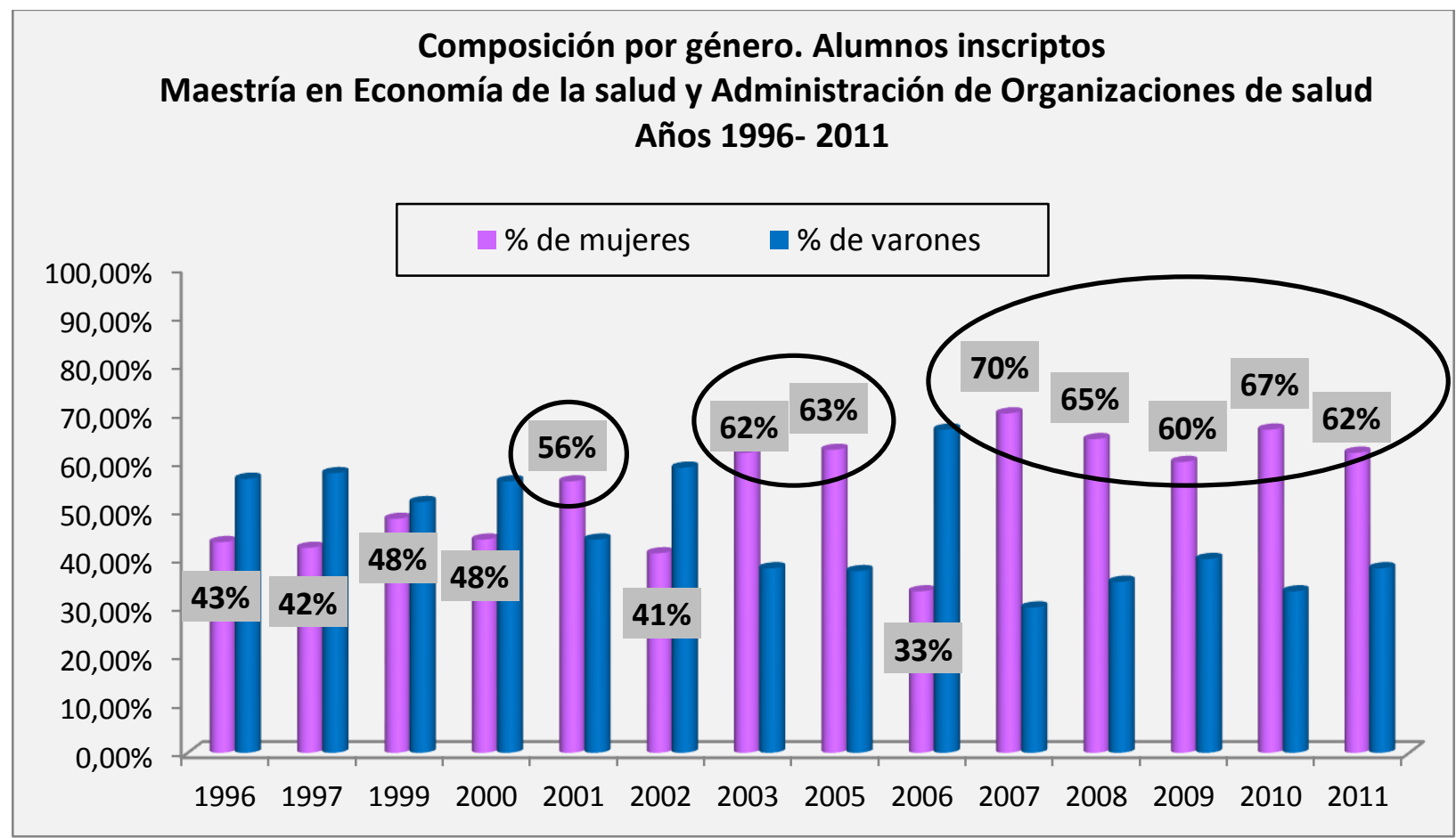

A su vez, de los datos obtenidos de la carrera de posgrado Especialización en Gestión de Organizaciones de Salud, perteneciente a la EGSalud de la FCE de la UNLP, es más apreciable aún la diferencia en favor del género femenino. Puede observarse que en todas sus ediciones las mujeres inscriptas conquistan el $50 \%$ y más en relación con el género masculino, siendo el año 2014 el que presenta los mayores porcentajes de concurrencia femenina con un $80 \%$ de inscriptas, según hacen referencia el gráfico 3 y 4 de este anexo y el cuadro 2 adjuntos: 
Anexo 7. Gráfico 3

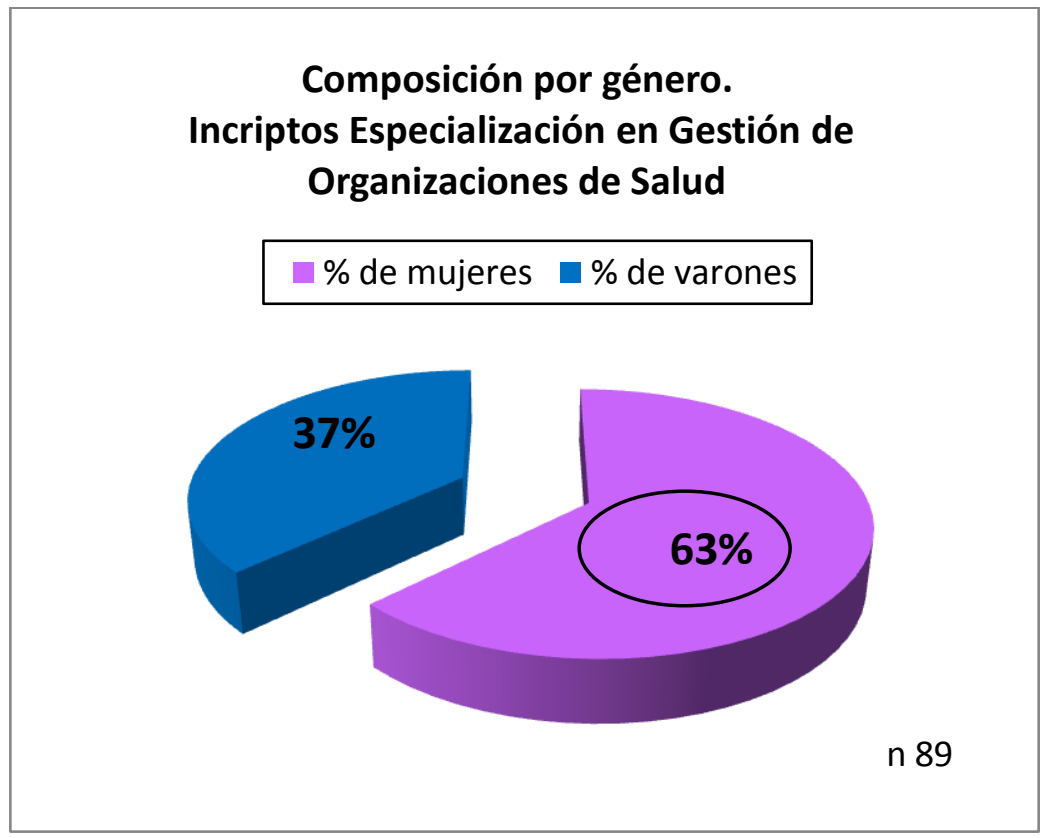

Anexo 7. Cuadro 2

\section{Especialización en Gestión de Organizaciones de Salud}

Alumnos inscriptos distinguidos por género

\begin{tabular}{|c|c|r|r|r|r|r|}
\hline Edición & $\begin{array}{c}\text { Año de } \\
\text { comienzo }\end{array}$ & Femenino & Masculino & Totales & $\begin{array}{c}\% \\
\text { femenino }\end{array}$ & $\begin{array}{c}\% \\
\text { masculino }\end{array}$ \\
\hline $1^{\circ}$ & 2007 & 8 & 5 & $\mathbf{1 3}$ & $61,54 \%$ & $38,46 \%$ \\
\hline $2^{\circ}$ & 2012 & 10 & 10 & $\mathbf{2 0}$ & $50,00 \%$ & $50,00 \%$ \\
\hline $3^{\circ}$ & 2013 & 13 & 9 & $\mathbf{2 2}$ & $59,09 \%$ & $40,91 \%$ \\
\hline $4^{\circ}$ & 2014 & 16 & 4 & $\mathbf{2 0}$ & $80,00 \%$ & $20,00 \%$ \\
\hline $5^{\circ}$ & 2015 & 9 & 5 & $\mathbf{1 4}$ & $64,29 \%$ & $35,71 \%$ \\
\hline \hline \multicolumn{2}{|r|}{ Total } & $\mathbf{5 6}$ & $\mathbf{3 3}$ & $\mathbf{8 9}$ & $\mathbf{6 3 \%}$ & $\mathbf{3 7 \%}$ \\
\hline
\end{tabular}


Anexo 7. Gráfico 4

Alumnos inscriptos desagregados por género Especialización en Gestión de Organizaciones de Salud

\begin{tabular}{|l|}
\hline$\%$ de mujeres $\quad$ \% de varones \\
\hline
\end{tabular}

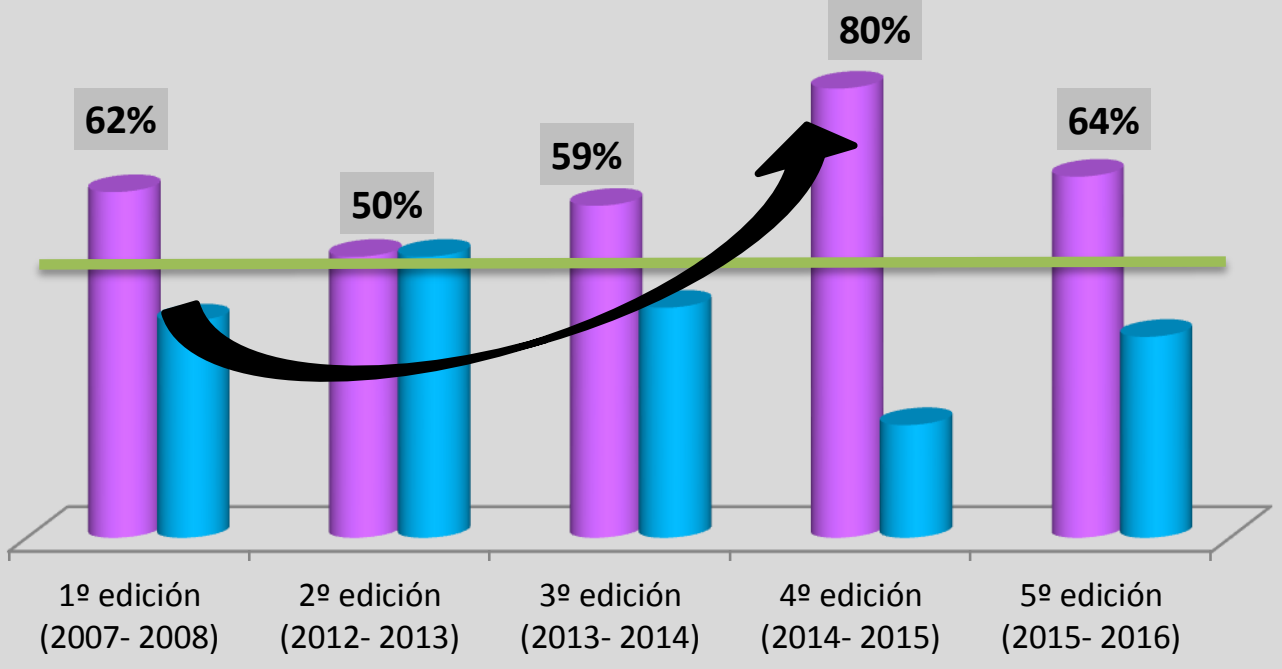

Analizando conjuntamente ambas carreras, los resultados vuelven a mostrar un predominio del género femenino con relación al género masculino, primordialmente a partir del año 2007 en adelante.

Es curioso observar que, al iniciar la primera cohorte de la Especialización en el año 2007 con un predominio del género femenino de 62\%, la maestría mostró su mayor concurrencia de público femenino en la carrera con una significación de $70 \%$ de mujeres sobre los varones.

En el gráfico pueden apreciarse los datos de las dos carreras en forma conjunta: 
Anexo 7. Gráfico 5

Porcentaje de mujeres inscriptas en las carreras de posgrado de la Escuela de Gestión de Organizaciones de Salud

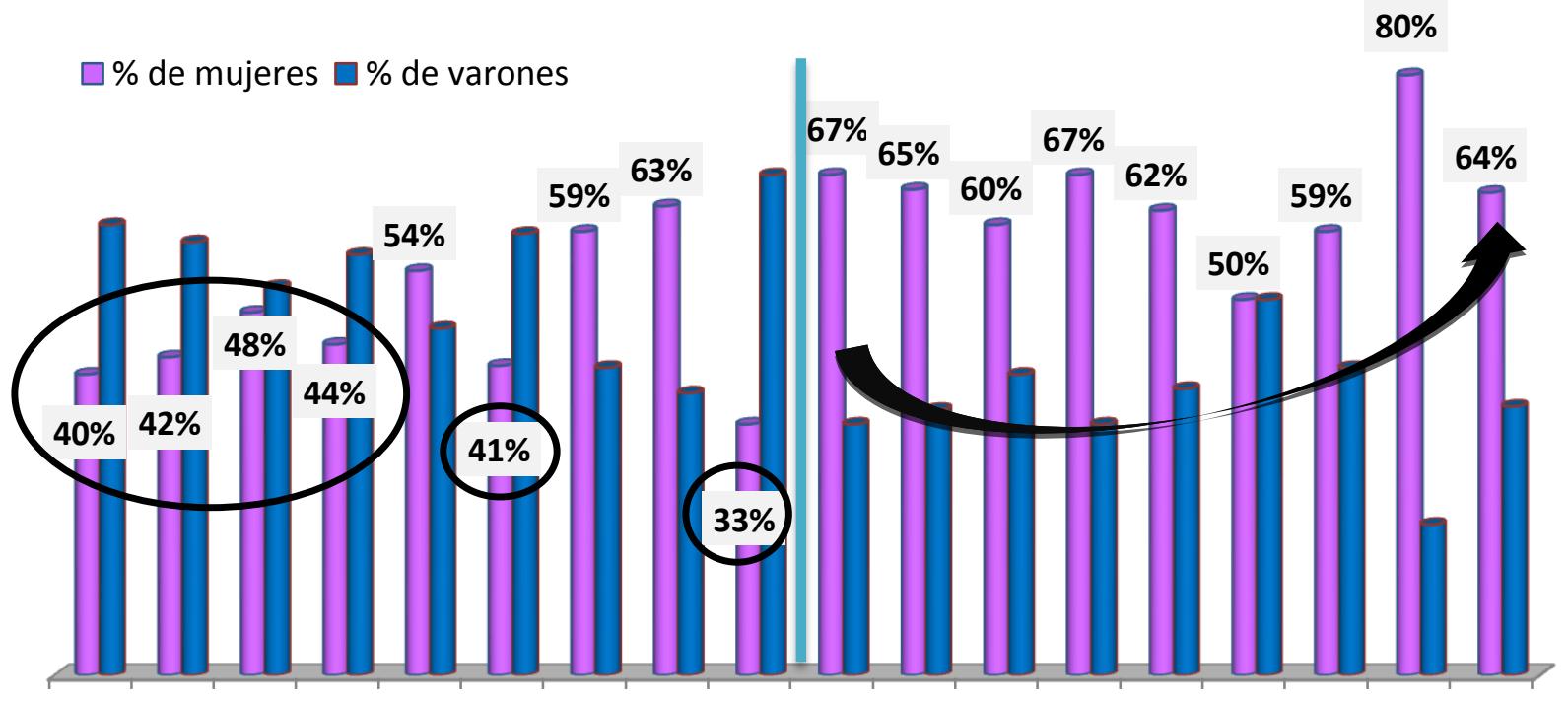

199619971999200020012002200320052006200720082009201020112012201320142015

Un escenario similar se presenta cuando se analiza la composición de género entre los graduados.

De este modo, tomando en cuenta el total de graduados, el $61 \%$ pertenece al género femenino mientras que el $39 \%$ refiere al género masculino.

Anexo 7. Gráfico 6

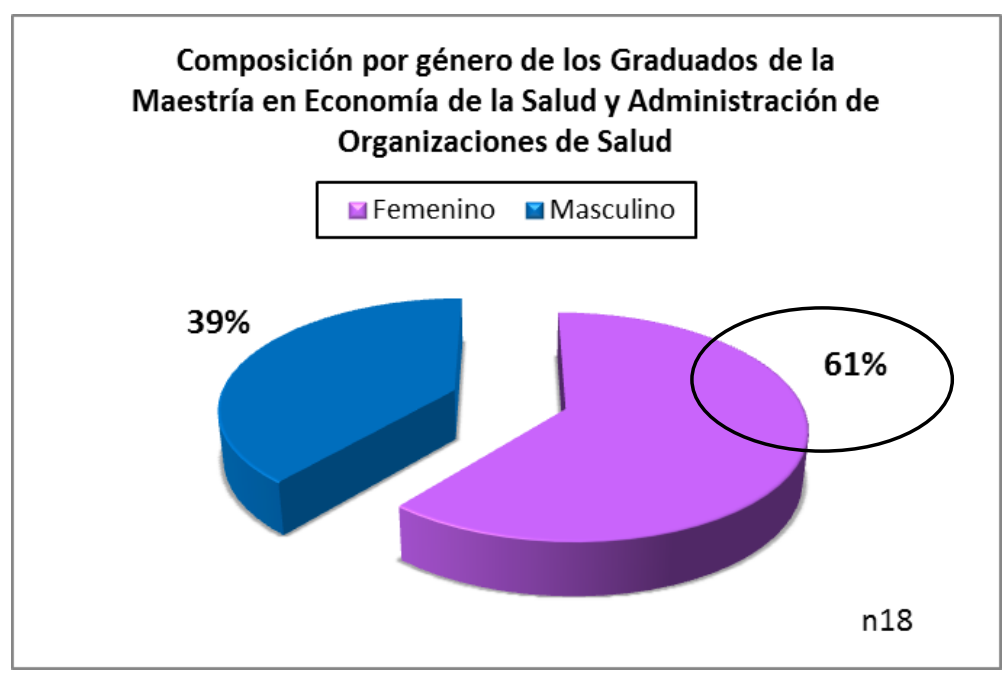


Si se analizan los datos tomando en cuenta la cantidad de graduados con relación a la cantidad de inscriptos por género, los valores difieren, pero sigue manteniendo un leve predominio el género femenino. Así puede apreciarse en el cuadro siguiente:

Anexo 7. Cuadro 3

\begin{tabular}{ccccc} 
Inscriptos en & $\begin{array}{c}\text { Mujeres } \\
\text { inscriptas }\end{array}$ & $\begin{array}{c}\text { Mujeres } \\
\text { graduadas }\end{array}$ & $\begin{array}{c}\text { Varones } \\
\text { inscriptos }\end{array}$ & $\begin{array}{c}\text { Varones } \\
\text { graduados }\end{array}$ \\
\hline 323 & 175 & 11 & 148 & 7 \\
& & $\mathbf{6 , 2 9 \%}$ & & $\mathbf{4 , 7 3 \%}$
\end{tabular}

Si se analiza a los graduados de la Maestría en Economía de la Salud y Administración de Organizaciones de Salud de la EGSalud, es notorio detenerse a observar cuales son las profesiones de base de acuerdo con el género.

Anexo 7. Cuadro 4

\begin{tabular}{|l|c|c|}
\hline \multicolumn{3}{|c|}{$\begin{array}{c}\text { Graduados de la Maestría en Economía de la Salud y } \\
\text { Administración de Organizaciones de Salud. EGSalud. FCE } \\
\text { UNLP }\end{array}$} \\
\hline \multicolumn{1}{|c|}{ Profesión de base } & Genero & $\begin{array}{c}\text { Año de } \\
\text { Graduación }\end{array}$ \\
\hline Lic. en Administración & F & 2015 \\
\hline Lic. en Economía & M & 2014 \\
\hline Médico & M & 2014 \\
\hline Veterinaria & F & 2014 \\
\hline Administradora en Salud & F & 2013 \\
\hline Lic. en Administración & F & 2013 \\
\hline Médica & F & 2013 \\
\hline Terapista ocupacional & F & 2012 \\
\hline Lic. en Administración & F & 2012 \\
\hline Bioquímica & F & 2012 \\
\hline Psicólogo & M & 2012 \\
\hline Lic. en enfermería & F & 2011 \\
\hline Odontóloga & F & 2011 \\
\hline
\end{tabular}




\begin{tabular}{|l|c|c|}
\hline Médico & M & 2009 \\
\hline Médico & M & 2004 \\
\hline Bioquímica & F & 2002 \\
\hline Médico & M & 2002 \\
\hline Médico & M & 2002 \\
\hline
\end{tabular}

Existe una multiplicidad de profesiones entre las mujeres graduadas, ocupando los mayores porcentajes, Licenciadas en Administración con un 36\%, mientras que, en el caso del género masculino, los graduados provienen especialmente de las ciencias de la salud, siendo los médicos el $71 \%$ de los graduados masculinos.

Anexo 7. Cuadro 5

\begin{tabular}{lc}
\multicolumn{1}{c}{ Profesión } & $\begin{array}{c}\text { Mujeres } \\
\text { graduadas }\end{array}$ \\
Médicas & 1 \\
Lic. En & \\
Administración & 4 \\
Veterinaria & 1 \\
\hline Terapista ocupacional & 1 \\
Lic. en enfermería & 1 \\
\hline Bioquímica & 2 \\
\hline odontóloga & 1 \\
\hline Total & 11
\end{tabular}

Anexo 7. Cuadro 6

\begin{tabular}{|cc} 
Profesión & $\begin{array}{c}\text { Varones } \\
\text { graduados }\end{array}$ \\
\hline Lic. en economía & 1 \\
Médicos & $\mathbf{5}$ \\
\hline Psicólogo & 1 \\
\hline Total & $\mathbf{7}$ \\
\hline
\end{tabular}


Anexo 7. Gráfico 7

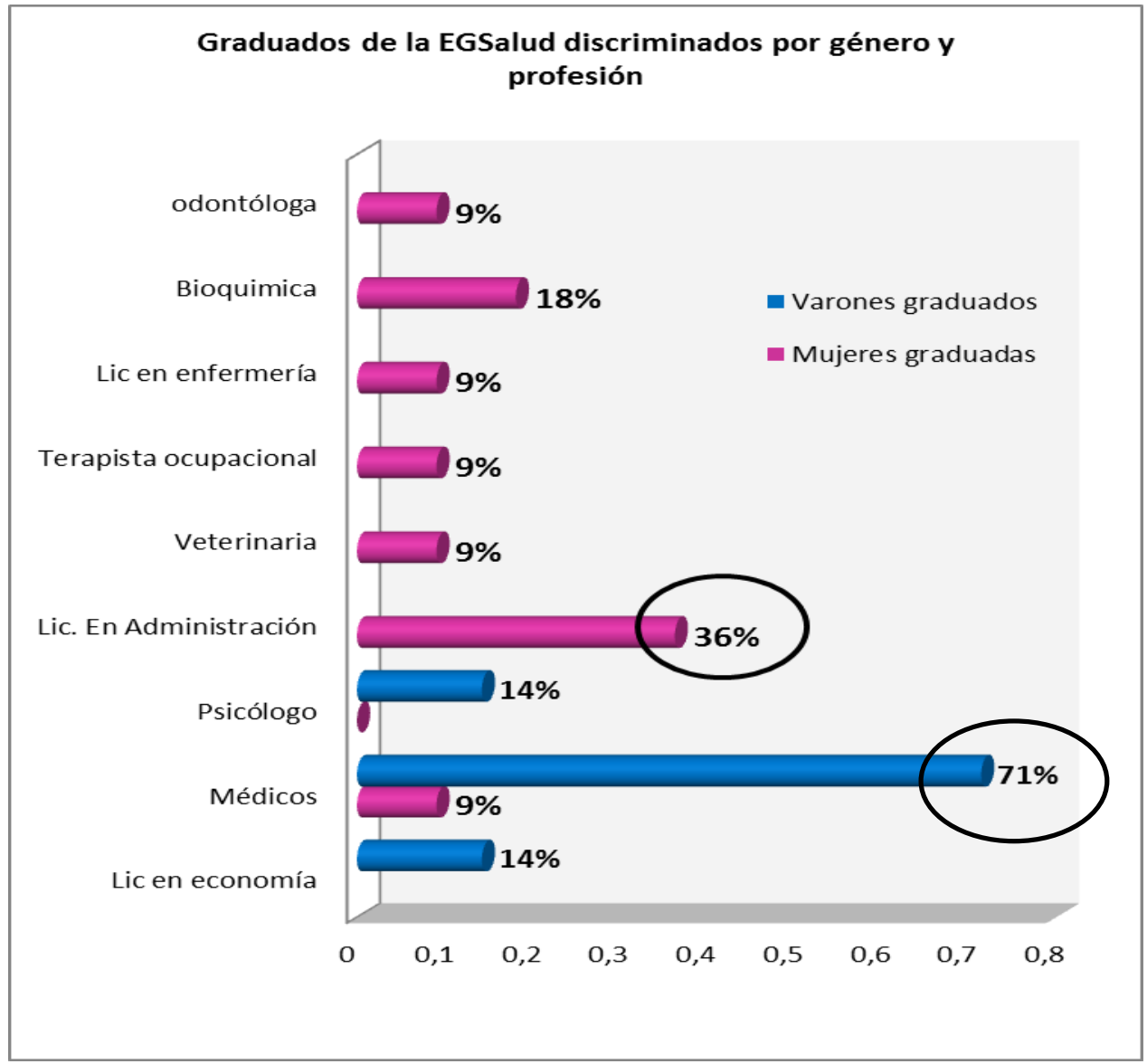

Un dato sumamente interesante surge al analizar a los graduados haciendo foco en los 5 años de estudio últimos para la presente investigación (2010 - 2015). En este contexto se puede observar que el $80 \%$ de esos graduados pertenecen al género femenino, mientras que sólo el $20 \%$ lo integra el género masculino. Esto induce a pensar que la carrera se ha feminizado en los últimos años de su desarrollo y se visualiza no solo en la composición de cada cohorte de los últimos años sino en la composición de los últimos nuevos graduados

Anexo 7. Cuadro 7

\begin{tabular}{|c|c|c|}
\hline \multicolumn{3}{|c|}{$\begin{array}{c}\text { Maestría en Economía de la salud y } \\
\text { Administración de Organizaciones de Salud } \\
\text { (periodo 2010- 2015) }\end{array}$} \\
\hline $\begin{array}{c}\text { Graduadas } \\
\text { Mujeres }\end{array}$ & $\begin{array}{c}\text { Graduados } \\
\text { hombres }\end{array}$ & $\begin{array}{c}\text { Total, } \\
\text { Graduados }\end{array}$ \\
\hline 11 & 3 & 14 \\
\hline $79 \%$ & $\mathbf{2 1 \%}$ & $\mathbf{1 0 0 \%}$ \\
\hline
\end{tabular}




\section{Anexo 8}

Análisis de la información por carrera de la unidad académica Facultad de Ciencias Médicas UNLP

Datos relevados de la Facultad de Ciencias Médicas de la UNLP

La facultad de Ciencias Médicas, de acuerdo con los datos a los que se pudo acceder para la presente investigación, cuenta con una única carrera de posgrado relacionada a la administración y gestión de organizaciones de salud: la Maestría en Salud Pública que acredita tres orientaciones: en Establecimientos y Servicios de Atención Médica; en Sistemas de Salud y en Sistemas Municipales de Salud.

La totalidad de alumnos inscriptos en dicha carrera contabiliza un total de 234 matriculados desde el año 2003, año que comenzó a editarse la primera edición, no existiendo en esta unidad académica antecedentes de otra carrera de posgrado relacionada con la temática bajo estudio en la presente investigación.

Del total de inscriptos en la carrera de posgrado de la Facultad de Ciencias Médicas puede advertirse que un $66 \%$ pertenece al género femenino mientras que el $34 \%$ corresponde al género masculino. Así se visualiza detalladamente:

Anexo 8. Cuadro 1

\begin{tabular}{|ccc|}
\hline Total & & \\
\hline Alumnos Inscriptos & Masculinos & Femeninos \\
\hline $\mathbf{2 3 4}$ & 80 & 154 \\
\hline $\mathbf{1 0 0} \%$ & $34 \%$ & $66 \%$ \\
\hline
\end{tabular}

Evaluando la composición de género entre los graduados de la maestría en Salud Pública se detalla que de un total de 16 graduados, el $69 \%$ corresponde al género femenino mientras que el $31 \%$ refiere al género masculino. Así se demuestra gráficamente: 
Anexo 8. Gráfico 1

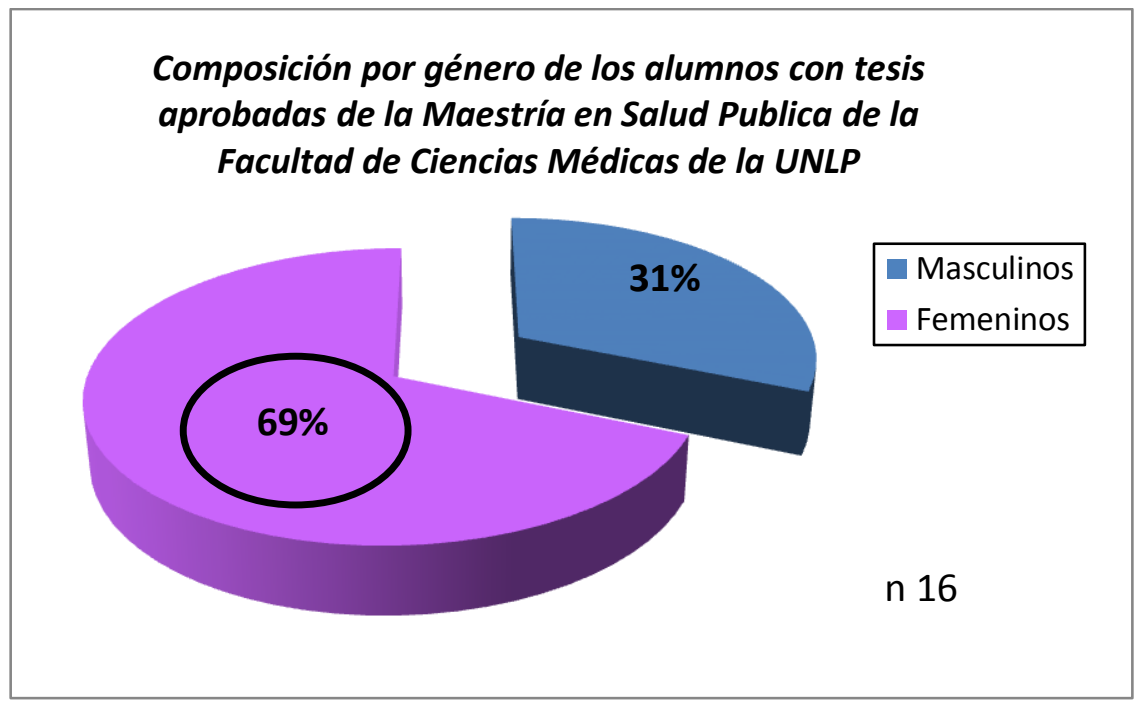

Cuando se examina la composición de género entre los graduados de la Maestría en Salud Pública en relación con la cantidad de inscriptos discriminada por género, continúa percibiéndose una leve hegemonía del género femenino sobre el masculino.

Anexo 8. Gráfico 2

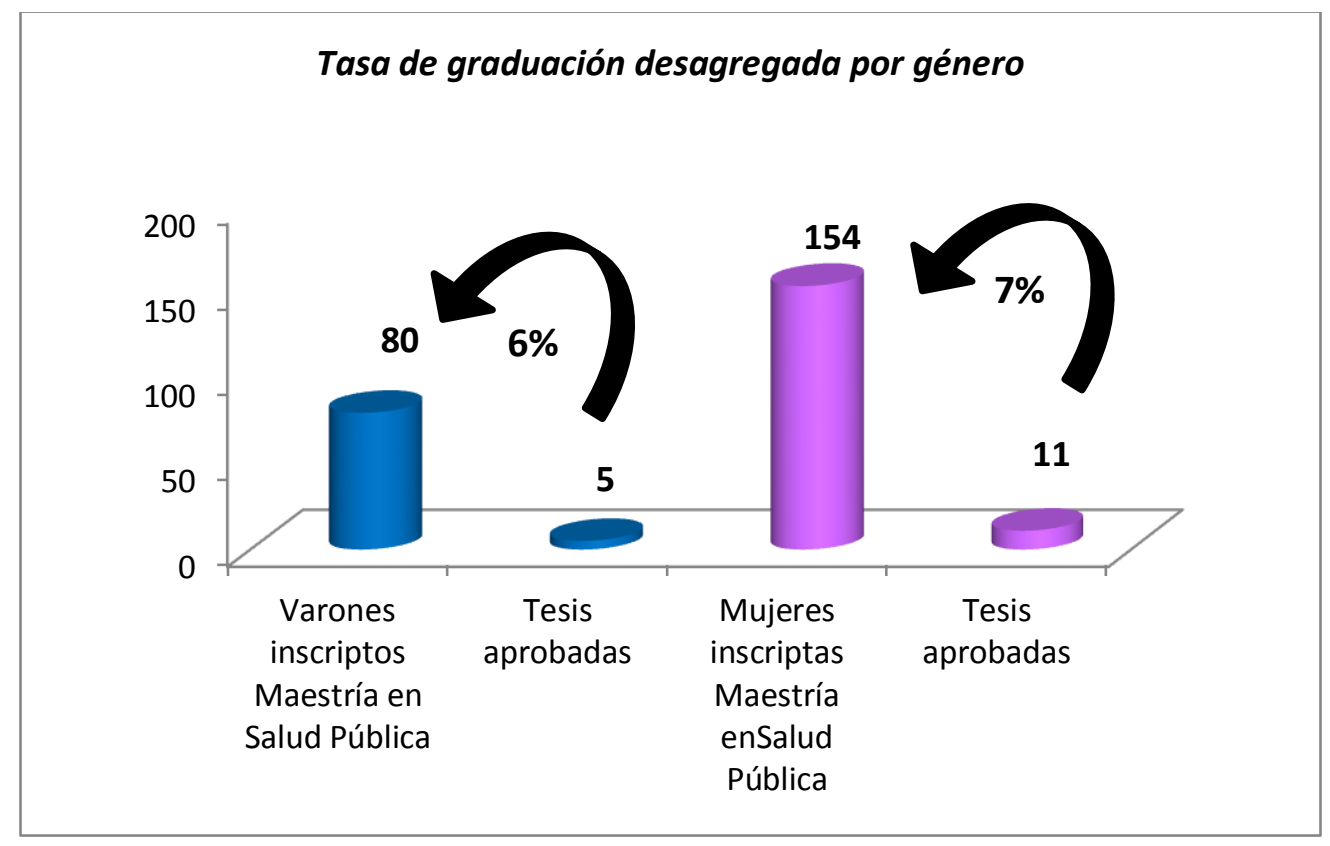


Examinando los graduados de la Maestría en Salud Pública de la Facultad de Ciencias Médicas de la UNLP según profesiones de procedencia, ocurre algo similar a lo observado en la otra unidad académica analizada anteriormente.

$\checkmark$ Las profesiones de base están monopolizadas por los médicos (80\%) para el género masculino mientras que, en el caso de las mujeres, las profesiones de base son multidisciplinarias, destacándose Médicas y Licenciadas en enfermería con los mayores porcentajes $(27 \%$ y $27 \%$ respectivamente). Así lo expresan los cuadros y gráficos adjuntos:

Anexo 8. Cuadro 2

\begin{tabular}{|l|l|}
\hline \multicolumn{2}{|c|}{$\begin{array}{c}\text { Graduados de la Maestría en Salud } \\
\text { Pública. Facultad de Ciencias Médicas } \\
\text { UNLP }\end{array}$} \\
\hline \multicolumn{1}{|c|}{ Profesión de base } & Género \\
\hline Médico & F \\
\hline Médico & M \\
\hline Médico & M \\
\hline Médico & M \\
\hline Lic. en Administración & F \\
\hline Médico & F \\
\hline Lic. Terapia Ocupacional & F \\
\hline Lic. en Biología & F \\
\hline Médico & F \\
\hline Sin datos & F \\
\hline Sin datos & F \\
\hline Médico & M \\
\hline Lic. en enfermería & F \\
\hline Fisioterapeuta & M \\
\hline Lic. en enfermería & F \\
\hline Lic. en enfermería & F \\
\hline
\end{tabular}


Anexo 8. Cuadro 3

\begin{tabular}{|c|c|}
\hline Varones por profesión & Tesis aprobadas \\
\hline Fisioterapeuta & 1 \\
\hline Medico & 4 \\
\hline Total & 5 \\
\hline
\end{tabular}

Anexo 8. Cuadro 4

\begin{tabular}{lc|} 
Mujeres por profesión & $\begin{array}{c}\text { Tesis } \\
\text { aprobadas }\end{array}$ \\
\hline Lic. En Administración & 1 \\
\hline Médico & 3 \\
\hline Lic en Biología & 1 \\
\hline Lic en terapia ocupacional & 1 \\
\hline Lic. En enfermería & 3 \\
\hline sin datos & 2 \\
\hline \multicolumn{1}{c}{ Total } & 11 \\
\hline
\end{tabular}

Anexo 8. Gráfico 3

Composición por profesión, varones graduados Maestría en Salud Pública. Facultad de Ciencias Médicas de la UNLP

$\square$ Fisioterapeuta Medico

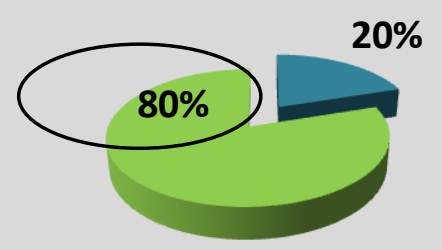


Anexo 8. Gráfico 4

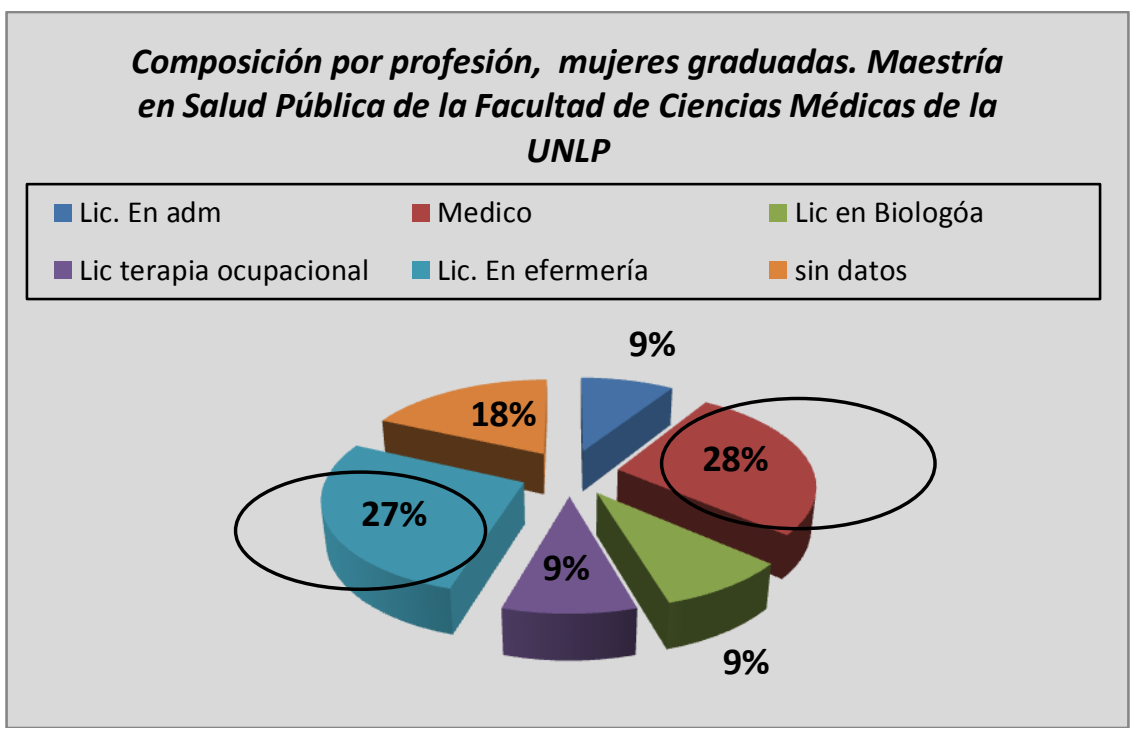




\section{Anexo 9}

Información adicional en base a los datos otorgados por las dos unidades académicas de la UNLP que ofrecen posgrados específicos en gestión sanitaria

Anexo 9 Cuadro 1

Análisis (1996-2002)

\begin{tabular}{ccrrr}
\hline \multicolumn{5}{c}{ Alumnos inscriptos discriminados por género } \\
$\begin{array}{c}\text { MES EGSalud FCE } \\
\text { UNLP }\end{array}$ & Años & Femenino & Masculino & Total \\
\hline $1^{\circ}$ edición & 1996 & 10 & 13 & 23 \\
$2^{\circ}$ edición & 1997 & 11 & 15 & 26 \\
$3^{\circ}$ edición & 1999 & 14 & 15 & 29 \\
$4^{\circ}$ edición & 2000 & 11 & 14 & 25 \\
$5^{\circ}$ edición & 2001 & 14 & 11 & 25 \\
$6^{\circ}$ edición & 2002 & 7 & 10 & 17 \\
Totales & & $\mathbf{6 7}$ & $\mathbf{7 8}$ & $\mathbf{1 4 5}$ \\
& & $\mathbf{4 6 \%}$ & $\mathbf{5 4 \%}$ & $\mathbf{1 0 0 \%}$
\end{tabular}

Anexo 9 Cuadro 2

Análisis (2003- 2015)

Alumnos inscriptos discriminados por género

Carreras de Posgrado de cada Unidad Académica

Femenino Masculino Total

MES EGSalud FCE UNLP ( de la $7^{\circ}$ a la $14^{\circ}$ edición)

$108 \quad 70 \quad 178$

ESAL EGSalud FCE UNLP ( $1^{\circ}$ a $5^{\circ}$ edición) 56 $33 \quad 89$

Maestría Salud Pública F. Cs. Médicas UNLP 154 $80 \quad 234$

Totales

318

$63 \%$ 
Anexo 9 Cuadro 3

Análisis (2007 -2015)

\begin{tabular}{crrr}
$\begin{array}{c}\text { Carreras de Posgrado de cada } \\
\text { Unidad Académica }\end{array}$ & Femenino & Masculino & Total \\
MES EGSalud FCE UNLP & 74 & 41 & 115 \\
\hline ESAL EGSalud FCE UNLP & 56 & 33 & 89 \\
\hline $\begin{array}{c}\text { Maestría Salud Pública F. Cs. } \\
\text { Médicas UNLP * }\end{array}$ & 106 & 55 & 161 \\
\hline Totales & 236 & 129 & 365 \\
& $65 \%$ & $35 \%$ & $100 \%$
\end{tabular}

* En la Maestría Salud Pública. F. Cs. Médicas UNLP se usó como criterio tomar el $69 \%$ de los inscriptos para ambos géneros para el período 2007 - 2015

Anexo 9. Cuadro 4

\begin{tabular}{|c|c|c|c|}
\hline \multicolumn{4}{|c|}{ Inscriptos } \\
\hline $\begin{array}{l}\text { Carreras de posgrados } \\
\text { en Gestión Sanitaria }\end{array}$ & $\begin{array}{l}\text { Matrícula } \\
\text { femenina }\end{array}$ & $\begin{array}{l}\text { Matrícula } \\
\text { masculina }\end{array}$ & $\begin{array}{c}\text { Total } \\
\text { Inscriptos }\end{array}$ \\
\hline $\begin{array}{c}\text { MES EGSalud FCE UNLP } \\
(1996-2011)\end{array}$ & 175 & 148 & 323 \\
\hline $\begin{array}{l}\text { ESAL EGSalud FCE UNLP } \\
(2007-2015)\end{array}$ & 56 & 33 & 89 \\
\hline $\begin{array}{l}\text { Maestría Salud Publica F. Cs. } \\
\text { Médicas UNLP (2003 - 2015) }\end{array}$ & 154 & 80 & 234 \\
\hline \multirow[b]{2}{*}{ Totales } & 385 & 261 & 646 \\
\hline & $60 \%$ & $40 \%$ & $100 \%$ \\
\hline
\end{tabular}


Anexo 10 a.

Modelos de Encuestas que se utilizaron para el tercer eje de estudio de esta investigación

a. Encuesta a ex alumnos de la Especialización en Gestión de Organizaciones de Salud

El objetivo de la presente encuesta tiene por finalidad recabar información de los ex alumnos de la Especialización, que se utilizará como sustento para uno de los ejes de estudio de mi trabajo de tesis de graduación. Los datos recabados serán confidenciales y no será divulgada su fuente.

*Obligatorio

1. Dirección de correo electrónico *

2. Género *

Selecciona todos los que correspondan.

Femenino

Masculino

3. Edad *

Marca solo un óvalo.

Menor de 30 años

Entre 30 y 39 años

Entre 40 y 49 años

Entre 50 y 59 años

60 o más años

4. ¿Antes de efectuar la carrera de posgrado Especialización en Gestión de Organizaciones de salud ocupaba algún cargo de Gestión en organizaciones de Salud? * 
Selecciona todos los que correspondan.

SI

NO

5. ¿Qué importancia cree usted que tiene la formación de posgrado como motor de acceso a cargos de alta gerencia en el sector sanitario? *

Selecciona todos los que correspondan.

Nada esencial

Poco esencial

Esencial

Absolutamente esencial

6. ¿Ocupa actualmente algún cargo en la gestión de organizaciones de salud? *

Marca solo un óvalo.

SI

NO

7. En caso afirmativo ¿cuál? 
8. ¿Cómo considera el impacto de estos factores en la accesibilidad a la alta gerencia en el sector sanitario? *

Marca solo un óvalo por fila.

$\begin{array}{llll}\text { Nada } & \text { Poco } & \text { Influyente } & \begin{array}{l}\text { Extremadamente } \\ \text { influyente }\end{array}\end{array}$

Género

Aptitudes personales
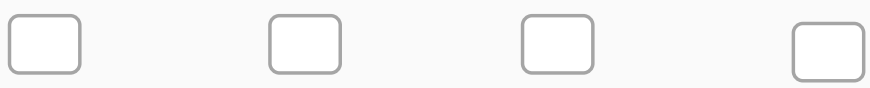
Formación de posgrado
Aspirante con o sin hijos
Cultura de la organización
Experiencia en cargos de gestión
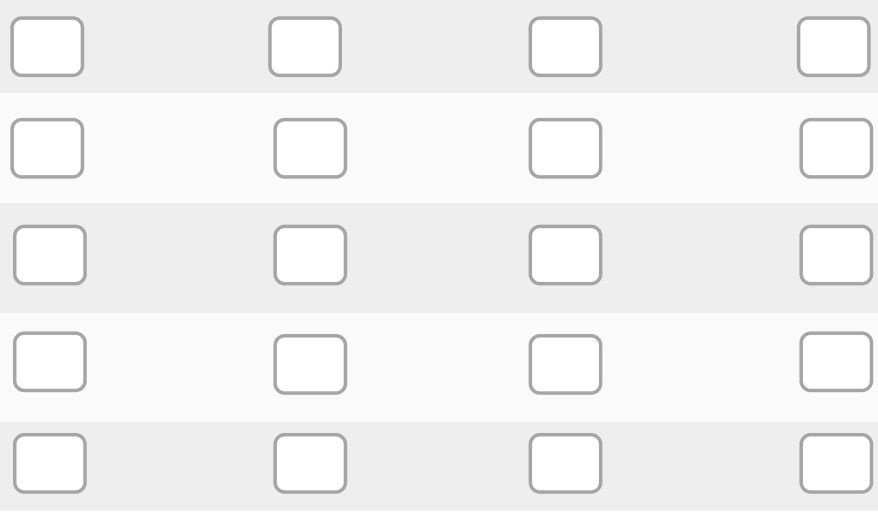

9. Considera algún otro factor no mencionado anteriormente que pueda tener impacto en la accesibilidad a la alta gerencia. ¿Cuál? Se considera opción válida responder NO *

Recibir una copia de mis respuestas 
Anexo $10 \mathrm{~b}$.

Modelos de Encuestas que se utilizaron para el tercer eje de estudio de esta investigación

b. Encuesta a ex alumnos de la Maestría en Economía de la Salud y Administración de Organizaciones de Salud

El objetivo de la presente encuesta tiene por finalidad recabar información de los ex alumnos de la Maestría, que se utilizará como sustento para uno de los ejes de estudio de mi trabajo de tesis de graduación. Los datos recabados serán confidenciales y no será divulgada su fuente.

*Obligatorio

1. Dirección de correo electrónico *

\section{Género *}

\section{Selecciona todos los que correspondan.}

Femenino

Masculino

\section{Edad *}

\section{Marca solo un óvalo.}

Menor de 30 años

Entre 30 y 39 años

Entre 40 y 49 años

Entre 50 y 59 años

60 o más años 
4. ¿Antes de efectuar la carrera de posgrado Especialización en Gestión de Organizaciones de salud ocupaba algún cargo de Gestión en organizaciones de Salud? *

\section{Selecciona todos los que correspondan.}

$\square$ SI

$\square$ NO

5. ¿Qué importancia cree usted que tiene la formación de posgrado como motor de acceso a cargos de alta gerencia en el sector sanitario? *

Selecciona todos los que correspondan.

Nada esencial

Poco esencial

Esencial

Absolutamente esencial

6. ¿Ocupa actualmente algún cargo en la gestión de organizaciones de salud? *

Marca solo un óvalo.

SI

NO

7. En caso afirmativo ¿cuál? 
8. ¿Cómo considera el impacto de estos factores en la accesibilidad a la alta gerencia en el sector sanitario? *

Marca solo un óvalo por fila.

$\begin{array}{llll}\begin{array}{l}\text { Nada } \\ \text { Influyente }\end{array} & \begin{array}{l}\text { Poco } \\ \text { influyente }\end{array} & \text { Influyente } & \begin{array}{l}\text { Extremadamente } \\ \text { influyente }\end{array}\end{array}$

Género

Aptitudes personales

Formación de posgrado

Aspirante con o sin hijos
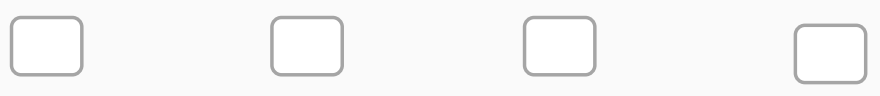

Cultura de la organización
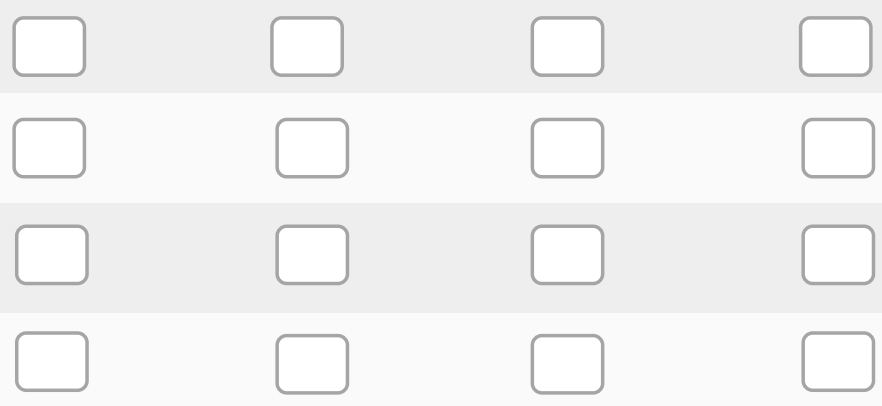

Experiencia en cargos de gestión
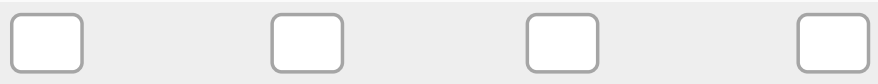

9. Considera algún otro factor no mencionado anteriormente que pueda tener impacto en la accesibilidad a la alta gerencia. ¿Cuál? Se considera opción válida responder NO *

Recibir una copia de mis respuestas

Con la tecnología de

Gloogle Forms 
Anexo $10 \mathrm{c}$.

Modelos de Encuestas que se utilizaron para el tercer eje de estudio de esta investigación

c. Encuesta a graduados de la Maestría en Economía de la Salud y Administración de Organizaciones de Salud

El objetivo de la presente encuesta tiene por finalidad recabar información de los graduados de la Maestría, que se utilizará como sustento para uno de los ejes de estudio de mi trabajo de tesis de graduación. Los datos recabados serán confidenciales y no será divulgada su fuente.

*Obligatorio

1. Dirección de correo electrónico *

\section{Género *}

\section{Selecciona todos los que correspondan.}

Femenino

Masculino

\section{Edad*}

\section{Marca solo un óvalo.}

Menor de 30 años

Entre 30 y 39 años

Entre 40 y 49 años

Entre 50 y 59 años

60 o más años 
4. ¿Antes de efectuar la carrera de posgrado Especialización en Gestión de Organizaciones de salud ocupaba algún cargo de Gestión en organizaciones de Salud? *

\section{Selecciona todos los que correspondan.}

$\square$ SI

$\square$ NO

5. ¿Qué importancia cree usted que tiene la formación de posgrado como motor de acceso a cargos de alta gerencia en el sector sanitario? *

Selecciona todos los que correspondan.

Nada esencial

Poco esencial

Esencial

Absolutamente esencial

6. ¿Ocupa actualmente algún cargo en la gestión de organizaciones de salud? *

Marca solo un óvalo.

SI

NO

7. En caso afirmativo ¿cuál? 
8. ¿Cómo considera el impacto de estos factores en la accesibilidad a la alta gerencia en el sector sanitario? *

Marca solo un óvalo por fila.

$\begin{array}{llll}\text { Nada } & \text { Poco } & \text { Influyente } & \begin{array}{l}\text { Extremadamente } \\ \text { influyente }\end{array}\end{array}$

Género

Aptitudes personales
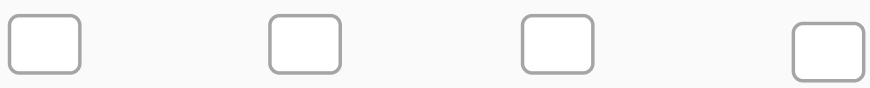
Formación de posgrado
Aspirante con o sin hijos
Cultura de la organización
Experiencia en cargos de gestión
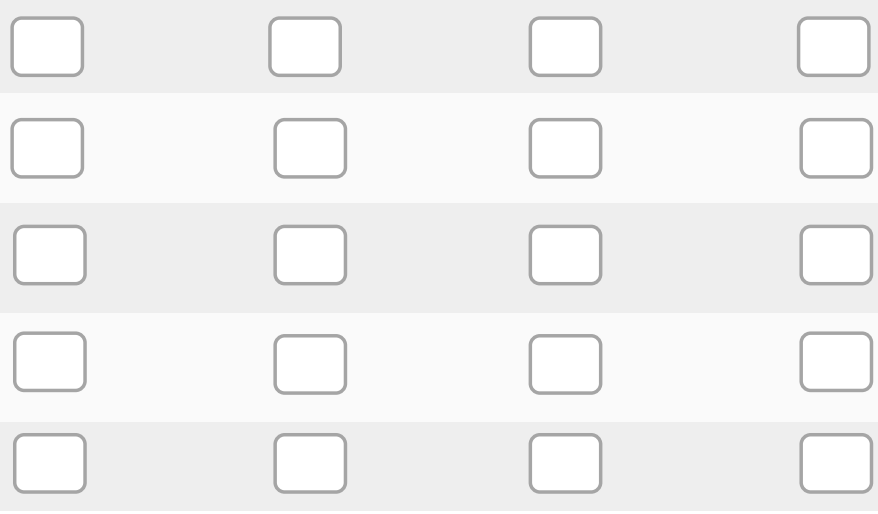

9. Considera algún otro factor no mencionado anteriormente que pueda tener impacto en la accesibilidad a la alta gerencia. ¿Cuál? Se considera opción válida responder NO *

Recibir una copia de mis respuestas 